Aus der Abteilung

Medizinische Psychologie und Medizinische Soziologie

(Prof. Dr. hum. biol. N. von Steinbüchel)

der Medizinischen Fakultät der Universität Göttingen

\title{
Adherence to paediatric antiretroviral therapy in South Africa
}

A comparison of two measures and an assessment of predictors

\author{
INAUGURAL - DISSERTATION \\ zur Erlangung des Doktorgrades \\ der Medizinischen Fakultät \\ der Georg-August-Universität zu Göttingen \\ vorgelegt von \\ Alexandra Denise Müller \\ aus \\ Ludwigshafen/Rhein
}

Göttingen 2009 
Dekan: Prof. Dr. med. C. Frömmel

I. Berichterstatterin: Prof. Dr. hum. biol. N. von Steinbüchel

\section{Berichterstatter/in:}

\section{Berichterstatter/in:}

Tag der mündlichen Prüfung: 


\section{Table of Contents}

List of Abbreviations ........................................................................................................................ 3

List of Figures .............................................................................................................................. 4

List of Tables................................................................................................................................. 5

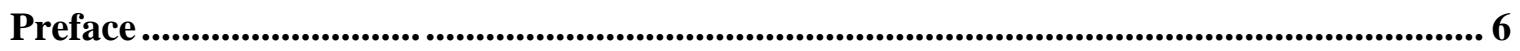

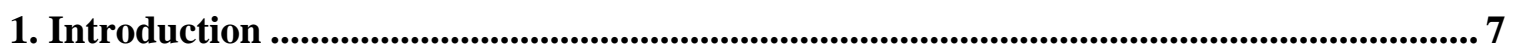

1.1 Human Immunodeficiency Virus Infection ............................................................... 7

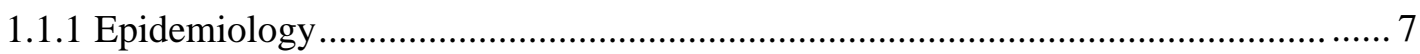

1.1.2 Impact of paediatric HIV on mortality and morbidity ........................................ 8

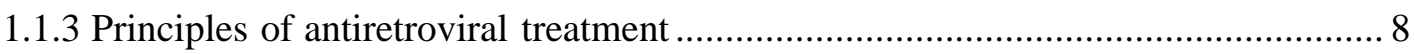

1.1.4 Treatment of HIV-infected children .............................................................. 10

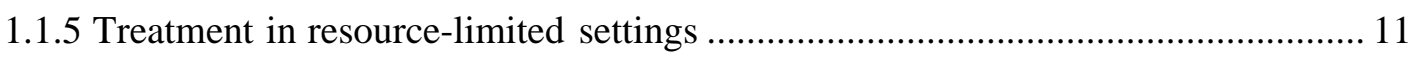

1.2 Adherence - "Drugs don't work in patients who don't take them" "......................... 13

1.2.1 Adherence - an updated definition ................................................................. 13

1.2.2 Adherence to Highly Active Antiretroviral Therapy ............................................ 15

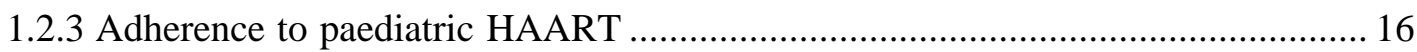

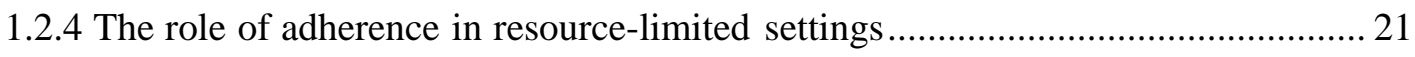

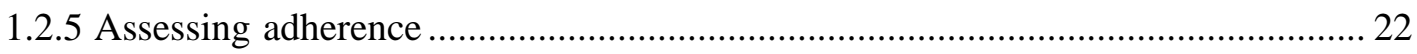

1.2.6 Assessing adherence to HAART in children ................................................... 23

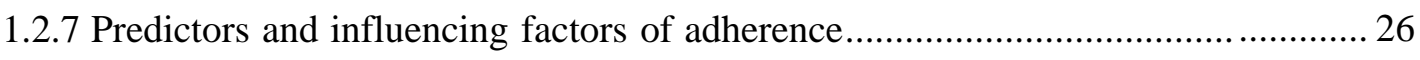

2. Objectives and methods ........................................................................................................... 28

2.1 Objectives ............................................................................................................................... 28

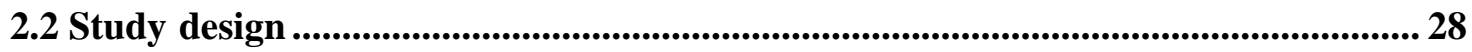

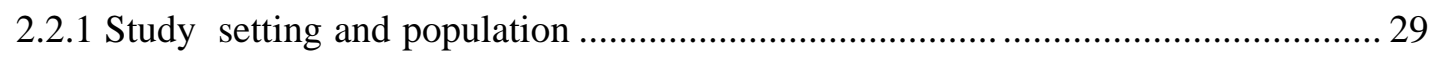

2.3 Methods ................................................................................................................... 32

2.3.1 Medication Event Monitoring System (MEMS) ……………………………..... 32

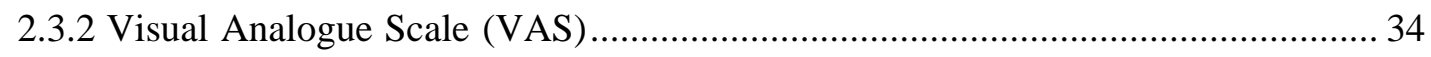

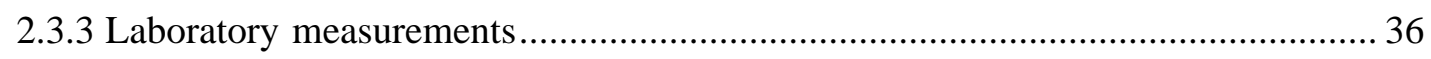

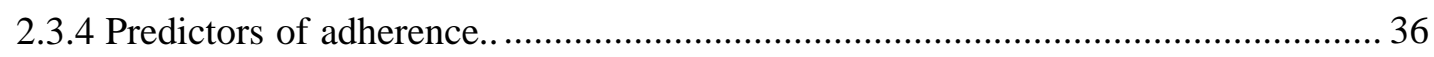

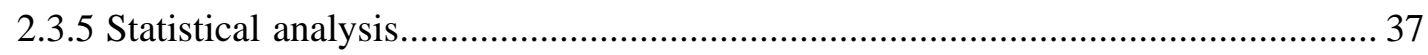

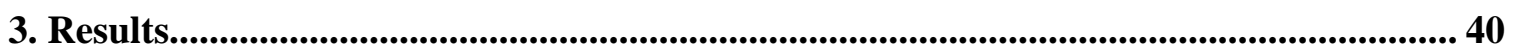

3.1 Description of the study cohort ......................................................................................40

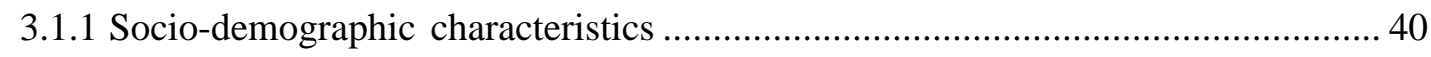

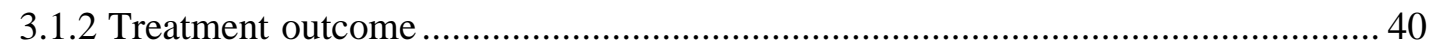

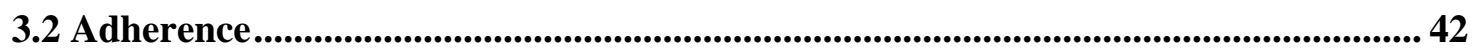

3.2.1 Adherence by Medication Event Monitoring System.......................................... 42 


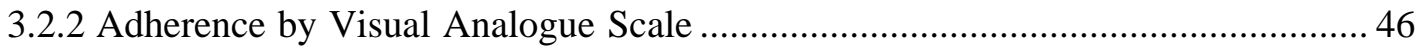

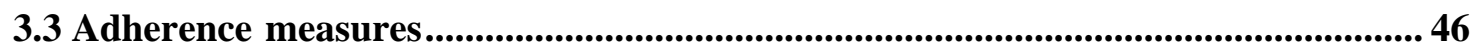

3.3.1 Relationship between MEMS and VAS adherence ......................................... 46

3.3.2 Correlation between continuous adherence measures and viral load .................... 48

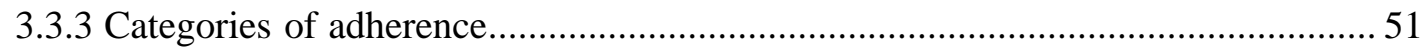

3.3.4 Categories of adherence and correlation with viral load .................................. 52

3.3.5 Validation of binary adherence measures by virological outcome........................ 55

3.3.6 Analyses of sensitivity, specificity and positive predictive value for predicting

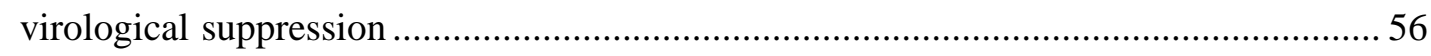

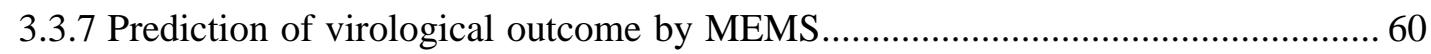

3.4 Predictors of adherence.................................................................................................6 63

3.4.1 Analysis of the Assessment of Demographics and Socioeconomics Questionnaire

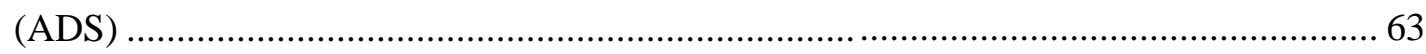

3.4.2 Analysis of the Social Environment, Attitudes and Culture Assessment Scale

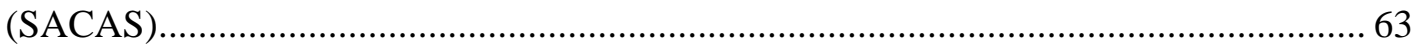

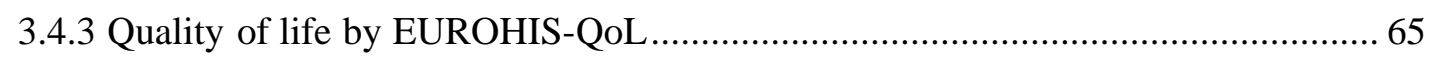

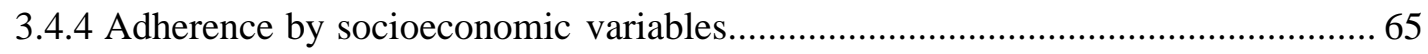

3.4.5 ADS items - correlations to adherence and virological outcome......................... 67

3.4.6 SACAS items - correlations to adherence and virological outcome.....................69

3.4.7 Superordinate structure of SACAS items ........................................................ 71

3.4.8 EUROHIS-QoL - correlations to adherence and virological outcome ................. 72

3.4.9 Items predictive of adherence and virological outcome ................................... 74

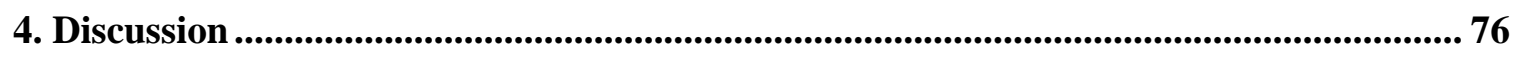

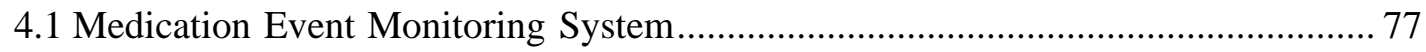

4.2 Caregiver report by Visual Analogue Scale ....................................................... 83

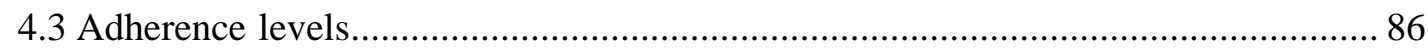

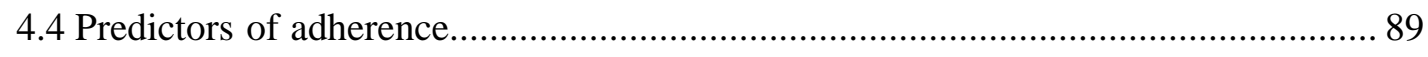

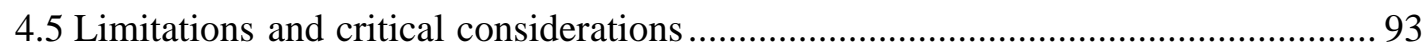

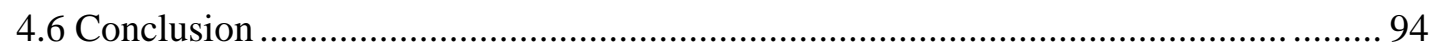

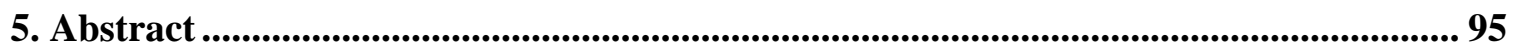

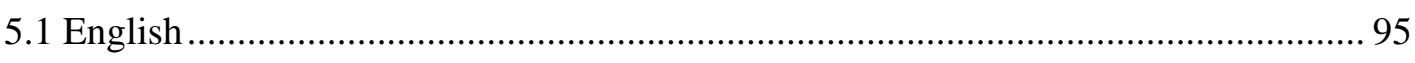

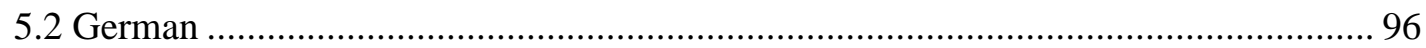

6. Appendix - Questionnaires........................................................................................................... 97

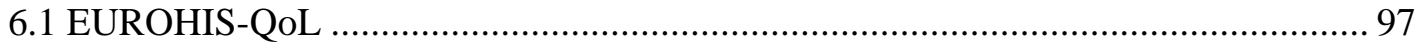

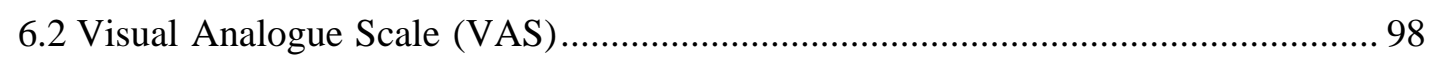

6.3 Assessment of Demographics and Socioeconomics questionnaire (ADS) ............... 99

6.4 Social Environment, Attitude and Culture Assessment Scale (SACAS) ............... 102

7. References ............................................................................................................................................. 105 


\section{List of Abbreviations}

ADS

AIDS

ART

ARV

CD4+

DNA

HAART

HAZ

HIV

IQR

MEMS

NNRTI

NRTI

PCR

PI

QoL

RNA

ROC

SACAS

SD

VAS

VS

WAZ

WHO
Assessment of Demographics and Socioeconomics

questionnaire

Acquired Immunodeficiency Syndrome

Antiretroviral Treatment

Antiretroviral Drug

Lymphocyte Cluster of Differentation - positive for marker 4

Desoxyribonucleic Acid

Highly Active Antiretroviral Therapy

Height-For-Age Z-Score

Human Immunodeficiency Virus

Interquartile Range

Medication Event Monitoring System

Non-Nucleosid Reverse Transcriptase Inhibitor

Nucleosid Reverse Transcriptase Inhibitor

Polymerase Chain Reaction

Protease Inhibitor

Quality of Life

Ribonucleic Acid

Receiver-Operator Characteristic

Social Environment, Attitudes and Culture Assessment Scale

Standard Deviation

Visual Analogue Scale

Virological Suppression (defined as less than 50 copies of HIV RNA per mL blood)

Weight-For-Age Z-Score

World Health Organization 


\section{List of Figures}

Figure 1: Relationship between virological outcome and adherence to antiretroviral therapy 16

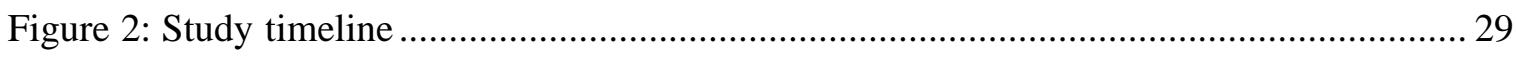

Figure 3: MEMS cap and MEMS communicator with containers ...................................... 34

Figure 4: Adherence report generated by PowerView from MEMS-collected data ................ 35

Figure 5: Distribution of adherence measured by Medication Event Monitoring System

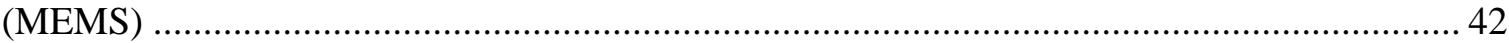

Figure 6: Median MEMS adherence during the first, second and third month ....................... 43

Figure 7: Median adherence by Medication Event Monitoring System (MEMS) generally and adjusted for the correct timing of doses (MEMS-correct timing)

Figure 8: Median adherence by Medication Event Monitoring System (MEMS) by the child's sex

Figure 9: Median adherence by Medication Event Monitoring System (MEMS), by regimen line.

Figure 10: Distribution of adherence measured by Visual Analogue Scale (VAS) 46

Figure 11: Scatterplot of mean adherence by Medication Event Monitoring System (MEMS), against mean adherence by Visual Analogue Scale (VAS).

Figure 12: Association between mean adherence by Medication Event Monitoring System (MEMS) and log viral load at follow-up

Figure 13: Association between mean adherence by Visual Analogue Scale (VAS) and log viral load at follow-up

Figure 14: Median adherence by Medication Event Monitoring System (MEMS) and Visual

Analogue Scale (VAS), by virological suppression at follow-up (VS)

Figure 15: Viral load at follow up (log transformed to the base 10)

Figure 16: Virological outcome by adherence as measured by Medication Event Monitoring

System (MEMS) and Visual Analogue Scale (VAS)....

Figure 17: Receiver-Operating-Characteristic (ROC) curve in predicting virological suppression for mean adherence by Medication Event Monitoring System (MEMS).

Figure 18: Receiver-Operating-Characteristics (ROC) curve in predicting virological suppression for mean adherence by Visual Analogue Scale (VAS)

Figure 19: Association between viral load at follow-up and duration of treatment in months 61

Figure 20: Association between viral load at study baseline and follow-up 


\section{List of Tables}

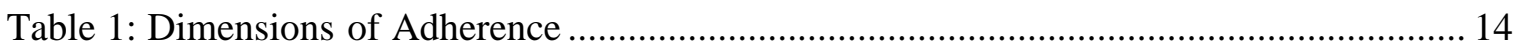

Table 2: A review of paediatric adherence studies from 1999 - 2008.................................. 18

Table 3: Details of antiretroviral treatment by regimen line and class.................................. 32

Table 4: Demographic and socio-economic details of population ......................................... 41

Table 5: Spearman rho correlations for mean MEMS adherence and viral load ..................... 48

Table 6: Distribution of adherence over the study period, by measure ................................. 52

Table 7: Distribution of adherence for all children with available viral load at follow-up, by

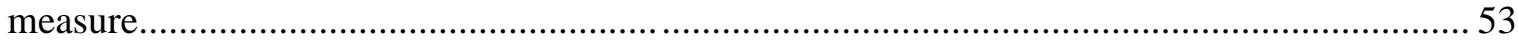

Table 8: Number of children in each adherence category and association with virological

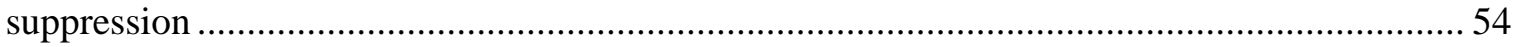

Table 9: Odd's ratio for virological suppression, by adherence category .............................. 55

Table 10: Sensitivity, specificity and positive predictive value for virological suppression ... 57

Table 11: Linear regression coefficients for chosen variables on viral load outcome ............. 60

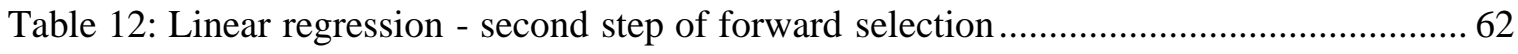

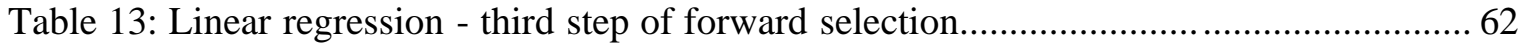

Table 14: Findings from the ADS questionnaire for children and caregivers ......................... 64

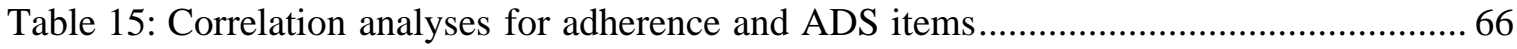

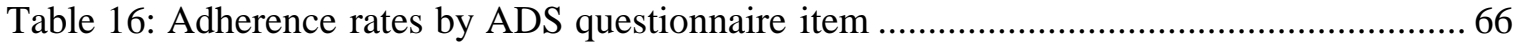

Table 17: Associations between socio-demographic variables (ADS) with adherence and

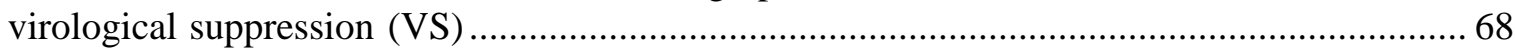

Table 18: Results from the SACAS and correlations with adherence and virological outcome

Table 19: Exploratory Principal-Components Analysis: varimax rotated factor matrix.......... 73

Table 20: Descriptive statistics and Pearson's correlations of superordinate SACAS factors with virological outcome and MEMS adherence .............................................................. 74

Table 21: Stepwise binary logistic regression predicting adherence and virological suppression by correlated socio-demographic and SACAS items 


\section{Preface}

This dissertation evolved out of personal interest. During numerous stays in South Africa, I had been involved with providing care to HIV infected women, men and their children. When I worked with the humanitarian organization "Iliso Lomzi" in Khayelitsha, one of Cape Town's numerous townships, I fully recognised the magnitude of the complex social implications of this infectious disease. This understanding was shaped and sharpened during an internship at an orphanage whose children are in the medical care of Dr. Paul Roux.

Dr. Paul Roux has been a pioneer in providing antiretroviral treatment to children in the South African public health care sector. He is the head of the Paediatric HIV/AIDS Service at Groote Schuur Hospital, the academic teaching hospital of the University of Cape Town. It was under his guidance and mentoring that I chose the topic and designed the study, on which this dissertation is based. During the three semesters spent at the University of Cape Town, I had the opportunity to work closely with him and his inspiring team of physicians. Furthermore, I had the pleasure of collaborating with Dr. Landon Myer, a lecturer at the Infectious Disease and Epidemiology Unit of the University of Cape Town and at the Mailman School of Public Health of Columbia University in New York. He guided me through the statistical analyses and sharpened my scientific thinking and writing.

At Göttingen University, I was supervised and supported by Prof. Nicole von Steinbüchel at the Institute for Medical Psychology and Medical Sociology. She had readily agreed to supervise this project when I presented it to her in the fall of 2005 . She also initiated my application for a scholarship of the German Academic Exchange Service (Deutscher Akademischer Auslandsdienst - DAAD), which I was awarded in 2007.

This dissertation has been a project in three phases. I researched and developed the study design in Göttingen and during the first months in South Africa. Data collection took place in South Africa, as did some of the statistical analyses. The final analysis and writing was then performed at Göttingen University. 


\section{Introduction}

\subsection{Human Immunodeficiency Virus Infection}

Since the first description of suspicious cases of patients with failing immune systems in Los Angeles in 1981 (GoTTLIEB et al. 1981), the human immunodeficiency virus, better known by its acronym HIV, has had an enormous impact on the health of people all over the world. The virus was discovered as the causal agent for these mysterious immunological failures in 1984 (BRODER and GALlo 1984; MONTAGNIER et al. 1984). From there on, the Acquired Immunodeficiency Syndrome (AIDS) developed from a disease mainly found in gay men to one of the biggest global epidemics and has often been compared to the Plague ${ }^{1}$. It is countries like South Africa that are affected the mostcountries where resources that can be directed towards the development of effective prevention and treatment are limited and where social inequalities lead to deteriorating health conditions (UNAIDS 2008). In many ways, this epidemic is a first: hardly any previous infectious disease highlights more the role that social and economic factors play in influencing the susceptibility to and the spread of the virus. It has led to the creation of a large global community of people infected and affected, scientists, politicians and donors. It has emphasised the political dimensions of health and health care, and has sparked debate over the human right to health and its implications. Remarkably, it has by far transcended the medical discipline and has become a social, political and economic phenomenon. At its roots, however, it remains a medical issue: a disease caused by a virus for which there needs to be prevention and treatment.

\subsubsection{Epidemiology}

At the end of 2007, a total of 33 million people worldwide were estimated to be living with HIV, including 2.3 million children under the age of 15 . Of these, $67 \%$ were living in countries of Sub-Saharan Africa, including 2 million children $(90 \%$ of all

\footnotetext{
${ }^{1}$ For example: LAURANCE and DAVIES: "HIV/AIDS: the $21^{\text {st }}$ century Plague". Published on $22^{\text {nd }}$ November 2005 in The Independent, London, United Kingdom
} 
infected children worldwide; UNAIDS 2008). In South Africa, the HIV prevalence rate among pregnant women attending antenatal clinics was 30.2\% in 2005 (SOUTH AFRICAN DePARTMENT OF HEALth 2007); in 2006, 38.000 children were born HIV-infected (DORRINGTON et al. 2008). In the same year, 240.000 children were estimated to be living with HIV in the country (UNAIDS 2006). According to DoRRINGTON et al. (2008), in the province of the Western Cape, which includes the Cape Town Metropolitan Area, an estimated 3.000 children were either born HIV-positive or infected through breastfeeding in the year 2006 . Of an overall $11.000 \mathrm{HIV}$-infected children living in the province, 3.500 received antiretroviral treatment for HIV infection.

\subsubsection{Impact of paediatric HIV on mortality and morbidity}

The lethality of untreated paediatric HIV infection in developing countries is high: SPIRA et al. (1999) showed that $62 \%$ of Rwandan HIV-infected children died before the age of $5(n=54)$. In the same study, the overall risk of death was 20.7 times higher for infected than for uninfected children. In South Africa, a study of 143 HIV-infected children, who were followed at an urban paediatric clinic, showed significant disease progression and highlighted that maintaining less than age-appropriate weight was significantly associated with low survival rates (KOOTEN NIEKERK et al. 2006). BOBAT et al. (1999) found that $68 \%$ of deaths in a cohort of both HIV-infected and uninfected children in the South African city of Durban were HIV-related, and 83\% of these deaths occurred before the age of 10 months. The main causes of death were diarrhoea and pneumonia. Thus showing that HIV infection makes children more vulnerable to diseases that are caused by common infectious agents that have a high prevalence in developing countries (HUSSEY 2001).

\subsubsection{Principles of antiretroviral treatment}

In the developed world, HIV infection has changed from being a deadly disease into being a chronic illness. The aim of antiretroviral therapy of HIV is to decrease the plasma HIV RNA viral load in the blood and therefore stop the progression of HIV disease, while providing treatment for HIV-related opportunistic infections (BARTLETT 
2004). Highly Active Antiretroviral Therapy (HAART) is a potent combination of drugs with antiviral effects and consists of drugs that belong to at least two different drug classes: either nucleoside reverse transcriptase inhibitors (NRTIs), non-nucleoside reverse transcriptase inhibitors (NNRTIs) or protease inhibitors (PIs) (BARTLETT 2002; WILSON et al. 2004). NRTIs are analogues of desoxynucleotides and act as chain terminators that block further extension of the proviral DNA chain during reverse transcription (SQUIRES 2001). NNRTIs block the HIV reverse transcriptase through interaction with an allosteric pocket site (DE CLERCQ 2001), while protease inhibitors prevent the cleavage of protein precursors during the viral replication cycle (FLEXNER 1998). The most common agents are zidovudine, lamivudine, stavudine, abacavir and didanosine for NRTIs; nevirapine and efavirenz for NNRTIs and nelfinavir, indinavir and ritonavir for PIs (WILSON et al. 2004). Because these agents interfere with different phases of the viral replication cycle they are most effective in combination; today, a three-drug regimen is considered state of the art (BARTLETT 2004).

To minimise the risk of developing resistant viral strains, constant high concentrations of the antiretroviral agents in the blood are required. Therefore, the correct and timely intake of doses is of utmost importance. To monitor the success of HAART, two outcome parameters closely associated with clinical disease progression are monitored: CD4+ lymphocyte count and HIV-RNA load. HIV-RNA load in the patient's blood is quantified by Polymerase Chain Reaction (PCR) and given either as an absolute count of viral copies per millilitre blood sample, or calculated as $\log (10)$. The goal of HAART is to suppress viral copies to a level that is undetectable by PCR - currently being less than 50 copies/ml or a $\log <1.49$ (WILSON et al. 2004). HAART has been shown to reduce morbidity and mortality. For example, in a group of 1255 patients from the United States, mortality declined from 29.4 per 100 person-years before antiretroviral treatment to 8.8 per 100 person-years after initiating treatment (PALELLA, JR. et al. 1998). In the same cohort, the incidence of the three major opportunistic infections (Pneumocystis carinii pneumonia, Mycobacterium avium complex disease, and cytomegalovirus retinitis) declined from 21.9 per 100 person-years to 3.7 per 100 personyears. 


\subsubsection{Treatment of HIV-infected children}

Combination therapy with HAART is the most effective treatment for HIV-infected children and is incorporated in paediatric treatment guidelines (ABRAMS et al. 2004; HAVENS et al. 2008; MCKINNEY 2006). The same antiretroviral agents for adults are used, although in different dosages and often in liquid formulations to improve palatability. PALUMBO et al. (1998) demonstrated that plasma HIV RNA levels and CD4+ lymphocyte count are significant predictors of time regarding clinical disease progression or death, and that at 24 months of HAART, plasma RNA levels under the detectable limit are associated with a greater than $93 \%$ 2-year progression-free survival. HAART in children should, therefore, have the goal of achieving non-detectable viral plasma RNA levels, and plasma RNA levels and CD4+ lymphocyte counts are used as prognostic markers in monitoring the efficacy of HAART (HAVENS et al. 2008; VAN ROSSUM et al. 2002b). The absolute amount of CD4+ cells changes with age, and the percentage of CD4+ cells out of all T-lymphocytes is the preferred prognostic marker in paediatric patients (VAN ROSSUM et al. 2002b), as opposed to absolute CD4+ lymphocyte counts as used in adults.

Outcomes that define the success of HAART are a decrease in plasma RNA levels and an absolute or relative increase in CD4+ cells, which lead to a strengthened immune system with lower mortality and morbidity. Anthropomorphic parameters such as weightand height-gain also serve as markers, with weight often being measured as the deviation from standardised weight-for-age z-scores (WAZ), height as the deviation from heightfor-age z-scores (HAZ). VAN Rossum et al. (2002b) reviewed 23 studies on efficacy of paediatric antiretroviral treatment and found virus suppression in $63-87 \%$ of all children on HAART. In a longitudinal study conducted with 1142 children in Italy, DE MARTINO et al. (2000) showed that survival was significantly higher in HIV-infected birth cohorts that had been treated with HAART than in untreated ones. GORTMAKER et al. (2001) demonstrated that HAART reduces mortality among children and adolescents with HIV infection. 


\subsubsection{Treatment in resource-limited settings}

There have been great concerns over whether the infrastructural, socio-economic and political difficulties in the countries of the developing world will allow for demanding and complicated treatment programs resulting in treatment success (HARRIES et al. 2001). The World Health Organization (WHO) advises that treatment principles in resourcelimited settings be the same as for the developed world (WHO 2004). In addition, recent initiatives such as the Global Fund To Fight AIDS, Tuberculosis and Malaria (GFATM) and the Presidential Emergency Plan for AIDS Relief (PEPfAR) have provided funding to ensure availability and sustainability of antiretroviral treatment for these countries.

Because the number of patients in developing countries is far greater than in the developed world (UNAIDS 2008), developing countries follow a public health approach in providing HAART for adults and children. The choice of antiretroviral drugs is limited, and fixed drug combinations are provided in so-called first- and second-line regimens. The term first-line regimen describes the initial antiretroviral drug combination with which a patient starts. Upon the development of resistance to one or more of the drugs a switch to the second-line regimen, which includes different drugs, is possible. These fixed combinations do not permit the patient-individualised, "tailor-made" regimens available in the developed world (WHO 2005). In this way, the cost of antiretroviral drugs is reduced and treatment programs are more affordable and can allow for large numbers of patients. Markers for successful treatment outcome are the same as in the developed world: low plasma RNA levels (although the technical equipment to measure plasma RNA levels might not be available everywhere), improvement in CD4+ lymphocyte count, reduced mortality and morbidity. Recent studies have shown that adults in resource-limited settings achieve high rates of undetectable plasma RNA levels and improve clinically after initiating HAART (COETZEE et al. 2004; KOENIG et al. 2004).

Studies in paediatric populations have shown that HAART improves immunological and virological parameters as well as anthropomorphic outcomes (ELEY et al. 2004; FASSINOU et al. 2004; Humblet et al. 2004; JibRIL et al. 2004; LODHA et al. 2005; NyAndiko et al. 2006; Rouet et al. 2006). A South African study, conducted when antiretroviral treatment was not yet widely available, showed that the few children who started on HAART had a $87 \%$ reduction in mortality compared to those not taking 
antiretrovirals (KoOTEn NiEKERK et al. 2006). REDDi et al. (2007) followed a South African cohort of $151 \mathrm{HIV}$-infected children starting HAART in an urban hospital in the province of KwaZulu-Natal. After 12 months, 96.6\% of the children $(n=59)$ had an increase in CD4+\% from baseline, and out of 61 patients with available viral loads, $80.3 \%$ had undetectable RNA plasma levels. The Kaplan Meier one year survival estimate was 90.9\%. $73.8 \%$ of the children showed a significant increase in WAZ-score after the first month, an important finding considering that low WAZ-scores are associated with poor survival rates (KoOTEN NIEKERK et al. 2006). FASSINOU et al. (2004) from Côte d'Ivoire report that the incidence of two of the most life-threatening conditions in childhood, pneumonia and severe diarrhoea, was significantly lower after children started HAART. SPIRA et al. (1999) documented that these conditions were the most common reasons for death in HIV-infected Rwandan children.

Given the limited financial resources, the SOUTH AFRICAN DEPARTMENT OF HEALTH (2004) has issued National Guidelines for Antiretroviral Therapy in Children that are applicable to all paediatric patients treated in the public health care sector and provide two treatment regimens. For children treated in the province of the Western Cape, the guidelines apply in combination with the Provincial Antiretroviral Protocol of the Western Cape (COHEN et al. 2004). The first line regimen is stavudine or zidovudine (depending on whether or not the patient has a refrigerator to store stavudine), lamivudine and lopinavir/ritonavir. The available second line regimen consists of didanosine, zidovudine and nevirapine or didanosine, abacavir and nevirapine (nevirapine to be switched to efavirenz in children over 3 years). Unlike in developed countries, the choice of the antiretroviral agent is not determined individually for each patient. Thus far, the optimal antiretroviral treatment combination for children in developed countries has not yet been examined in terms of virological and immunological outcome, treatment safety and efficacy, as well as long-term survival. A recent retrospective examination of children receiving antiretroviral treatment at an academic hospital in Cape Town showed that regimens based on protease inhibitors may be associated with a better virological outcome than regimens based on non-nucleoside reverse transcriptase inhibitors (JASPAN et al. 2008). In Romania, children on PI-based regimes achieved good outcomes over long periods of treatment (KLINE et al. 2007). It is known from adults that boosted lopinavir 
(LPV/r), a particularly potent PI with relatively high genetic resistance barrier (KEMPF et al. 2004; MoORE et al. 2006), can lead to sustained virus suppression over up to 6 years in almost all patients (LANDAY et al. 2007). The use of a drug with a higher resistance barrier may seem advantageous in children who are still at the beginning of their life-long treatment. However, there have been no studies examining this in resource-limited settings.

\subsection{Adherence - 'Drugs don't work in patients who don't take them"2}

\subsubsection{Adherence - an updated definition}

Chronically ill patients need to take medication for the rest of their life. This requires discipline and commitment on the patient's part, as well as good education and communication from the health care providers. Formerly, the term "compliance" was used to characterise how the patients' followed the health care providers' instructions. As models of patient-physician relationship have evolved, the definition of "compliance" has changed to encompass a viewpoint that focuses more on cooperation between patient and health care provider. The term "compliance" has been replaced with "adherence" in order to acknowledge the patient's active participation in the decision-making process and, in addition, to see medication-taking behaviour from the patient's perspective: "Adherence is the engaged and accurate participation of an informed patient in a plan of care. It is a broader term than compliance - the extent to which patients follow the instructions of their healthcare providers - and implies understanding, consent, and partnership. Adherence includes entering into and continuing in a program or care plan, attending appointments and tests as scheduled, taking medications as prescribed, modifying lifestyle as needed, and avoiding risk behaviours. It includes adherence to care and adherence to medication, but is usually regarded as more than the sum of its parts."3. OSTERBERG and BLASCHKE (2005) further elaborate on the difference between 'compliance' and

\footnotetext{
${ }^{2}$ C. Everett Koop, Professor of Pediatrics and Paediatric Surgery, University of Pennsylvania; Surgeon General of the United States 1982 - 1989, quoted in: OSTERBERG and BLASCHKE (2005; p. 487)

${ }^{3}$ Quote from RABKIN et al. (2005; p. 11)
} 
'adherence:' "The word 'adherence' is preferred by many health care providers, because 'compliance' suggests that the patient is passively following the doctor's orders and that the treatment plan is not based on a therapeutic alliance or contract established between the patient and the physician." The World Health Organization suggests broadening the definition of the term 'adherence' to "the extent to which a person's behaviour - taking medication, following a diet, and/or executing lifestyle changes, corresponds with agreed recommendations from a health care provider" (WHO 2003; p. 3). According to BERG and ARnSten (2006; p. S79) this behaviour is "individual, complex and dynamic". Table 1 illustrates the various dimensions of adherence[r1], and each dimension's correlate in the patient's behaviour.

Table 1: Dimensions of Adherence ${ }^{4}$

\begin{tabular}{ll}
\hline Adherence Behavior & Behavioral Task \\
\hline Medication-refill adherence & Patient picks up a prescription refill \\
Medication-interval adherence & Patient takes a medication at the right time of the \\
day & Patient takes the right number of pills \\
Medication-quantity adherence & Patient takes medication in accordance with dietary \\
Medication-diet adherence & requirements (if specified) \\
\hline
\end{tabular}

Contrary to this concept, clinical practice often limits the term 'adherence' to the intake of medication and disregards the broader implications of its definition. Adherence [r2] is usually reported as the percentage of the prescribed doses actually taken by the patient over a specified period of time, and thus reduced to recommendations that instruct the patient on tablet intake. For these instructions, adherence can vary along a continuum from 0 to 100 percent, sometimes over 100 percent if patients take more than the prescribed amount of medication. Adherence can also be reported as a dichotomous variable, classifying patients into the categories 'adherent' or 'non-adherent.' Because there is no consensual standard for what constitutes adequate adherence, the cut-off value for these categories depends on the patient's condition, the characteristics of the regimen prescribed, pharmacokinetics of the prescribed medication and on individual research

\footnotetext{
${ }^{4}$ Table taken from KERR et al. (2005; p. 201)
} 
protocols. For HIV infection, an adherence rate greater than 95 percent is considered adequate and necessary for treatment success (CHESNEY 2003; ICKOVICS et al. 2002; PATERSON et al. 2000). However, common to all these definitions of adherence is the fact that they focus solely on the intake of medication and do not allow for an inclusion of dietary instructions, lifestyle changes or general health behaviour of patients.

\subsubsection{Adherence to Highly Active Antiretroviral Therapy}

Adherence has been the focus for medication of chronic diseases such as diabetes and hypertension, or for patients taking immunosuppressants after organ transplantation. With HIV infection emerging as a relatively new chronic illness and the introduction of HAART in its treatment, adherence to antiretroviral therapy also needs to be assessed in more detail. Adherence has been shown to have a significant impact on all outcome parameters of antiretroviral treatment: on plasma HIV RNA levels, on CD4+ lymphocyte count as well as on survival rates. BANGSBERG et al. (2000) demonstrated a strong linear relationship between adherence to HAART and plasma HIV RNA levels, with a 10\% decrease in adherence leading to a doubling of HIV RNA plasma levels. Among patients with undetectable HIV RNA load, adherence predicts the time that viral load is kept at undetectable levels (RABOUD et al. 2002). Adherence was found to be significantly associated with successful virological outcome (PATERSON et al. 2000) and an increase in CD4+ lymphocyte count (SINGH et al. 1999).

MANNHEIMER et al. (2002) showed the effect of adherence on virological and immunological outcomes of 540 patients from different study sites in the United States. After a 12-month follow-up period, study participants were classified into groups of $100 \%, 80-99 \%$ and $0-79 \%$ adherence. The percentage of subjects with non-detectable HIV RNA plasma levels was $66 \%, 47 \%$, and $17 \%$, respectively. During the same period, the CD4+ lymphocyte count revealed a significant increase by 179,159 and 53 cells/mm3 in each adherence group. Similar results were reported by PATERSON et al. (2000) and are visualised in Figure 1. 


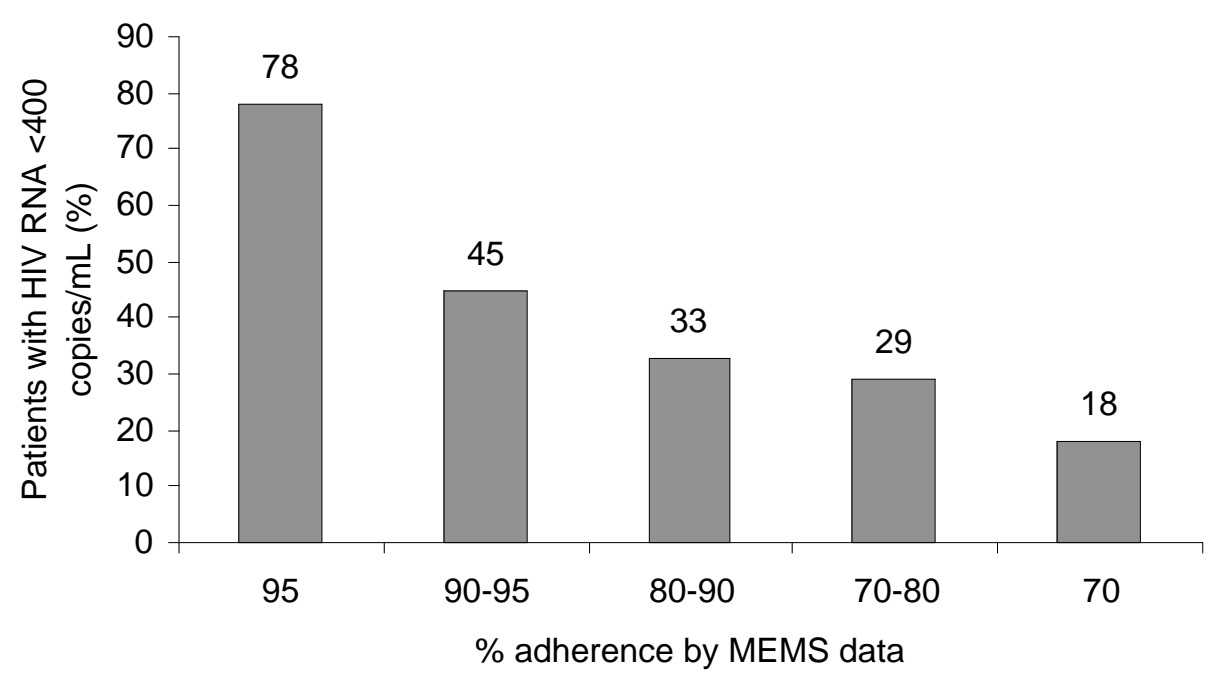

Figure 1: Relationship between virological outcome and adherence to antiretroviral therapy MEMS: Medication Event Monitoring System for measuring adherence. HIV RNA $<400$ copies $/ \mathrm{mL}$ is equivalent to virological suppression. The percentage of patients with virological suppression decreases with lower adherence levels. Figure adapted after PILIERO (2004; p. S3), using data by PATERSON et al. (2000)

GARCIA et al. (2002) showed that adherent patients had significantly higher 3-year survival rates than non-adherent patients, with 81.2 and 72.9 percent respectively. To the same extent that adequate adherence is linked to positive treatment outcomes, nonadherence can result in an increased viral load, emerging drug resistance that limits further treatment options and, ultimately, in more rapid progression to clinical AIDS and increased mortality (CARRIERI et al. 2003; KNOBEL et al. 2001). Even though data for adherence in children is scarcer than for adults, it is suggested that adherence to HAART is a strong predictor of treatment success in this population as well (FEINGOLD et al. 2000; FUNK et al. 2008; VAN DYKE et al. 2002).

\subsubsection{Adherence to paediatric HAART}

For children receiving HAART, the responsibility for correctly administering the child's treatment lies with the caregiver, especially in very young children who are unable to care for themselves. It is therefore necessary to deal not only with the issues of the young patient but also with the issues of the parents or other caregivers, thus adding to the complexity of paediatric medication adherence. Especially in this population, measuring 
adherence is a challenge that makes comparison between study results difficult because of its variety. Table 2 summarises studies on paediatric adherence to HIV treatment and compares adherence measurements and outcomes in different settings. In summary of the listed studies, it is clear that no single measure of adherence is established as goldstandard yet. Therefore, this makes it difficult to compare results across studies and populations. Self-reported adherence rates are higher than pharmacy refill or pill counts, and the two studies using electronic monitoring devices show even lower rates of adherence. To date there are thirteen studies from resource-limited settings, with similar adherence results as found in studies from the developed world (BIADGILIGN et al. 2008; BiKAAKO-KAJURA et al. 2006; DAVIES et al. 2008; Elise et al. 2005; FASSINOU et al. 2004; HansudewechaKul et al. 2006; KiboneKa et al. 2008; Mukhtar-Yola et al. 2006; NABUKEERA-BARUNGi et al. 2007; NATU and DAGA 2007; NyANDIKo et al. 2006; REDDI et al. 2007; SAFREED-HARMON et al. 2007).

Most of these studies from resource-limited settings rely on self-reporting as an adherence measure, and no electronic monitored adherence data is yet available. Common to all studies is a wide age range of participating children, which makes it difficult to determine adherence levels for specific age groups that face age-specific challenges (for example palatability and refusal to swallow for very young children; disclosure and rebellious behaviour for adolescents). For young children in the age group from 0-6 years, very little data is available: the only results come from a South African cohort described by DAVIES et al. (2008). Taking into account the fact that most current paediatric HIV infections, as well as expected future infections, will occur in countries of the developing world, BIKAAKO-KAJURA et al. (2006) formulate the need for expanded research in this field. 
Table 2: A review of paediatric adherence studies from 1999 - 2008

\begin{tabular}{|c|c|c|c|c|}
\hline Authors & Measurement method & Sample characteristics & $\begin{array}{l}\text { Estimated } \\
\text { adherence }\end{array}$ & Metric of assessment \\
\hline AlBANO et al. (1999) & Therapeutic drug monitoring & $\begin{array}{l}\mathrm{N}=10 \\
\text { (mean age } 4 \text { yrs } 10 \\
\text { months) } \\
\text { Italy }\end{array}$ & $50 \%$ & $\begin{array}{l}\text { Showed adequate plasma } \\
\text { levels of the monitored drug }\end{array}$ \\
\hline $\begin{array}{l}\text { BIADGILIGN et al. } \\
(2008)\end{array}$ & Caregiver report & $\begin{array}{l}\mathrm{N}=390 \\
(1-14 \text { years }) \\
\text { Ethiopia }\end{array}$ & $87 \%$ & $\begin{array}{l}\text { Reported no missed dose in } \\
\text { last } 7 \text { days }\end{array}$ \\
\hline \multirow[t]{2}{*}{$\begin{array}{l}\text { BIKAAKO-KAJURA et } \\
\text { al. (2006) }\end{array}$} & Caregiver interview & $\begin{array}{l}\mathrm{N}=42 \\
\text { (median age } 12 \text { years) }\end{array}$ & $29 \%$ & Reported no missed doses \\
\hline & Caregiver interview & Uganda & $31 \%$ & $\begin{array}{l}\text { Reported frequently missed } \\
\text { doses }\end{array}$ \\
\hline \multirow[t]{2}{*}{ BONI et al. (2000) } & Caregiver report & $\begin{array}{l}\mathrm{N}=25 \\
\text { (mean age } 8.2 \text { years) }\end{array}$ & $24 \%$ & $\begin{array}{l}\text { Missed >1 dose in last } 3 \\
\text { days }\end{array}$ \\
\hline & & Italy & $44 \%$ & $\begin{array}{l}\text { Missed }>1 \text { dose since last } \\
\text { visit }\end{array}$ \\
\hline \multirow[t]{4}{*}{ BYRNE et al. (2002) } & Caregiver report & $\begin{array}{l}\mathrm{N}=42 \\
\text { (4 months to } 18 \text { years) }\end{array}$ & $97 \%$ & $\begin{array}{l}\text { Reported missing no doses } \\
\text { in last week }\end{array}$ \\
\hline & Pharmacy refill & U.S. & $100 \%$ & $\begin{array}{l}\text { Filled all ART prescriptions } \\
\text { in last } 3 \text { months }\end{array}$ \\
\hline & Clinic attendance & & $88 \%$ & $\begin{array}{l}\text { Missing no appointments in } \\
\text { last } 3 \text { months }\end{array}$ \\
\hline & Caregiver report & & $88 \%$ & $\begin{array}{l}\text { Mean adherence by Visual } \\
\text { Analogue Scale (VAS) }\end{array}$ \\
\hline \multirow[t]{2}{*}{ DAVIES et al. (2008) } & Caregiver report & $\begin{array}{l}\mathrm{N}=122 \\
\text { (median age } 37 \text { months) } \\
\text { South Africa }\end{array}$ & $86 \%$ & $\begin{array}{l}\text { Reported no missed doses in } \\
\text { last } 3 \text { days }\end{array}$ \\
\hline & Medication return & & $73 \%$ & $>95 \%$ adherence \\
\hline ELISE et al. (2005) & Caregiver report & $\begin{array}{l}\mathrm{N}=112 \\
\text { Côte d'Ivoire }\end{array}$ & $67 \%$ & $\begin{array}{l}\text { Reported no missed doses in } \\
\text { last month }\end{array}$ \\
\hline \multirow[t]{3}{*}{ FARLEY et al. (2003) } & Caregiver report & $\begin{array}{l}\mathrm{N}=26 \\
\text { (mean age } 6.9 \text { years) }\end{array}$ & $100 \%$ & $\begin{array}{l}\text { Reported no missed doses in } \\
\text { last } 3 \text { days }\end{array}$ \\
\hline & Pharmacy refill & U.S. & $92 \%$ & $\begin{array}{l}\text { Doses dispensed/ doses } \\
\text { prescribed }\end{array}$ \\
\hline & Electronic monitoring device & & $81.4 \%$ & $\begin{array}{l}\text { Doses taken/ doses } \\
\text { prescribed }\end{array}$ \\
\hline FASSINOU et al. (2004) & $\begin{array}{l}\text { Individual caregiver } \\
\text { interviews }\end{array}$ & $\begin{array}{l}\mathrm{N}=78 \\
\text { (mean age } 7.2 \text { years) } \\
\text { Côte d'Ivoire }\end{array}$ & $\begin{array}{l}\text { "globally } \\
\text { good" }\end{array}$ & $\begin{array}{l}\text { Reports from caregivers in } \\
\text { psychologist sessions }\end{array}$ \\
\hline $\begin{array}{l}\text { FEINGOLD et al. } \\
(2000)\end{array}$ & Caregiver report & $\begin{array}{l}\mathrm{N}=70 \\
(5 \text { months to } 17 \text { years }) \\
\text { U.S. }\end{array}$ & $26 \%$ & Missed $>4$ doses/week \\
\hline
\end{tabular}




\begin{tabular}{|c|c|c|c|c|}
\hline $\begin{array}{l}\text { GIACOMET et al. } \\
\text { (2003) }\end{array}$ & Caregiver report & $\begin{array}{l}\mathrm{N}=129 \\
\text { Italy }\end{array}$ & $84 \%$ & $\begin{array}{l}\text { Missed less than } 5 \% \text { of } \\
\text { prescribed doses in last } 4 \\
\text { days }\end{array}$ \\
\hline GIBB et al. (2003) & Child/ Caregiver report & $\begin{array}{l}\mathrm{N}=108 \\
\text { Europe }\end{array}$ & $74 \%$ & $\begin{array}{l}\text { Reported no missed doses in } \\
\text { last week }\end{array}$ \\
\hline GoODE et al. (2003) & Caregiver report & $\begin{array}{l}\mathrm{N}=18 \\
\text { Australia }\end{array}$ & $67 \%$ & $\begin{array}{l}\text { Reported no missed doses in } \\
\text { last } 3 \text { weeks }\end{array}$ \\
\hline $\begin{array}{l}\text { HAMMAMI et al. } \\
\text { (2004) }\end{array}$ & Caregiver report & $\begin{array}{l}\mathrm{N}=11 \\
\text { (4 months to } 19 \text { years) } \\
\text { Belgium }\end{array}$ & $73 \%$ & $\begin{array}{l}\text { Reported no missed doses in } \\
\text { last } 3 \text { days }\end{array}$ \\
\hline $\begin{array}{l}\text { HANSUDEWECHAKUL } \\
\text { et al. (2006) }\end{array}$ & Pill Count & $\begin{array}{l}\mathrm{N}=110 \\
\text { (median age } 9.3 \text { years) } \\
\text { Thailand }\end{array}$ & $90 \%$ & $\begin{array}{l}\text { Took }>95 \% \text { of doses } \\
\text { prescribed in last } 6 \text { months }\end{array}$ \\
\hline KATKO et al. (2001) & Caregiver report & $\begin{array}{l}\mathrm{N}=34 \\
\text { U.S. }\end{array}$ & $34 \%$ & Reported $100 \%$ adherence \\
\hline $\begin{array}{l}\text { KIBONEKA et al. } \\
\text { (2008) }\end{array}$ & $\begin{array}{l}\text { Combined pharmacy refill }+ \\
\text { caregiver report }+ \text { pill count }\end{array}$ & $\begin{array}{l}\mathrm{N}=770 \\
\text { (median age } 9 \text { years) } \\
\text { Uganda }\end{array}$ & $95 \%$ & $>95 \%$ adherent \\
\hline $\begin{array}{l}\text { MARHEFKA et al. } \\
\text { (2004) }\end{array}$ & Pharmacy refill & $\begin{array}{l}\mathrm{N}=51 \\
\text { ( } 2 \text { to } 12 \text { years) } \\
\text { U.S. }\end{array}$ & $49 \%$ & $\begin{array}{l}\text { More than } 90 \% \text { adherent in } \\
\text { last } 3 \text { months }\end{array}$ \\
\hline MARTIN et al. (2007) & Electronic monitoring device & $\begin{array}{l}\mathrm{N}=17 \\
\text { (mean age } 13.9 \text { years) } \\
\text { U.S. }\end{array}$ & $80 \%$ & $\begin{array}{l}\text { Of doses in last } 6 \text { months } \\
\text { given within } 2 \text { hours of } \\
\text { prescribed time }\end{array}$ \\
\hline MELLINS et al. (2004) & Caregiver report & $\begin{array}{l}N=75 \\
\text { ( } 3 \text { to } 13 \text { years) }\end{array}$ & $60 \%$ & $\begin{array}{l}\text { Reported } 100 \% \text { adherence } \\
\text { in last month }\end{array}$ \\
\hline & Child report & U.S. & $44 \%$ & $\begin{array}{l}\text { Reported } 100 \% \text { adherence } \\
\text { in last month }\end{array}$ \\
\hline $\begin{array}{l}\text { MUKHTAR-YOLA et al. } \\
\text { (2006) }\end{array}$ & Caregiver/ Child report & $\begin{array}{l}\mathrm{N}=40 \\
\text { Nigeria }\end{array}$ & $80 \%$ & Reported $>95 \%$ adherence \\
\hline $\begin{array}{l}\text { NAAR-KING et al. } \\
(2005)\end{array}$ & Caregiver report & $\begin{array}{l}\mathrm{N}=40 \\
\text { (mean age } 9 \text { years) } \\
\text { U.S. }\end{array}$ & $97 \%$ & Of doses given in last month \\
\hline \multirow[t]{2}{*}{$\begin{array}{l}\text { NABUKEERA-BARUNGI } \\
\text { et al. (2007) }\end{array}$} & Caregiver report & $\begin{array}{l}\mathrm{N}=170 \\
\text { (mean age } 9.8 \text { years) }\end{array}$ & $99 \%$ & $\begin{array}{l}\text { Reported no missed doses in } \\
\text { last } 3 \text { days }\end{array}$ \\
\hline & $\begin{array}{l}\text { Pill count (announced/ } \\
\text { unannounced) }\end{array}$ & Uganda & $97 \% / 94 \%$ & $\begin{array}{l}\text { Adherence over past } 3 \\
\text { weeks }\end{array}$ \\
\hline
\end{tabular}




\begin{tabular}{|c|c|c|c|c|}
\hline $\begin{array}{l}\text { NATU and DAGA } \\
(2007)\end{array}$ & Follow-up appointments & $\begin{array}{l}\mathrm{N}=25 \\
\text { (median age } 6 \text { years } 8 \\
\text { months) } \\
\text { India }\end{array}$ & $95 \%$ & $\begin{array}{l}\text { Of } 175 \text { overall follow-up } \\
\text { visits kept on schedule }\end{array}$ \\
\hline $\begin{array}{l}\text { NICHOLSON et al. } \\
(2006)\end{array}$ & Caregiver report & $\begin{array}{l}\mathrm{N}=75 \\
\text { (mean age } 8 \text { years) } \\
\text { U.S. }\end{array}$ & $40 \%$ & $\begin{array}{l}\text { Reported missing one or } \\
\text { more doses during last } \\
\text { month }\end{array}$ \\
\hline $\begin{array}{l}\text { NYANDIKO et al. } \\
\text { (2006) }\end{array}$ & Child/ Caregiver report & $\begin{array}{l}\mathrm{N}=279 \\
\text { Kenya }\end{array}$ & $75 \%$ & $\begin{array}{l}\text { Reported no missed doses in } \\
\text { last month }\end{array}$ \\
\hline REDDI et al. (2007) & Caregiver report & $\begin{array}{l}\mathrm{N}=132 \\
\text { (median age } 5.7 \text { years) } \\
\text { South Africa }\end{array}$ & $89 \%$ & $\begin{array}{l}\text { Reported }<2 \text { doses missed in } \\
\text { last month }\end{array}$ \\
\hline $\begin{array}{l}\text { REDDINGTON et al. } \\
(2000)\end{array}$ & Caregiver report & $\begin{array}{l}\mathrm{N}=90 \\
(0 \text { to } 14 \text { years }) \\
\text { U.S. }\end{array}$ & $\begin{array}{l}17 \% \\
43 \%\end{array}$ & $\begin{array}{l}\text { Reported missing doses } \\
\text { within past } 24 \text { hours } \\
\text { Reported missing doses } \\
\text { within past week }\end{array}$ \\
\hline \multirow[t]{2}{*}{$\begin{array}{l}\text { SAFREED-HARMON et } \\
\text { al. (2007) }\end{array}$} & Pill count & $\mathrm{N}=29$ & $99 \%$ & $\begin{array}{l}\text { No missed doses in last } \\
\text { month (biological parents) }\end{array}$ \\
\hline & & & $98 \%$ & $\begin{array}{l}\text { No missed doses in last } \\
\text { month (non-biological } \\
\text { parents) }\end{array}$ \\
\hline \multirow[t]{2}{*}{ STEELE et al. (2001) } & Caregiver report & $\begin{array}{l}\mathrm{N}=30 \\
\text { (mean age } 5.21 \text { years) }\end{array}$ & $94 \%$ & $\begin{array}{l}\text { Adherence with doses in } \\
\text { past } 3 \text { days }\end{array}$ \\
\hline & Pill Count & U.S. & $89 \%$ & $\begin{array}{l}\text { Adherence over the past } 30 \\
\text { days }\end{array}$ \\
\hline TEMPLE et al. (2001) & Pill Count & $\begin{array}{l}\mathrm{N}=21 \\
\text { (mean age } 6.9 \text { years) } \\
\text { U.S. }\end{array}$ & $70 \%$ & Overall adherence \\
\hline $\begin{array}{l}\text { VAN DYKE et al. } \\
\text { (2002) }\end{array}$ & Caregiver report & $\begin{array}{l}\mathrm{N}=125 \\
\text { (median age } 6.3 \text { years) } \\
\text { U.S. }\end{array}$ & $70 \%$ & $\begin{array}{l}\text { Reported "full adherence" } \\
\text { in past } 3 \text { days }\end{array}$ \\
\hline $\begin{array}{l}\text { VAN ROSSUM et al. } \\
\text { (2002a) }\end{array}$ & Therapeutic drug monitoring & $\begin{array}{l}\mathrm{N}=40 \\
(3 \text { months to } 18 \text { years }) \\
\text { Netherlands }\end{array}$ & $67 \%$ & $\begin{array}{l}\text { Classified as full adherent } \\
\text { (defined as drug plasma } \\
\text { level above concentration } \\
\text { ratio limit) }\end{array}$ \\
\hline $\begin{array}{l}\text { WATSON and FARLEY } \\
\text { (1999) }\end{array}$ & Pharmacy refill & $\begin{array}{l}\mathrm{N}=72 \\
(3 \text { months to } 12 \text { years }) \\
\text { U.S. }\end{array}$ & $52 \%$ & Previous 180 days \\
\hline $\begin{array}{l}\text { WILLIAMS et al. } \\
\text { (2006) }\end{array}$ & Child/ Caregiver report & $\begin{array}{l}\mathrm{N}=2088 \\
\text { (median age } 11.5 \text { years) } \\
\text { U.S. }\end{array}$ & $84 \%$ & $\begin{array}{l}\text { Reported no missed doses in } \\
\text { last } 3 \text { days }\end{array}$ \\
\hline
\end{tabular}




\subsubsection{The role of adherence in resource-limited settings}

In a public statement made in 2001, then chief of the U.S. Agency for International Development (USAID), Andrew Natsios, was quoted as saying that Africans "don't know what Western time is" and thus could not take antiretroviral treatment on the proper schedule. In addition, he reportedly stated that when Africans were asked to take their drugs at a certain time of the day, they "do not know what you are talking about". This statement, implying that the culture and the general attitude of people living in African countries would render them unable to adhere to antiretroviral treatment, has been strongly condemned by patients, physicians and patients from these countries. In the following years, a number of studies from resource-limited settings with HIV infected adults taking antiretroviral treatment have shown that adherence is, in fact, rather good (BYAKIKA-TUsiIme et al. 2005; IDIGBE et al. 2005; IliYasu et al. 2005; LAURENT et al. 2004; LAURENT et al. 2005; NACHEGA et al. 2004; VAN OOSTERHOUt et al. 2005). In the first of two South African studies, OrRell et al. (2003) from Cape Town found that of 278 adults followed over 48 weeks, the median adherence was $94 \%$, and concluded that low socio-economic status was not a barrier to achieving good adherence to antiretroviral triple therapy. In the other South African study, NACHEGA et al. (2004) showed that $97 \%$ of HIV-infected adults receiving antiretroviral treatment at a public hospital in Johannesburg had adherence levels of greater than 90 percent. These findings are consistent with a meta-analysis comparing the adherence to antiretroviral treatment in patients from the United States to the adherence in patients from Sub-Saharan Africa, which found that the latter patient group showed higher pooled rates of adherence, and underlined the ability of African patients to adhere to their treatment (MiLLS et al. 2006). To date, there are few studies that have assessed adherence in children in countries of Sub-Saharan Africa, but those that do exist indicate rather good adherence levels, similar to those observed in adult patients (VREEMAN et al. 2008).

In these resource-limited settings, adherence is of even greater importance, yet may also be more difficult to achieve (GILL et al. 2005; HARRIES et al. 2001). In order not

\footnotetext{
${ }^{5}$ See ATtARAN et al.: "Dead wrong on AIDS". Published on 15 ${ }^{\text {th }}$ July 2001 in The Washington Post, United States.
} 
to jeopardise the limited treatment options, virological suppression should be sustained for as long as possible. Emerging studies from various settings in resource-limited countries support the findings of MiLLS et al. (2006) and show adherence rates that are as high or even higher than in the developed world (BYAKIKA-TUSIIME et al. 2005; LAURENT et al. 2005; OYUGI et al. 2004). In the context of these countries, structural and social inequalities have a considerable impact on the health status of patients. A recent report by the WHO Commission on Social Determinants of Health (CSDH 2008) indicates that the quality of urban and rural living conditions such as housing, sanitation and access to clean water are vital contributors to health. This should be borne in mind when comparing the outcomes of antiretroviral treatment in developing countries to outcomes from Europe and North America. It should also be borne in mind that the risk of treatment failure is higher when health status is poorer, regardless of adherence.

\subsubsection{Assessing adherence}

Accurately measuring levels of adherence to medication is important in clinical trials as well as in clinical practice. For clinical trials, the knowledge that patients actually take the medication studied is imperative to allow examination of dose-response relationships and treatment efficacy. In clinical practice, the failure of a therapy to provide the desired clinical outcome can be due to either drug failure or poor adherence, and health care providers need information on adherence to make the appropriate clinical decision. In the case of HAART it is known that adherence levels decrease over time (HowARD et al. 2002), and adherence monitoring is necessary to identify patients in need of adherence-improvement interventions before the clinical effects of non-adherence start to show. Measures in clinical settings should be effective, practical and inexpensive, with the aim of identifying poorly adherent patients. This is of even greater importance in resource-limited settings where limited treatment options often do not accommodate for drug changes that become necessary after the development of resistant viral strains due to poor adherence (GILL et al. 2005). Among the variety of available adherence measures, one can differentiate between direct and indirect measures (FARMER 1999). Direct measures provide proof that the drug has been taken by the patient, either by therapeutic 
drug monitoring in the blood or urine, by detection of a biologic marker given with the drug or by direct observation of the patient taking the medication. Indirect measures can be categorised into self-reporting by the patient, medication measurement (pill count or estimation of liquid drug formulations), use of electronic monitoring devices (EMD) or pharmacy prescription record review. Most of the methods used to measure adherence are indirect, and each method has advantages and disadvantages that need to be weighed against each other. In general, the accuracy of measures is determined by calculating the sensitivity and specificity of the method with a standard of reference (RANSOHOFF and FEINSTEIN 1978). For adherence measures, sensitivity denotes the proportion of adherent patients that are correctly identified as adherent; high specificity means that as few nonadherent patients as possible should be wrongly identified as adherent. The overall accuracy of the method is calculated by incorporating the proportion of patients that are correctly identified as adherent or non-adherent. A further way of validating adherence measures is by determining their correlation with a surrogate marker of adherence. Undetectable HIV RNA plasma levels, indicating that the HAART effectively works against the HI virus, serve as surrogate markers for adherence to HAART (ARNSTEN et al. 2001; LiU et al. 2001; PATERSON et al. 2000). KIRKLAND et al. (2002) showed that $85 \%$ of patients achieved virological suppression (VS) with a mean adherence of $94 \%$ as measured by directly observed therapy - the link between adherence and VS can be established with a high degree of confidence, since adherence is known precisely by observation. However accurate one single measure of adherence may be, it is recommended to use a combination of measures to adjust for possible bias of each single method: "A multi-method approach that combines feasible self-reporting and reasonable objective measures is the current state-of-the-art in measurement of adherence behaviour." (WHO 2003).

\subsubsection{Assessing adherence to HAART in children}

In HIV infected children, assessing adherence is a crucial component of good clinical care, yet also challenging and labour intensive (FARLEY 2006). PRENDERGAST et al. (2007) argue that good adherence is more difficult to achieve in children than in adults 
owing to numerous challenges such as tablet size, syrup palatability and the dependence on possibly unreliable caregivers. Methods used to measure adherence include self reporting (caregiver report for young children), pill count, electronic monitoring, pharmacy refill records, therapeutic drug monitoring and assessment of appointmentkeeping patterns. Knowledge about the validity and reliability of these methods is mostly taken from studies of adult patients; yet there is an emergence of paediatric studies in the field, which are urgently needed.

Self reporting is an inexpensive and quick tool to assess adherence at a health care facility or at home. It can be employed by doctors or nurses, counsellors, social workers, or clinical psychologists. Depending on the relationship of the patient to the interviewer or the administering physician, the results can vary in reliability. Self report measures can be e.g. structured questionnaires asking about doses that were missed during a specified time before the clinic visit and thus quantifying non-adherence ${ }^{6}$ (BONI et al. 2000; BYRNE et al. 2002; GibB et al. 2003; RedDington et al. 2000; STEELE et al. 2001; VAn DyKE et al. 2002). Information on missed doses is used to classify patients or caregivers into adherent and non-adherent groups. Visual Analogue Scales (VAS) require caregivers to self-rate their child's adherence in percent and measure adherence as a continuous variable (BYRnE et al. 2002; GIORDANO et al. 2004; OYUGI et al. 2004; WALSH et al. 2002). Open interviews can highlight problems around adherence but make it more difficult to quantify adherence rates. A recent meta-analysis of various self-report measures in adult patients showed that in $85 \%$ of all studies reviewed, self-reported adherence was significantly associated with virological outcome (SIMONI et al. 2006).

For pill count adherence measurement, caregivers are asked to return their unused medication at each clinic visit. A health care provider or researcher then calculates the percentage of prescribed pills that are absent from the medication container, thus enabling a measurement of adherence as a continuous variable (STEELE et al. 2001). This measure is only applicable for children in older age groups that are able to swallow pills.

Electronic monitoring is a relatively new assessment method that uses pressuresensitive microchips, such as the Medication Event Monitoring System (MEMS), which is

\footnotetext{
${ }^{6}$ These questionnaires can be handed out to the patients to be filled out anonymously. For patients with poor literacy or eye-sight, they can be read by the interviewer to assure that the information given is correct.
} 
implanted in the caps of medication bottles (AARDEX Ltd. 2009). The microchip records time and date of all bottle opening events as presumptive doses taken by the patient. The data is stored in the chip until downloaded onto a computer. MEMS caps allow the examination of patterns of adherence and detailed aspects of medication-taking, such as dose interval adherence, correct timing of dose-taking and prospective adherence assessment over time (HowARD et al. 2002; LEVINE et al. 2005; LiU et al. 2001; MCNABB et al. 2003). MEMS caps are often used as a "gold standard" for adherence assessment in adults because of a closer correlation with undetectable HIV RNA plasma levels than other single measures (ARNSTEN et al. 2001; LiU et al. 2001). So far, only two studies have examined adherence in children using the MEMS caps (FARLEY et al. 2003; STEELE et al. 2001).

The underlying premise of pharmacy refill records is that if patients are not receiving timely refills of their medication at their pharmacy, they are missing doses. Hence an adherence rate is calculated when comparing the number of doses prescribed and the number of doses obtained from the pharmacy. This method is more applicable for population-based studies where individual adherence rates are of less importance (Steiner and Prochazka 1997) and has been found to be correlated with virological outcome in adults (Grossberg et al. 2004; LOW-BEER et al. 2000). A study by WATSON and FARLEY (1999) used this method to assess adherence in 42 children in the United States.

With therapeutic drug monitoring, the concentration of the studied drug in a blood sample is used as an indicator of medication-taking behaviour. This method requires knowledge of the pharmacokinetics of the studied drug and is an invasive procedure for the patient. Based on the drug plasma concentration the patient is classified as adherent or non-adherent. One paediatric study showed that adherence measured by this method has significant association with plasma viral load (VAN Rossum et al. 2002a).

FARLEY et al. (2003) assessed the correlation between successful appointment keeping and viral response in children, showing that not missing an appointment was significantly correlated with undetectable viral load. This, however, should be regarded as an assessment of variables rather than an actual adherence measure. 


\subsubsection{Predictors and influencing factors of adherence}

Adherence to medication is a learned behaviour. Since the emergence of adherence research, quantitative as well as qualitative studies have tried to identify distinct factors that influence adherence behaviour both in a supportive and a discouraging way. Four categories of influencing factors have emerged, namely patient-related, medication-related, provider-related and health care system-related factors (PONTALI 2005; WHO 2003). Patient-related factors are patient's age, gender, education, literacy and factors linked to psychosocial issues such as substance abuse or depression. Patients' understanding of the necessity of treatment, belief in self-efficacy and the efficacy of treatment as well as knowledge of their medical condition are further listed. Medicationrelated factors include the numbers of pills that need to be taken each day and special dietary instructions. A provider's ability to communicate with the patient and show compassion, in addition to the patient's perception of the provider's competence, is also related to adherence. Lastly, because the accessibility and cost of health care affects adherence behaviour, it might be even more important in resource-limited settings with poor health care infrastructure.

Children are rarely responsible for the administration of their medication and rely on caregivers to ensure their daily dose-taking. MELLINS et al. (2004) showed that for paediatric adherence, caregiver-related factors might be more influential than child-related factors. In their study assessing the associations of various child and caregiver-related factors with caregiver-reported adherence, no child-related factors could be identified except for age. However, poor child-caregiver communication, low caregiver quality of life and high caregiver-perceived stress were each associated with decreased adherence. It has also been indicated that children were more adherent if they received their medication from a caregiver that was not a biological parent (GIACOMET et al. 2003; VAN DYKE et al. 2002; WiLliams et al. 2006). This might be because biological parents are most often HIV infected as well and thus in a more complicated psychosocial condition than uninfected foster parents or relatives. Across paediatric literature, no consistent child or caregiver demographic factors have been related to adherence (SIMONI et al. 2007). WiLliams et al. (2006) conducted the largest study (thus far) on predictors of selfreported adherence, with 2088 children receiving HAART through the Pediatric AIDS 
Clinical Trial Group (PACTG) in the United States. In their sample, older child age, female gender, recent stressful life events and bad performance at school were each associated with poorer adherence. Of recent stressful life events, experiencing financial stress or a change in family structure were most strongly associated with poor adherence. Higher caregiver education and the use of a buddy system to remember taking medication were associated with improved adherence. No association between adherence and numbers of pills taken was noted, which was consistent with findings of REDDINGTON et al. (2000). Given the inconsistencies for child- and caregiver-related factors across studies, HAMmAmi et al. (2004) developed a theoretical approach based on findings from their qualitative study conducted in Belgium. Data from 11 caregiver interviews were compared to caregiver self-report, and the following three domains emerged as predictors of good adherence: caregiver knowledge, capacity and motivation. Adherent caregivers seemed to have internalised their knowledge about HIV and its treatment, whereas nonadherent caregivers often externalised this information. Caregivers' capacity to adhere to treatment was determined by their cognitive and technical skills, perceived self-efficacy and problem-solving capacity to overcome new challenges. Similar dynamics have been described by REDDINGTON et al. (2000). The process of coping with a HIV diagnosis and its implications was the decisive factor for the motivation to adhere; additionally, adherent caregivers showed an internal locus of control as opposed to non-adherent caregivers who tended towards a more external locus of control.

For resource-limited settings, only limited information is available on possible predictors for and barriers to paediatric adherence. While it may be hypothesised, based on known predictors from resource-rich settings, that barriers may be numerous due to difficult socio-economic, educational and family situations as well as poor health care infrastructure, only BIKAAKO-KAJURA et al. (2006) have examined some of these factors in an Ugandan setting. In a qualitative study they identified disclosure to the child as the most important predictor of adherence, but also named individual (caregiver attitude towards treatment, perceptions of HIV disease and perceived benefits of treatment), relational (child's relationships to significant others) and structural (economic situation of the family, stigma, caregiver availability to care for the child) barriers. 


\section{Objectives and methods}

\subsection{Objectives}

Given the scarcity of objectively measured adherence data in paediatric populations in resource-limited settings and the lack of knowledge in methodology, the objectives of this study were

- To measure adherence in a cohort of HIV infected children receiving HAART at a specialised HIV clinic in Cape Town, South Africa.

- To evaluate the feasibility of electronic monitoring devices for children on liquid drug formulations and compare the outcomes of this method to caregiver reported adherence rates and clinical outcomes.

- To describe the socio-economic situation, the cultural background and the subjectively-rated quality of life of the children and their caregivers and to assess caregiver-related factors that act as predictors for adherence behaviour.

\subsection{Study design}

The study was designed as a prospective study monitoring participants' adherence for three months. At study baseline, virological and immunological parameters were recorded for each subject. Adherence was monitored monthly for three consecutive months, and virological and immunological outcomes subsequently recorded at the follow-up visit. Socio-economic and socio-demographic variables, culturally-influenced belief systems and quality of life were recorded by a self-administered questionnaire after completion of the adherence monitoring (see Figure 2). 
Baseline: information, consent, recruitment Laboratory measures

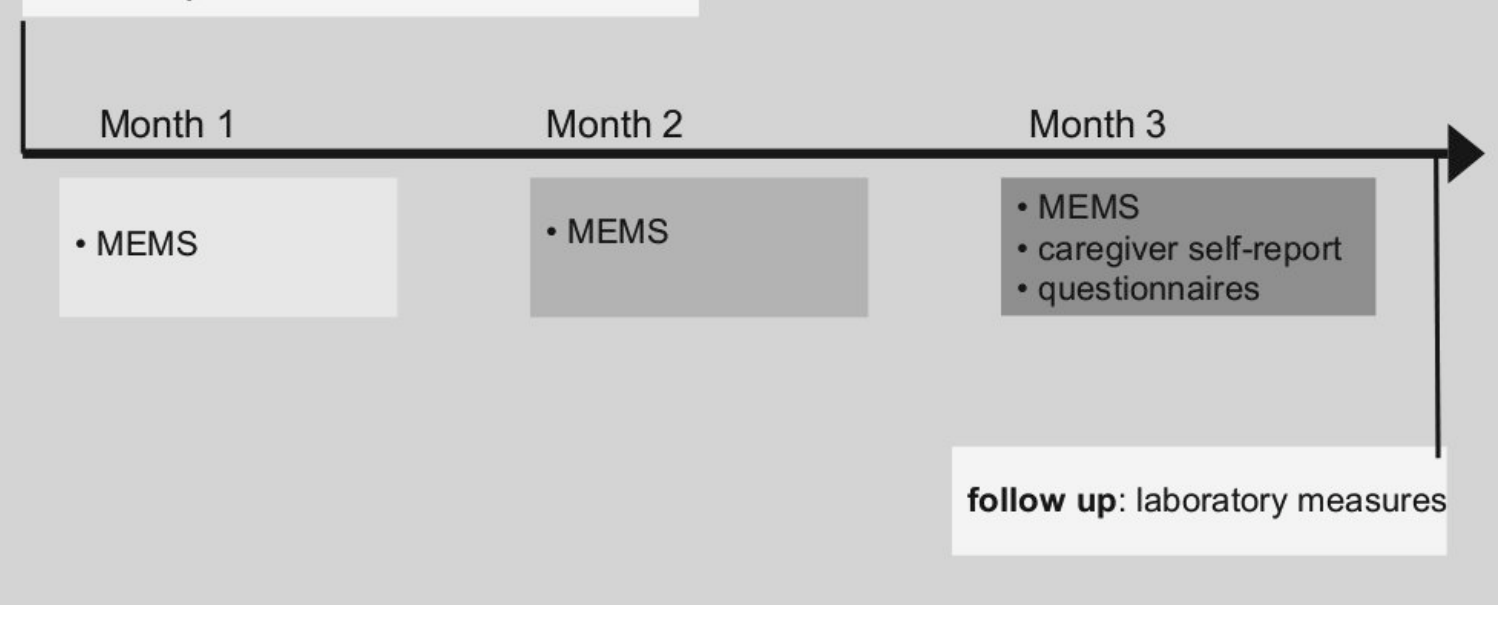

Figure 2: Study timeline

Adherence measurement took place at the monthly clinic visits. A research assistant attended to the participants at each visit. MEMS (Medication Event Monitoring System)

\subsubsection{Study setting and population}

Groote Schuur Hospital is a tertiary academic hospital in Cape Town, South Africa. Being a public hospital, the cost of health care is determined by the income of the patient. It serves a large, poor population coming mainly from previously disadvantaged communities outside the city centre. Given the multicultural background of South Africa, three languages are predominantly spoken among patients and hospital staff: Xhosa, Afrikaans and English. While most health care providers are trained in English, the first language of most patients is either Xhosa or Afrikaans, and non-understanding of the other is common. Antiretroviral treatment has been available in the South African public health care sector since November 2004 (South African Department of Health 2004). However, with the support of private funding, the paediatric HIV clinic at Groote Schuur commenced its first antiretroviral treatment program in 2002. As of February 2006 the clinic had enrolled 331 children and 67 mothers on antiretroviral treatment.

The clinic operates on an integrated model of health care that includes physicians, nurses and so-called counsellors. Counsellors have received training in psychosocial support and HIV education and, often, are patients themselves. They thus come from a 
background and culture similar to the clinic's patients and are an integral part of the HIV care provided. Their tasks include some of the following: providing educational workshops about HIV and antiretroviral treatment, assessment of patients for their readiness to start antiretroviral treatment, and ongoing psychosocial support for patients who receive antiretroviral treatment. In addition, they often serve as interpreters between patients and physicians. At the time of this study, the outpatient clinic was run on 2 days per week with approximately 40 patients per day. The staff included 4 full-time physicians, one nurse and 4 counsellors, and was managed by an on-site consultant.

Children who tested positive for HIV either at birth or at another occasion were referred to the clinic for an initial assessment. If they were found to match the WHO paediatric criteria to initiate antiretroviral treatment (WHO 2005), they were offered three counselling sessions to prepare the caregiver and the child for beginning a chronic medication regimen. Once antiretroviral treatment was initiated, patients returned to the clinic once a month to refill their medication prescription, and were routinely seen by a physician every 3 months. Patients who did not yet fulfil the criteria for treatment initiation were re-assessed every 6 months. Caregivers who were attending the clinic were offered free participation in weekly adherence support groups in Xhosa run by one of the counsellors. The clinic was also associated with a privately funded income-generating project that allowed participating caregivers the opportunity to earn a basic income through creating beaded artwork.

For patients and their caregivers, attending the clinic often meant spending an entire day at the health care facility. Patients were managed on a first-come-first-serve basis, which lead to extensive waiting times for most patients. Because the clinic is located in one of the inner suburbs, most patients spent approximately 4 hours commuting via public transport to and from their homes on the outskirts of the city.

For this study, all eligible children and caregivers attending the clinic between February and May 2006 were asked to participate. To be eligible, children were required to have one designated consenting caregiver responsible for their antiretroviral treatment, an antiretroviral regimen that included either lamivudine or abacavir in liquid formulations not exceeding the amount of $625 \mathrm{ml}$ per month and needed to reside in the 
wider Cape Town area. The primary caregiver had to be over the age of 18 and be able to come to the clinic once a month to collect new medicine supplies.

Based on a review of the pharmacy prescription charts prior to their scheduled visit, potentially eligible children on liquid lamivudine or abacavir were identified by the doctoral candidate (researcher). The caregivers of these children were then approached by a research assistant during their scheduled visit and checked for the other eligibility criteria. If eligible, they were invited to an individual information session with the researcher, received written information on the study and asked for their consent to be enrolled.

Eighty caregivers fulfilled the inclusion criteria and were approached to participate in this study; 78 agreed and were enrolled after providing written consent. The two caregivers who did not agree to participate stated that the reason they declined was because they would not be able to come for the follow-up visit in person. For all 78 enrolled children, laboratory data at the beginning of the study was available. Adherence analysis by MEMS was conducted for 73 children - one patient was transferred out to another treatment centre within the first month; one MEMS cap did not collect data due to technical problems and 3 MEMS caps were used incorrectly. Of all caregivers, 66 completed questionnaires. Non-completion of the questionnaires was due to the fact that a caregiver other than the primary caregiver brought the child to the follow-up visit and was therefore not interviewed. Laboratory data after the adherence monitoring period was available for 69 children (viral load; CD4 percentage was available for 54 children). Missing data was due to insufficient or clotted blood samples that were not suitable for analyses.

In the following sample description, data will be reported for all 78 children that were enrolled in the study. The mean age of the children at the time of enrolment was 50.7 months (SD, 23.7); the median age was 48 months (IQR, 33.5 - 65.3). 47 (60\%) of the children were male, 31 female. Most children had started antiretroviral treatment at an early age; the mean number of months on treatment was 25.8 (SD, 13.8). Of all children, $14(18 \%)$ had already failed their first line treatment regimen and were receiving a second line regimen. Fifty-six children received combination therapy with 2 nucleoside reverse transcriptase inhibitors (NRTIs) and a protease inhibitor (PI); the other 22 received 2 
NRTIs and a non-nucleoside reverse transcriptase inhibitor (NNRTI). Table 3 shows details on treatment regimen for all children. Eleven children (14\%) were concurrently being treated for tuberculosis, and thus received Ritonavir instead of boosted Lopinavir, due to drug-drug interaction with the anti-tuberculosis medication.

Table 3: Details of antiretroviral treatment by regimen line and class

\begin{tabular}{llll}
\hline Treatment option & Class of drugs & Regimen & Total N, (\%) \\
\hline First line & 2 NRTI+ NNRTI & AZT, 3TC, NVP & $19(24 \%)$ \\
& & AZT, 3TC, EFV & $1(1 \%)$ \\
& 2 NRTI+ PI & d4T, 3TC, EFV & $2(3 \%)$ \\
& AZT, 3TC, LPV/r & $14(18 \%)$ \\
Second line & d4T, 3TC, LPV/r & $18(23 \%)$ \\
& d4T, 3TC, Ritonavir & $5(6 \%)$ \\
& AZT, 3TC, Ritonavir & $4(5 \%)$ \\
& & d4T, ABC, LPV/r & $14(18 \%)$ \\
& d4T, ABC, Ritonavir & $1(1 \%)$
\end{tabular}

NRTI (Nucleoside Reverse-Transcriptase Inhibitor), NNRTI (Non-Nucleoside Reverse Transcriptase Inhibitor), PI (Protease Inhibitor), AZT (zidovudine), 3TC (lamivudine), NVP (nevirapine), d4T (stavudine), LPV/r (ritonavir-boosted lopinavir - kaletra ${ }^{\circledR}$ )

\subsection{Methods}

\subsubsection{Medication Event Monitoring System (MEMS)}

Upon enrolment in the study, each caregiver was equipped with a Medication Event Monitoring System (MEMS) cap fitted on the medication bottle of either lamivudine or abacavir syrup (Figure 3). The hospital pharmacist was trained to decant the lamivudine or abacavir syrup into a bottle that fitted the MEMS cap and this was done immediately before dispensing the medication to the patient. Caregivers were instructed to return the MEMS cap for every monthly pharmacy visit when they received a refill of medication. At each of these visits the data from the cap was transferred to the patient database by the researcher using the Aardex communicator (Aardex Ltd., Zug, Switzerland; see Figure 3). Caregivers who returned the cap received an incentive of 10 
Rand (approximately $€ 1$ ), as suggested by BovA et al. (2005). All caregivers received information on the handling of the MEMS during an information session with the research assistant, and written instructions were distributed in all three local languages at enrolment. To control for proper handling of the MEMS caps and also to detect potential corruption of the data, a short MEMS reliability questionnaire was read to the caregivers at the end of the monitoring period and they were asked for any irregularities. This has been proposed to allow for the adjustment of MEMS data in cases where the use of caps was not entirely according to the researcher's instructions (BOVA et al. 2005; FENNIE et al. 2006).

Data from the MEMS cap was transferred to the patient's database and the raw data was displayed with PowerView 3.3 (Aardex Ltd., Zug, Switzerland, see Figure 4). Each patient's raw data was compared to the MEMS reliability questionnaire and, if necessary, adjusted manually to avoid the corruption of data through unaccounted or missing bottle openings. Days for which the caregiver reported to have used another bottle for administering medication were excluded from the analysis. Mean adherence was calculated as the percentage of

(doses taken during monitoring period)

(doses prescribed for monitoring period)

for the twice-daily regimen of each patient. The correct timing of the administration of doses for the whole monitoring period was assessed by calculating the percentage of

(doses taken within \pm 1 hour of the prescribed dosing time)

(doses prescribed for monitoring period) 

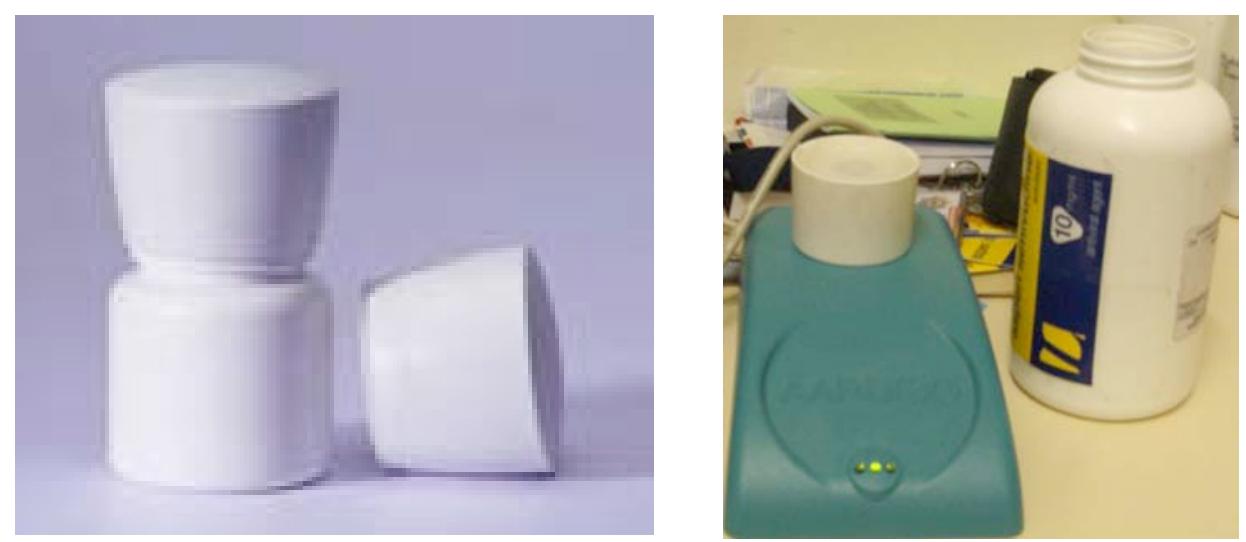

\section{Figure 3: MEMS cap and MEMS communicator with containers}

The cap is fitted on a medication bottle with a normal screw-neck. When it is removed from the bottle, it records the time and date of each opening. By placing the MEMS cap on the communicator, data can be transferred to a computer and visualised with PowerView. The bottle shows the local label for lamivudine and contains 500mL (www.aardexgroup.com).

\subsubsection{Visual Analogue Scale (VAS)}

Caregivers were asked about their adherence in administering their child's antiretroviral treatment when returning the MEMS cap for the last time. To measure adherence as a continuous variable, an adapted Visual Analogue Scale (Appendix 6.2) was explained and administered by a research assistant at the end of the monitoring period. One type of Visual Analogue Scale is a horizontal line of $100 \mathrm{~mm}$ length that shows percentages from 0 to 100 in steps of ten (GIORDANO et al. 2004). To simplify the depiction for the caregivers in our setting, the line was changed to be vertical and thus visualise the concept of an amount that can be less or more, similar to a bottle that can be fuller or emptier. Caregivers were asked to indicate their level of adherence to the MEMS-measured antiretroviral drug in the previous 30 days by pointing at the corresponding spot on the scale. 


\section{AARDEX ${ }_{\text {Ltd. }} \quad$ PowerView Compliance Report}

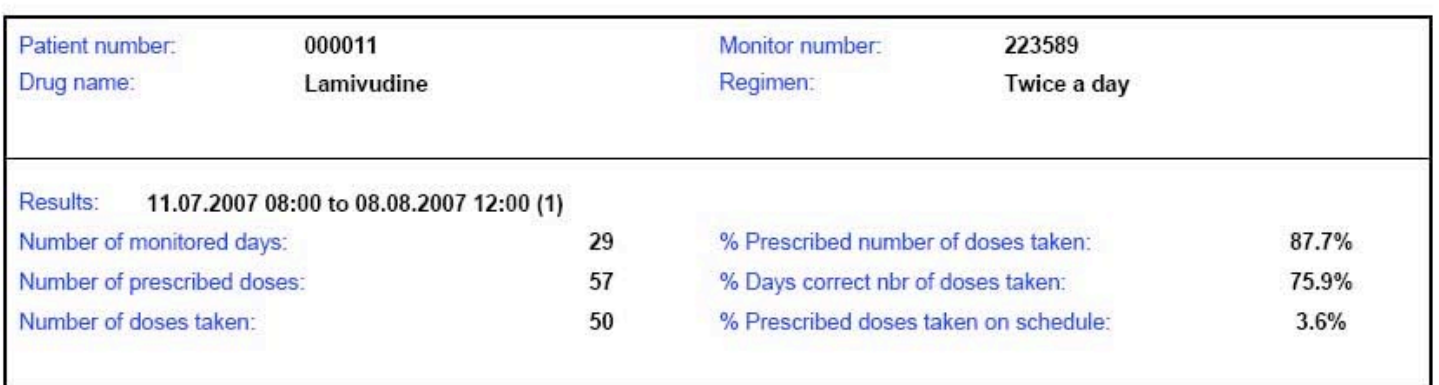
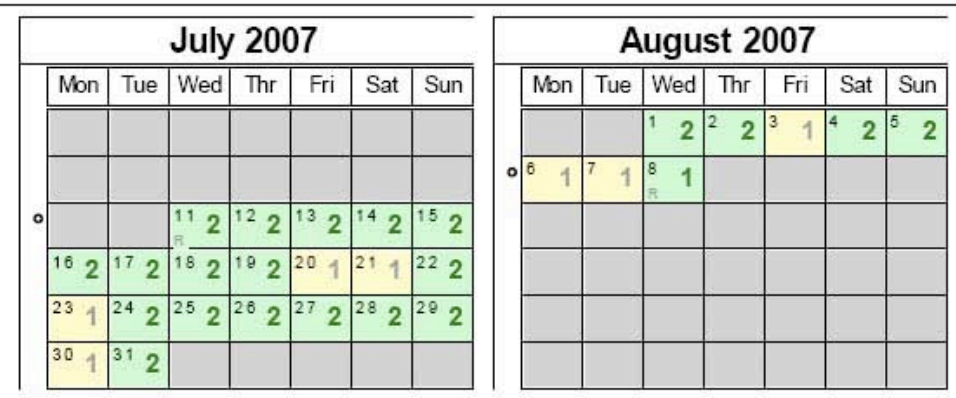

\section{Chronology}

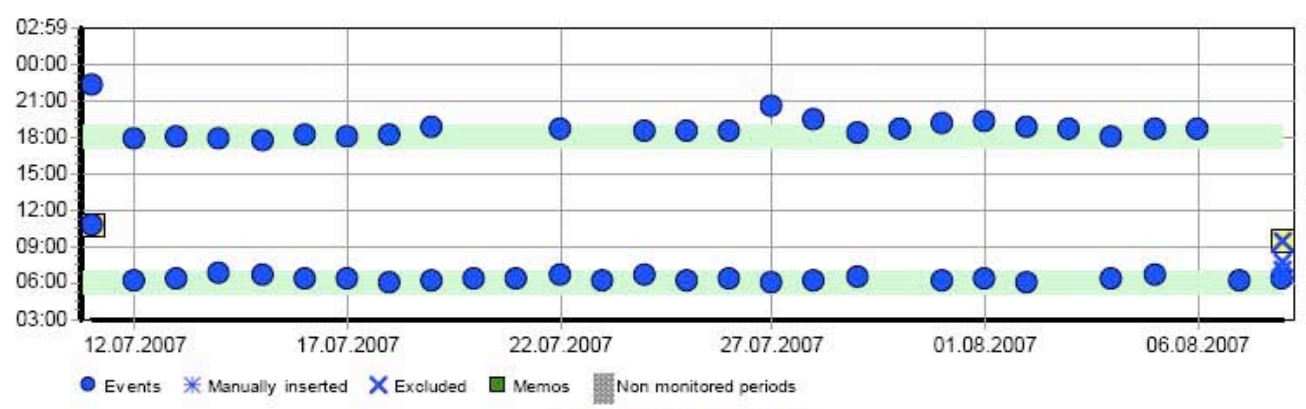

Missing doses

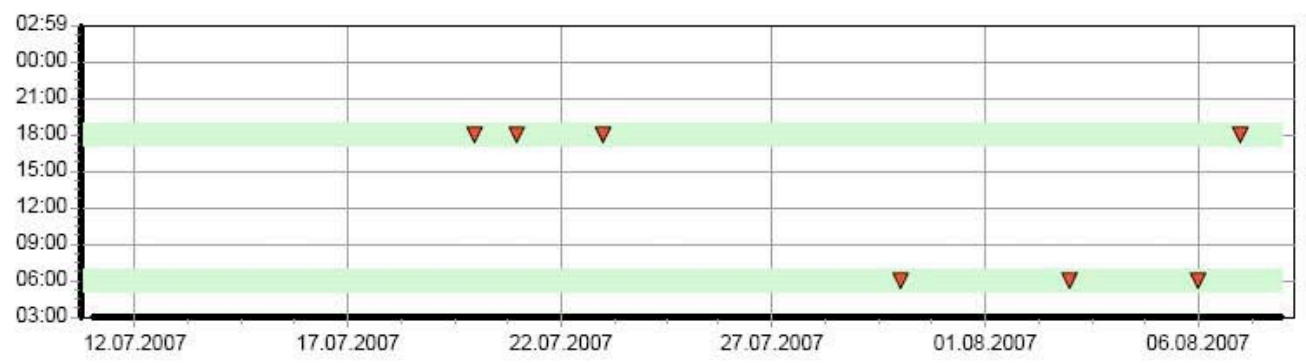

Figure 4: Adherence report generated by PowerView from MEMS-collected data

The calendar indicates the number of doses taken on each day. The chronology shows the date and time of each opening event. Each event is marked as a blue dot. The green area represents the period of \pm 1 hour of the administration time indicated by the caregiver. Missing doses are represented by red triangles. 


\subsubsection{Laboratory measurements}

Virological and immunological responses to treatment were assessed by HIV RNA plasma levels (viral loads) and CD4+ lymphocyte counts at study baseline and the closest follow-up visit after the adherence monitoring period. HIV RNA plasma levels were determined by NASBA polymerase chain reaction assay, the lowest limit of detection is 50 RNA copies per millilitre. CD4+ lymphocyte counts were performed by flow cytometry. All laboratory measurements were performed as part of the routine care. The blood samples were analysed by National Health Laboratory Services on the hospital premises (CD4+ lymphocyte counts) and at their central laboratory facilities (HIV RNA plasma levels).

\subsubsection{Predictors of adherence}

Possible predictors of adherence were classified into four groups: sociodemographic factors for both caregiver and child, economic factors for the caregiver, culturally-influenced attitudes and beliefs towards health and the health care system, and quality of life of the caregiver. Socio-demographic data for the child were taken from the clinical records. All questionnaires were available in English, Xhosa and Afrikaans, after undergoing linguistic validation following the guidelines for translation of psychometric inventories (ACQUADRO et al. 1996). From the original English version, two independent translators performed forward translation into the target language; the two versions were then merged into one. In a second step an independent native speaker translated the merged version back into the original language and this version was then compared to the original version on item-level. Conflicting results of the translation process were discussed with all translators and changes were made based on the consensus of this process.

\subsubsection{Assessment of Demographics and Socio-Economics questionnaire (ADS)}

For socio-demographic and economic factors of caregivers, a self-administered questionnaire was developed, covering age, education, home language, economic and 
living situation, use of offered support structures and disclosure status (Assessment of Demographics and Socioeconomics questionnaire: ADS, see Appendix 6.3).

\subsubsection{Social Environment, Attitudes and Culture Assessment Scale (SACAS)}

Potential culturally-influenced factors were identified through a literature review as well as focus interviews with health care professionals prior to the study. These were related to cultural perceptions of health care providers and the health care system, the patient-provider relationship, the perception of the efficacy of antiretroviral treatment and the provider's knowledge about it as well as the caregiver's perceived support from his social environment. Taken from these topics, a 36-item questionnaire was created, answered on a Likert scale containing rating possibilities from "strongly agree" to "strongly disagree". It was named "Social Environment, Attitudes and Culture Assessment Scale" (SACAS; see Appendix 6.4).

\subsubsection{EUROHIS-QoL}

Caregivers' self-rated quality of life (QOL) was assessed using the EUROHISQOL 8-item index (Appendix A). This tool was developed as an adaptation of the WHOQOL-100 (SKEVINGTON 1999) and the WHOQOL-BREF (SKEVINGTON et al. 2004) and consists of 8 items. The overall QOL score is formed by a simple summation of scores on the eight items, with higher scores indicating better QOL. Conceptually the psychological, physical, social and environmental domains are each represented by two items. All answer scales have a 5-point response format on a Likert scale, ranging from 'not at all' to 'completely'. Schmidt et al. (2005) recently tested the psychometric properties of this tool, in terms of reliability, convergent and discriminant validity as well as cross-cultural performance. It has been recommended for cross-cultural public health research.

\subsubsection{Statistical analysis}

All statistical analyses were performed using SPSS 12.0 (SPSS Inc., Chicago, IL) and STATA 9.0 (StataCorp, College Station, TX). All variables reflecting the study 
cohort's characteristics were analysed by means of descriptive statistics (frequencies, means, medians, standard deviations and interquartile ranges).

The data for MEMS adherence was imported from PowerView. Using these data, cut-off points were defined at 95\%, 90\%, 80\% and 60\% and adherence was dichotomised by defining patients as adherent or non-adherent based on these cut-off points. In keeping with adherence literature, the data on viral load were log transformed to the base 10 , so that a one unit increase in the log viral load then corresponded to a ten-fold increase in the virological response). Viral load data were also dichotomised to indicate whether or not a patient achieved virological suppression, defined as less than 50 HIV RNA copies $/ \mathrm{mL}$ blood or less than $\log 1.49$. CD4+ percentage was treated as a continuous variable. All continuous variables were tested for Gaussian distribution with the Kolmogorov-Smirnov test to ensure that the conditions for Analyses of Variance (ANOVA), t-statistics and Pearson correlations were kept. In general, for all performed analyses a level of $p<0.05$ was considered statistically significant.

Associations between continuous, normally distributed variables were analysed by Pearson correlation analyses. The results hereof were expressed as correlation coefficients $(r)$ and $p$-values for the statistical significance test. Associations between variables with non-normal distributions were analysed by the nonparametric method of Spearman rank correlation. Associations between dichotomous variables were analysed by chi-square $\left(\chi^{2}\right)$ tests. For analyses of subgroups that included less than 10 observations, Fisher's exact test was used to obtain more accurate results.

When comparing metric data between experimental groups, Student's t-tests and Analyses of Variance (ANOVAs) were used; for rank-data (ordinal data), Mann-WhitneyU-tests and Kruskal-Wallis-H-tests were used. Wilcoxon signed-rank tests were used for non-parametric data. To rate the validity of the adherence measures, two-by-two contingency tables and receiver-operator characteristic (ROC) curves were calculated. The two-by-two tables were used to calculate sensitivity and specificity of the measure against virological outcome. ROC curves reported the area under the curve (AUC) to compare the performance of measures.

To analyse the predictive value of one or more variables on a dependent variable, simple and multiple regression models were computed. Results were expressed as odds 
ratios (within a 95\% confidence interval) and $p$-values. For continuous outcome (dependent) variables, linear regression models were calculated. For dichotomous outcome (dependent) variables, logistic regression models were calculated. The variables entered into the multiple regression models were chosen by stepwise forward selection. First, simple linear regression models were calculated for each proposed variable on the dependent variable. In a second step, for variables that showed significant correlation, the variable with the highest $\mathrm{r}^{2}$-value was included in the regression and each of the other variables was added separately. In the third step, the variable that added most to the increase of the $r^{2}$-value was also added. This was repeated until there was no significant increase in $\mathrm{r}^{2}$-value, or until all variables were fitted.

An explorative principal component analysis (PCA) with varimax rotation was calculated for the 36 SACAS items to test for a consistent factor structure of the scale. The analysis was based on the correlation matrix of the items. Missing values were replaced with the subscale means. The resulting factors were used to investigate their relationship to the adherence and virological outcome. 


\section{Results}

\subsection{Description of the study cohort}

\subsubsection{Socio-demographic characteristics}

For the analyses of socio-economic characteristics, data from 66 caregivers were collected by questionnaire. Some caregivers did not respond to certain items, in this case a smaller sample size will be shown when reporting on the item.

Most children were cared for by caregivers who were related to them by family ties $(80 \%$ mothers, $8 \%$ grandmothers and $8 \%$ aunts). The rest was in the care of foster families. The mean age of caregivers was 33.9 years (SD, 9.5), median age 31 years (IQR, 28 - 37). Although most caregivers were HIV infected (80\%), only 32 of these infected caregivers received antiretroviral therapy (60\%). Of all infected caregivers, only $74 \%$ $(n=39)$ had disclosed their HIV status to the household they stayed in. Of all caregivers, both infected and uninfected, 79\% ( $n=52)$ had disclosed the child's HIV status to the household they lived in. Most caregivers $(54 \%, \mathrm{n}=35)$ reported not having an own income, and another 20\% ( $=13)$ earned less than 500 Rand (approximately $€ 50)$ per month. Table 4 shows all demographic data for children and caregivers.

\subsubsection{Treatment outcome}

At the beginning of the study, $44 \%$ of all 78 children $(n=34)$ had achieved virological suppression on their antiretroviral regimen. The median log viral load however was 3.59 (IQR, $1.69-4.80)$. At follow-up 6 months later, 65\% $(n=45)$ of the children whose data was available ( $\mathrm{N}=69)$ achieved virological suppression; the median log viral load was 1.69 (IQR, $1.69-3.31$ ). Of all 34 children with suppressed viral load at begin, 30 remained suppressed at follow-up, 2 showed a raise in viral load and data for the other 2 was not available. The mean CD4+ percentage at begin was 23.7 (SD, 7.8) and increased to 28.5 at follow-up (SD, 1.1). These results reflect the fact that the study cohort was not antiretroviral treatment (ART) naïve, and had been treated with ART for a while. Since most virological changes occur within the first months of ART, it was not surprising to see a fairly stable level of virological suppression and immunological status. 
Table 4: Demographic and socio-economic details of population

\begin{tabular}{|c|c|}
\hline & n [\%] or mean $( \pm$ SD $)$ \\
\hline \multicolumn{2}{|l|}{ Child characteristics $(\mathrm{N}=78)$} \\
\hline Female & $31(39.7 \%)$ \\
\hline Male & $47(60.3 \%)$ \\
\hline Mean amount of additional medications & $6 \pm 0.13$ \\
\hline On TB treatment & $11(14.1 \%)$ \\
\hline \multirow{2}{*}{ On second line treatment } & $14(17.9 \%)$ \\
\hline & $\mathrm{n} / \mathrm{N}[\%]$ or mean \\
\hline \multicolumn{2}{|l|}{ Caregiver characteristics* } \\
\hline Mother & $52 / 65(80 \%)$ \\
\hline Extended family & $10 / 65(15 \%)$ \\
\hline $\mathrm{HIV+}$ & $48 / 64(75 \%)$ \\
\hline Living in shack & $47 / 66(71 \%)$ \\
\hline No running water & $21 / 66(32 \%)$ \\
\hline No electricity & $17 / 66(26 \%)$ \\
\hline Unemployed & $46 / 64(72 \%)$ \\
\hline Mean years of education $(n=63)$ & $10 \pm 0.40$ \\
\hline Receiving government grant & $55 / 66(83 \%)$ \\
\hline Home language Xhosa & $56 / 66(85 \%)$ \\
\hline Married & $18 / 64(28 \%)$ \\
\hline Single & $42 / 64(66 \%)$ \\
\hline Widowed & $3 / 64(5 \%)$ \\
\hline Mean no of rooms in house $(n=60)$ & $2.27 \pm 1.5$ \\
\hline Mean no of people living in house $(n=63)$ & $5 \pm 0.36$ \\
\hline Mean no of children looked after by CG $(n=64)$ & $2 \pm 0.27$ \\
\hline Disclosed own status & $43 / 58(74 \%)$ \\
\hline Experienced AIDS death in family & $31 / 62(50 \%)$ \\
\hline Participation in community support group & $43 / 65(66 \%)$ \\
\hline Participation in clinic support group & $44 / 65(68 \%)$ \\
\hline CG only drug administrator & $41 / 61(67 \%)$ \\
\hline
\end{tabular}

SD (standard deviation), HIV+ (Human Immunodeficiency Virus infected),

CG (Caregiver), AIDS (Acquired Immundeficiency Syndrom)

* Denominators vary due to incomplete data 


\subsection{Adherence}

Adherence measured by MEMS covered a mean monitoring period of 76 days (SD, 20; range 20-120), and data from 73 patients were included in the analysis. Data for the VAS were obtained from 65 caregivers.

\subsubsection{Adherence by Medication Event Monitoring System}

The mean adherence as measured by MEMS (mMEMS) for the whole monitoring period was 79.6\% (SD, 22.3); median MEMS adherence (medMEMS) was $87.5 \%$ (IQR, 69-97). The MEMS adherence results showed a significant deviation from Gaussian distribution in the Kolmogorov-Smirnov test (K-S $|z|=1.60, p=0.01$; see Figure 5).

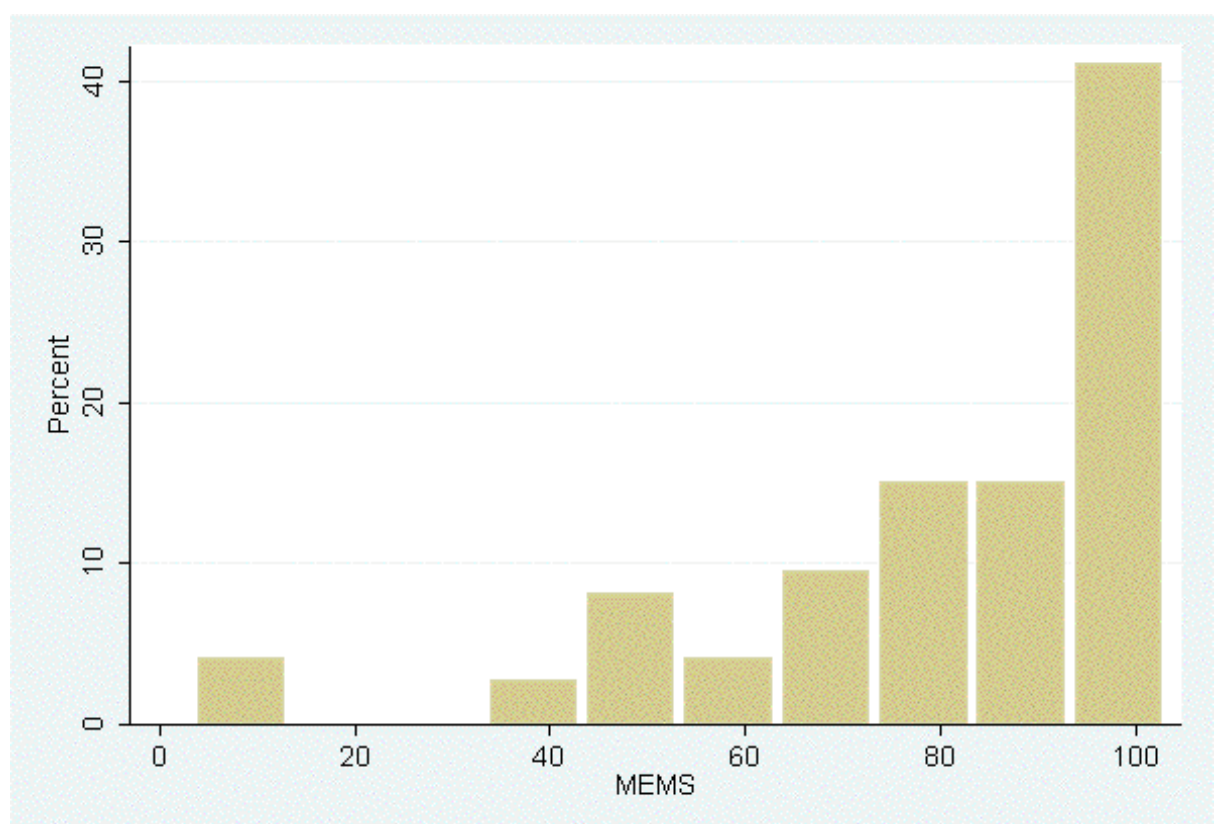

Figure 5: Distribution of adherence measured by Medication Event Monitoring System (MEMS)

The $\mathrm{x}$-axis shows MEMS adherence in percent, the y-axis shows the percentage of observations in the sample. Most participants showed mean MEMS adherence levels above $70 \%$.

When analysing medMEMS adherence for the first, second and third month separately, the adherence rates were 89.5\% (IQR, 73-98; $\mathrm{n}=73$ ), 85.7\% (IQR, 65-98; $\mathrm{n}=68$ ) and $87.7 \%$ (IQR, 72-97; n=58) respectively (see Figure 6). An applied Wilcoxon matched-pairs signed-rank test did not find significant differences in the distribution of 
MEMS adherence for month 1, 2 and 3 (with $z=1.20, p=0.2$ for month 1 and 2; and $z=0.90, p=0.4$ for month 1 and 3 ).

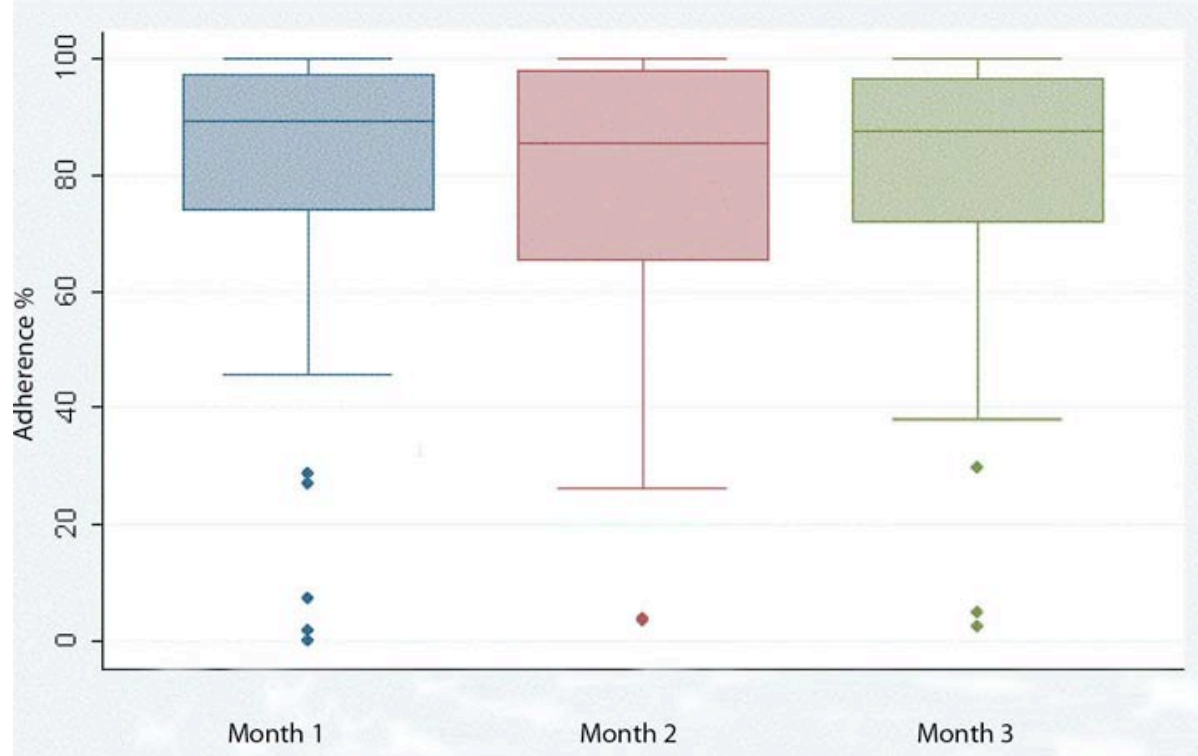

Figure 6: Median MEMS adherence during the first, second and third month

Adherence is displayed by a boxplot, with a confidence interval from $25-75 \%$ (box) and range. The single dots are outliners. The y-axis shows the percentage of adherence. MEMS adherence did not significantly differ by months. Fifty-eight participants were entered into the analysis, because the other 15 dropped out before month 3, mostly due to logistical problems with the MEMS cap.

When adjusting MEMS adherence for the correct timing of doses (only doses taken within 2 hours of the prescribed time were considered as adherent), median adherence was significantly lower and at 78.6\% (IQR, 42-95; Wilcoxon test, $z=6.24$, $p<0.01$; see Figure 7). To assess the amount of doses that were missed during days of the weekend, when the daily routine might have been disrupted, the overall amount of missed doses for all patients over the whole monitoring period was counted. A total of 1711 doses were missed, and of these, 641 doses (37\%) were missed on days of the weekend. This accounts to an accumulated mean daily amount of 214 missed doses for the days from Monday to Friday; and of 321 missed doses for Saturday and Sunday. 


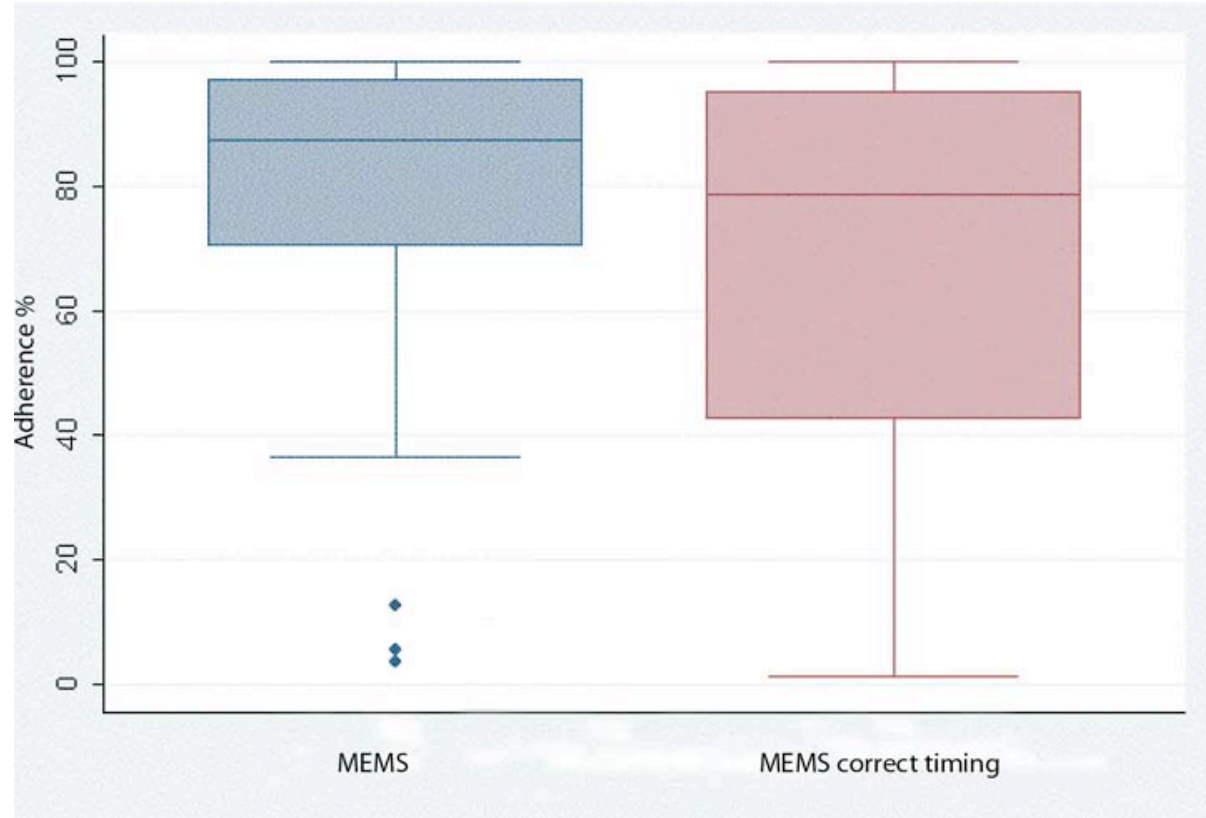

Figure 7: Median adherence by Medication Event Monitoring System (MEMS) generally and adjusted for the correct timing of doses (MEMS-correct timing)

Adherence is displayed by a boxplot, with a confidence interval from $25-75 \%$ (box) and range. The single dots are outliners. The y-axis shows the percentage of adherence. MEMS adherence was lower when adjusted for the correct timing of doses.

Median MEMS adherence showed non-significant variations in boys and girls: $83 \%$ for boys (IQR, 64-97; $\mathrm{n}=43$ ) and 92\% for girls (IQR, 70-96; n=30; Kruskal-Wallis test, $\chi^{2}(1)=0.37, p=0.54$; see Figure 8). Children who had already failed one regimen and were treated with a drug combination belonging to a second line regimen also showed a trend of higher median adherence that was not significant $(95 \%, I Q R, 75-98 ; n=13$, versus $87 \%$, IQR, 67-96; $n=60 ; \chi^{2}(1)=1.05, p=0.31$; see Figure 9). 


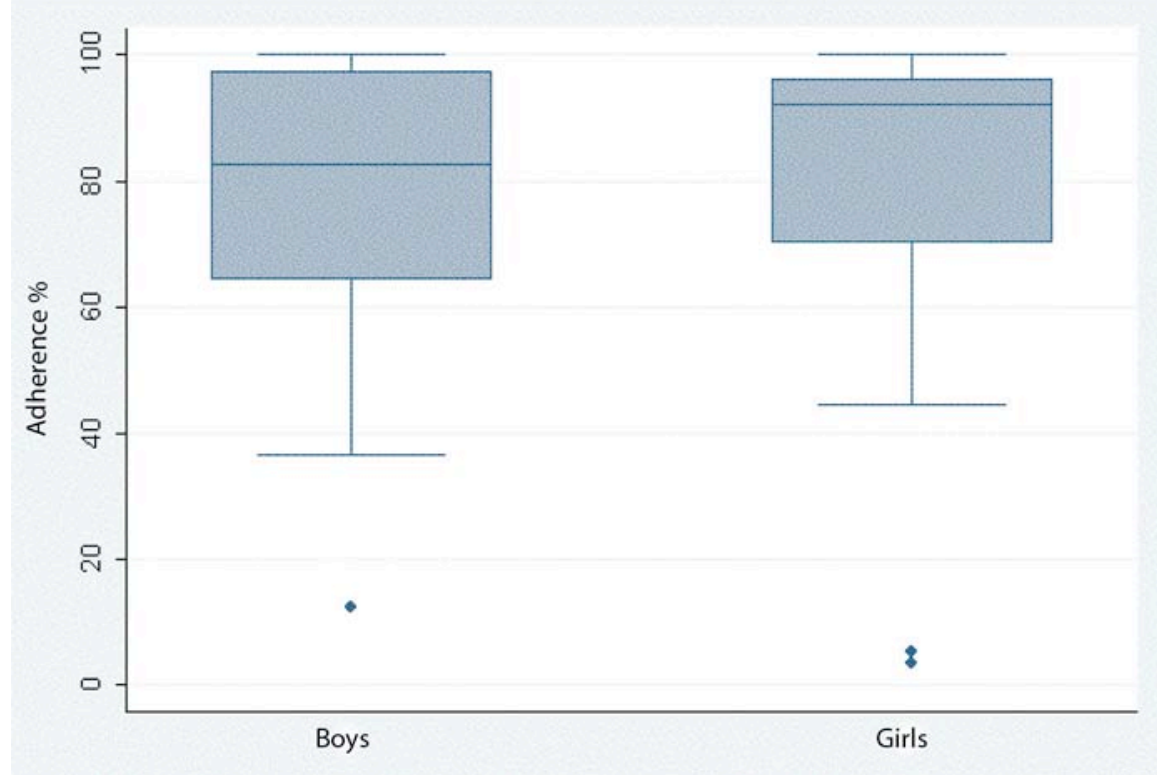

Figure 8: Median adherence by Medication Event Monitoring System (MEMS) by the child's sex Displayed are box plots with a confidence interval from 25 to $75 \%$ (box) and the range. Single dots signify outliers. The x-axis shows the sex of the children, the y-axis shows MEMS adherence in percent. MEMS adherence showed a trend to be higher in girls than in boys.

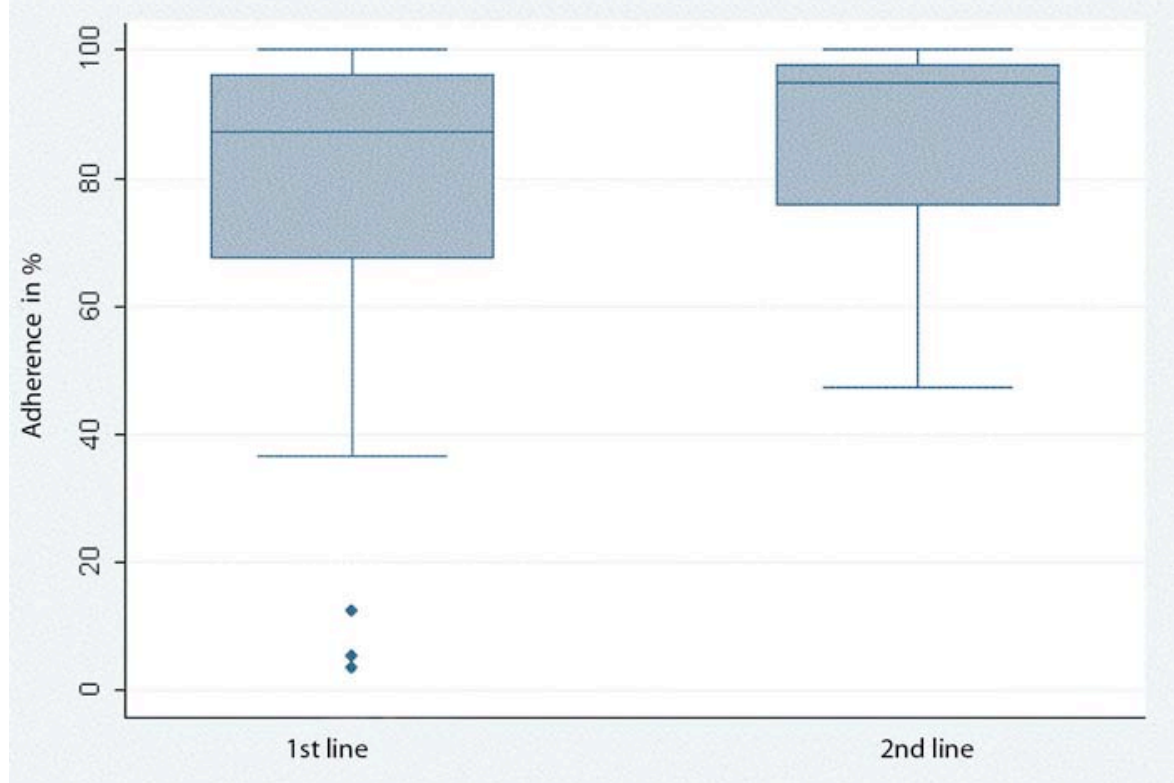

Figure 9: Median adherence by Medication Event Monitoring System (MEMS), by regimen line Displayed are box plots with a confidence interval from 25 to $75 \%$ (box) and the range. Single dots signify outliers. The $\mathrm{x}$-axis shows the antiretroviral treatment regimen, the $y$-axis shows MEMS adherence in percent. MEMS adherence tended to be higher when the child was taking a regimen of the second line. 


\subsubsection{Adherence by Visual Analogue Scale}

Adherence data measured by Visual Analogue Scale (VAS) were available for 65 children. The mean VAS adherence was $98.6 \%$ (SD, 3), and the median was $100 \%$ (range, 90-100). As predictable by the narrow range, the data was found to be non-Gaussian distributed (K-S $|z|=3.85, p<0.01$; see Figure 10).

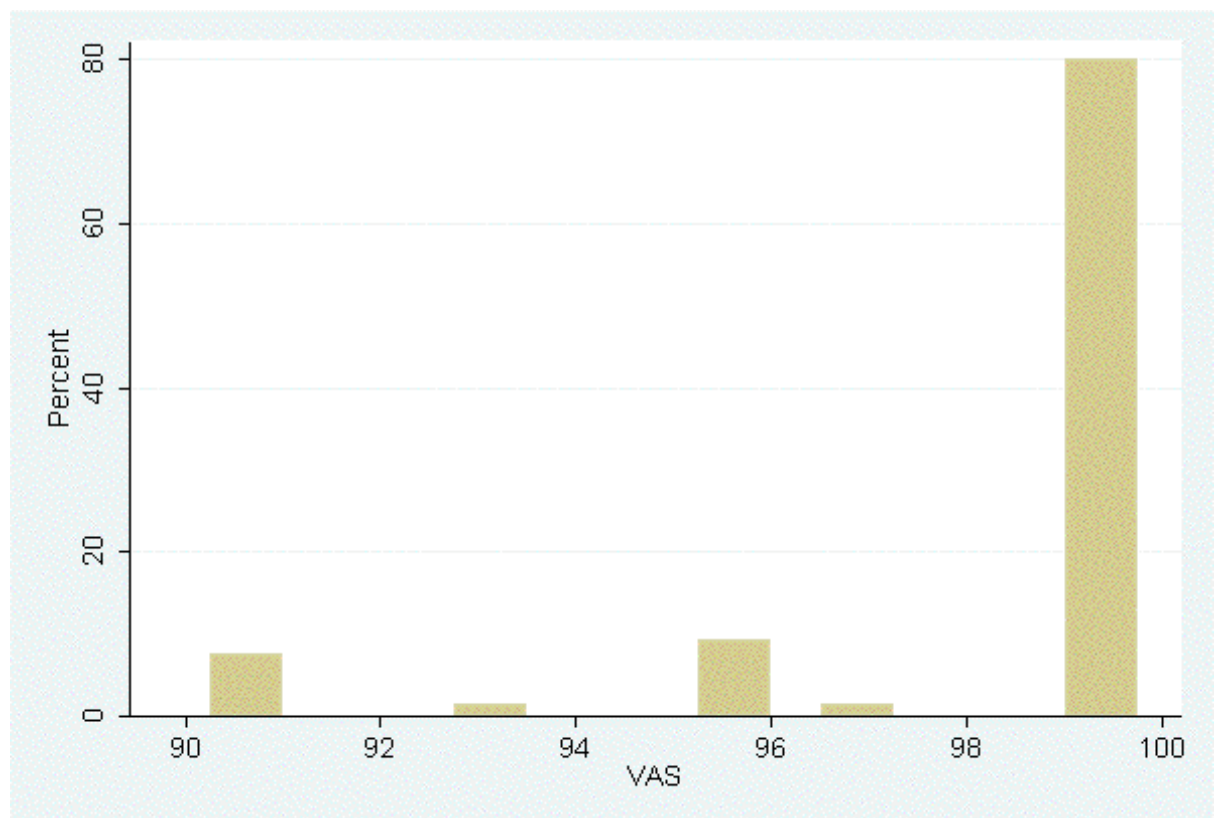

Figure 10: Distribution of adherence measured by Visual Analogue Scale (VAS)

The $\mathrm{x}$-axis shows VAS adherence in percent (with a range from 90 to 100\%), the y-axis the percentage of observations in the sample. All caregivers reported a mean VAS adherence greater than $90 \%$. The large majority reported perfect adherence (100\%).

\subsection{Adherence measures}

\subsubsection{Relationship between MEMS and VAS adherence}

To examine the validity of both continuous adherence measures, MEMS and VAS, correlations were assessed between the two measures and virological outcome. The scatterplot in Figure 11 shows that the spread of MEMS and VAS data points was wide and hardly had any tendency of clustering. It further shows that all VAS data points 
accumulate at 100 percent, leading to a lack of variance in the VAS data and indicating little agreement between the measures. This lack of variance in the VAS data does not allow for further statistical analyses.

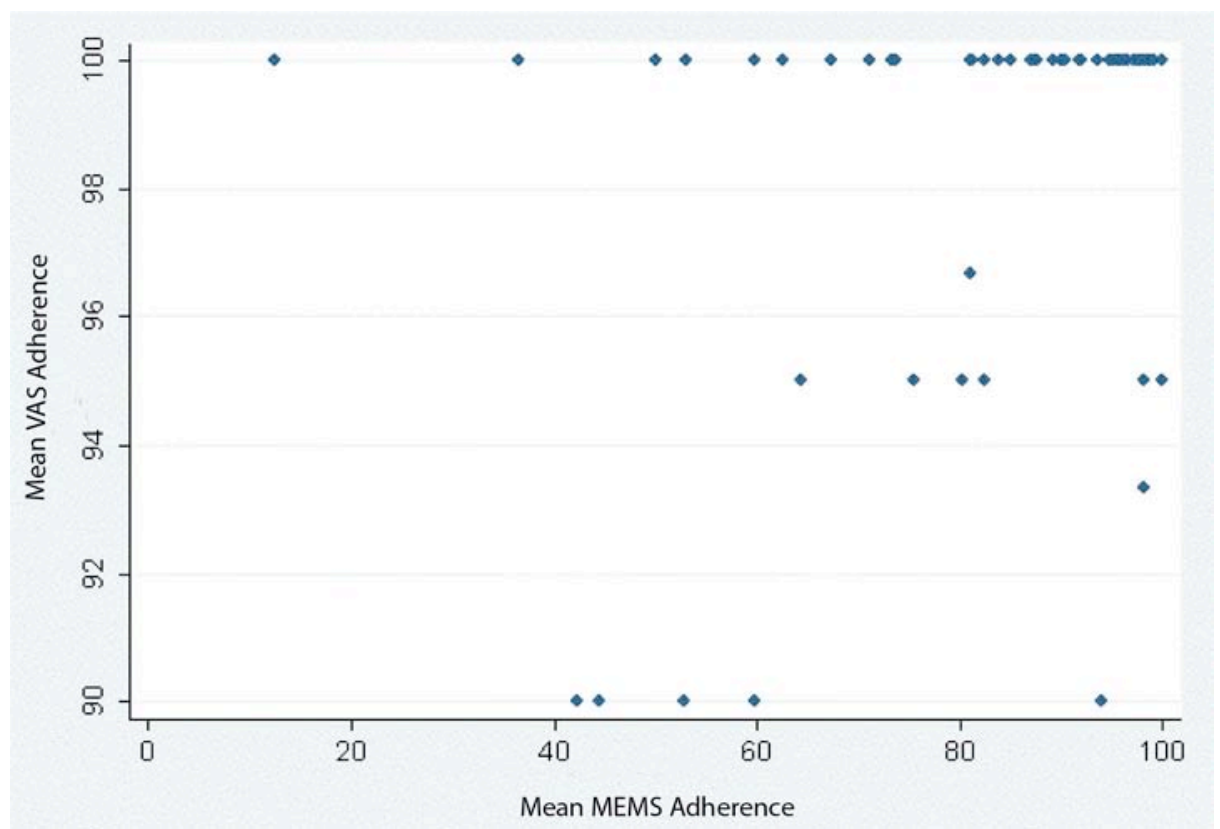

Figure 11: Scatterplot of mean adherence by Medication Event Monitoring System (MEMS), against mean adherence by Visual Analogue Scale (VAS)

The $\mathrm{x}$-axis indicates the percentage of adherence as measured by MEMS, the $\mathrm{y}$-axis the percentage of adherence measured by VAS. Each dot represents one VAS and one MEMS value. While MEMS data shows a fairly wide spread, all VAS data points accumulate at the $100 \%$ mark, indicating that there is no variance in the data of this measure.

Children who were reported to be $100 \%$ adherent by VAS $(n=48)$ showed a median MEMS adherence of 92\% (IQR, 81-98), children who reportedly had less than $100 \%$ adherence by VAS $(n=13)$ showed a median MEMS adherence of $80 \%$ (IQR, 6094). However, these differences in MEMS adherence were not significant (MannWhitney-U test, $z=1.76, p=0.08)$. 


\subsubsection{Correlation between continuous adherence measures and viral load}

To examine the association between the MEMS measure and the virological outcome, Spearman's rho correlation analyses were computed with the variables mean MEMS adherence and log viral load at follow-up. The correlation matrix is displayed in Table 5. Mean MEMS adherence was negatively correlated with the log viral load at follow-up, indicating that an increase in adherence is correlated to a decrease of viral load or vice versa. The correlation between mean VAS adherence and virological outcome could not be analysed due to the fact that there was no variability in the VAS data.

Table 5: Spearman rho correlations for mean MEMS adherence and viral load

\begin{tabular}{ll}
\hline & VL \\
\hline MEMS $(\boldsymbol{r})$ & -0.53 \\
$p$-value & $<0.01$ \\
\hline VL (log viral load), MEMS (Medication Event Monitoring System)
\end{tabular}

VL (log viral load), MEMS (Medication Event Monitoring System)

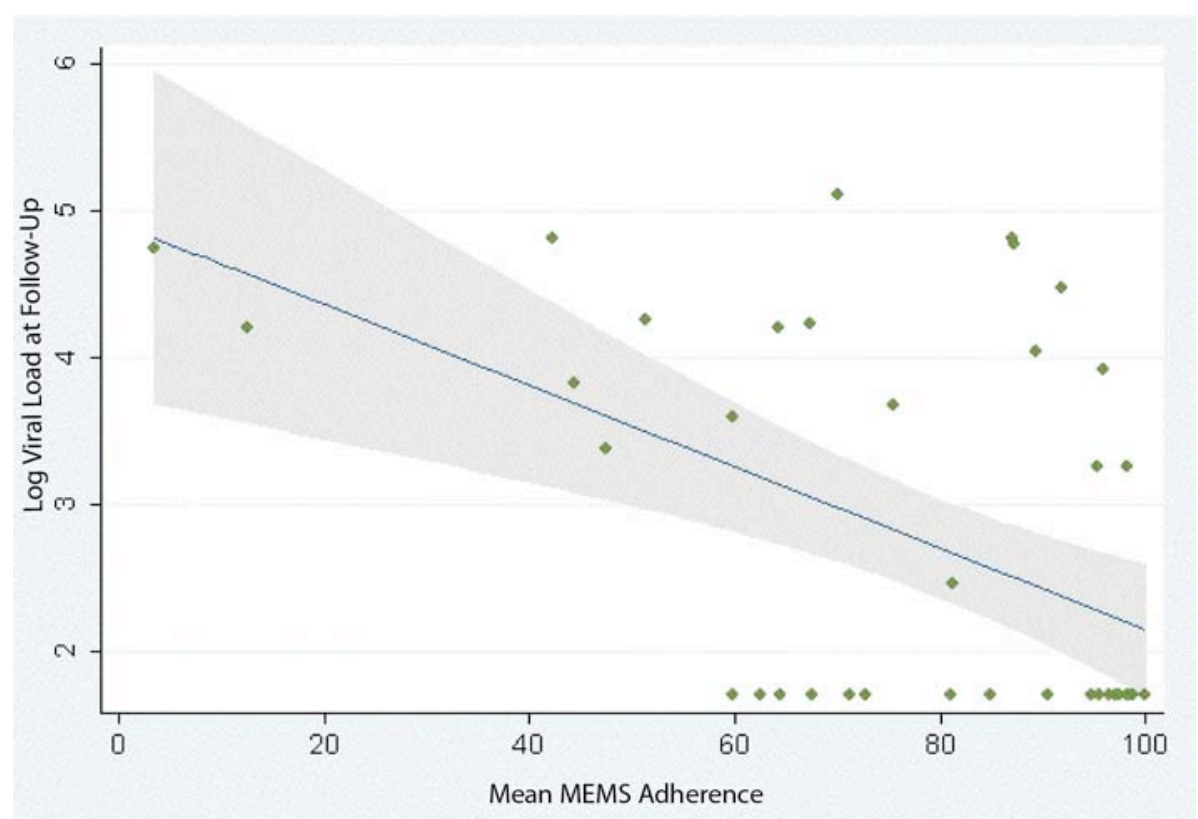

Figure 12: Association between mean adherence by Medication Event Monitoring System (MEMS) and log viral load at follow-up

The $\mathrm{x}$-axis shows the percentage of mean MEMS adherence, the y-axis shows the viral load, log transformed to the base 10. Couples of data points are indicated by dots, the confidence interval of 25-75\% is displayed as the grey area around the regression line. Both MEMS adherence and log viral load show a spread across the spectrum, even though there is a number of viral load points at log 1.69 (equivalent to $<50$ copies/mL). 
This variance of MEMS and VAS data is further illustrated in the Figures 12 and 13 which show regression lines for mean MEMS, mean VAS adherence and log viral load. MEMS adherence is spread across the spectrum from 0 to 100 percent adherence. VAS only spread in the area of 90 to 100 percent adherence, and only very mildly, with most data points accumulating at $100 \%$.

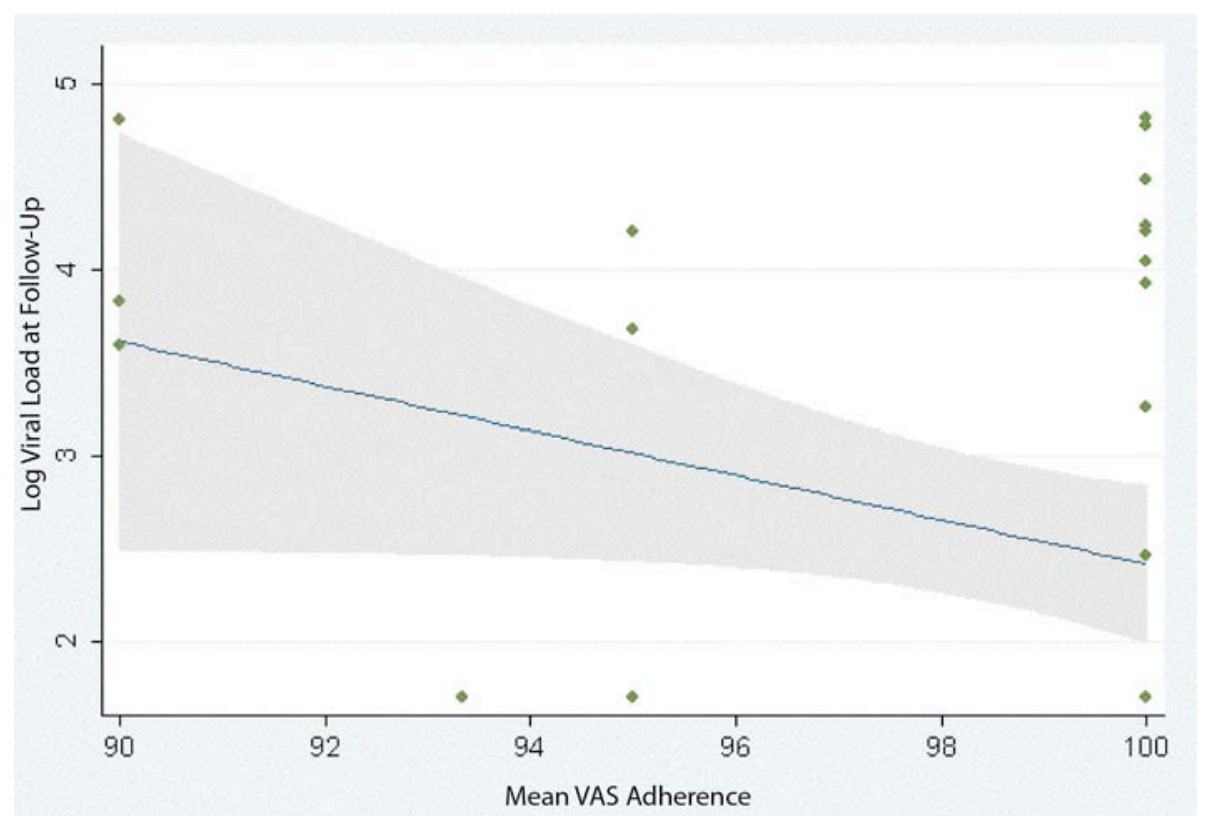

Figure 13: Association between mean adherence by Visual Analogue Scale (VAS) and log viral load at follow-up

The x-axis shows the percentage of mean VAS adherence (ranging from 90 to 100\%), the y-axis shows the viral load, log transformed to the base 10 . Couples of data points are indicated by dots, the confidence interval of $25-75 \%$ is displayed as the grey area around the regression line. The VAS adherence data points only spread in a narrow area and clot at the $100 \%$ mark, indicating a lack of variance in the dataset.

To compare the median adherence levels measured by each method in patients with and without virological suppression at the follow-up visit, Mann-Whitney-U tests were computed to compare the two groups. MEMS measured a median adherence of $95 \%$ (IQR, 80-98) for patients who did achieve virological suppression at the follow-up visit, and a median adherence of $73 \%$ (IQR, 49-91) for patients who did not. The median VAS adherence was $100 \%$ (no range) for patients with virological suppression and 100\% (range, 90-100) for patients without virological suppression (Figure 14). The difference in median measured adherence for patients with and without virological suppression was 
significant for MEMS (Mann-Whitney-U test, $z=-3.34, p<0.01$ ). For VAS, a statistically meaningful comparison could not be performed due to the lack of variance in the dataset.

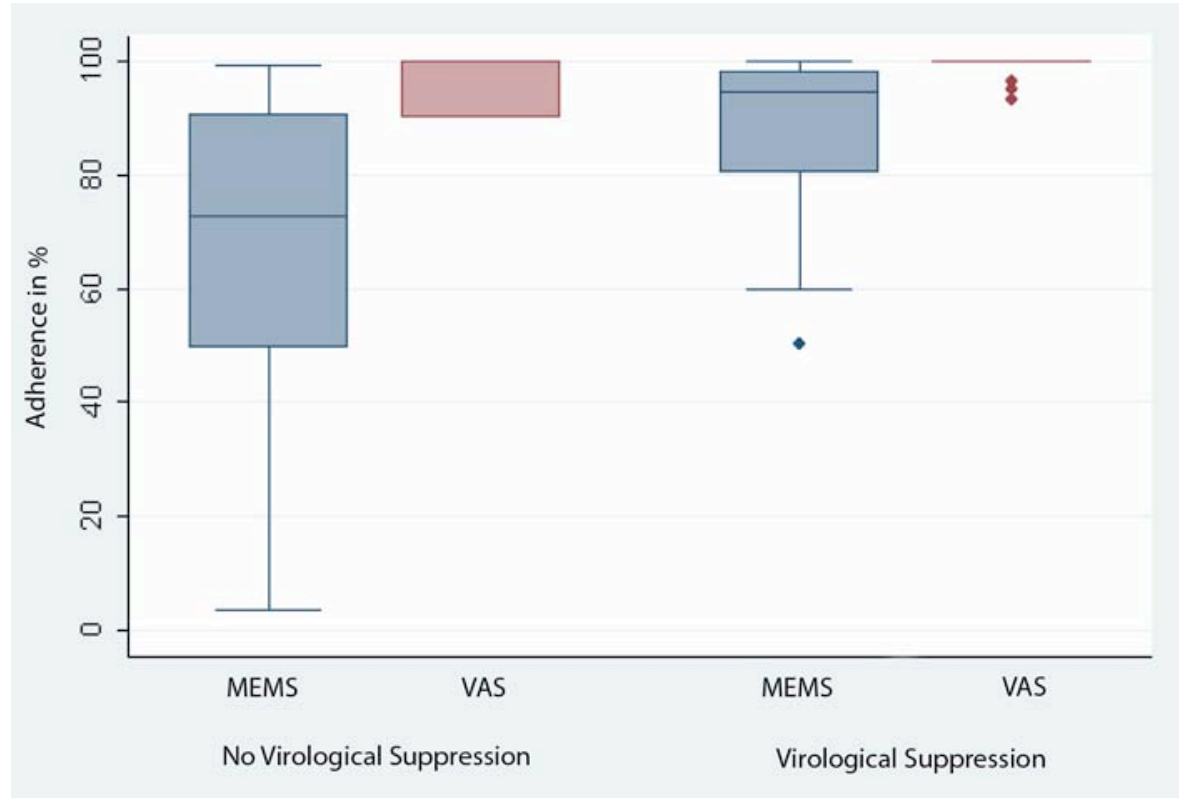

Figure 14: Median adherence by Medication Event Monitoring System (MEMS) and Visual Analogue Scale (VAS), by virological suppression at follow-up (VS)

Displayed are boxplots with a confidence interval of 25 to $75 \%$ (box) and the range. The $\mathrm{X}$-axis shows patients who did and did not achieve VS. The y-axis displays the percentage of adherence measured. Single dots represent outliers. MEMS measured higher adherence levels in patients who subsequently achieved VS, while the lack of variance in the VAS data did not allow for valid analyses.

In summary, the analyses of the two measures, MEMS and VAS, describe differing results in the measure of adherence. A comparison of the results suggests two possible explanations: the first would be that VAS correctly depicts adherence levels of mostly $100 \%$ without much variance. Performing further analyses with this measure would not be possible. Secondly, MEMS might correctly depict adherence, showing a larger spread and differentiated levels of adherence. Virological outcome might serve as an indicator as to which measure has the higher validity. Viral load at follow-up serves as the biological validation variable and showed a spread of data (see Figure 15). It also showed significant correlations with MEMS-measured adherence as presented in Table 5 and Figure 12. These results suggest that MEMS might be a more valid and accurate 
measure than VAS, and should therefore be used in the subsequent analyses as a measure of continuous adherence.

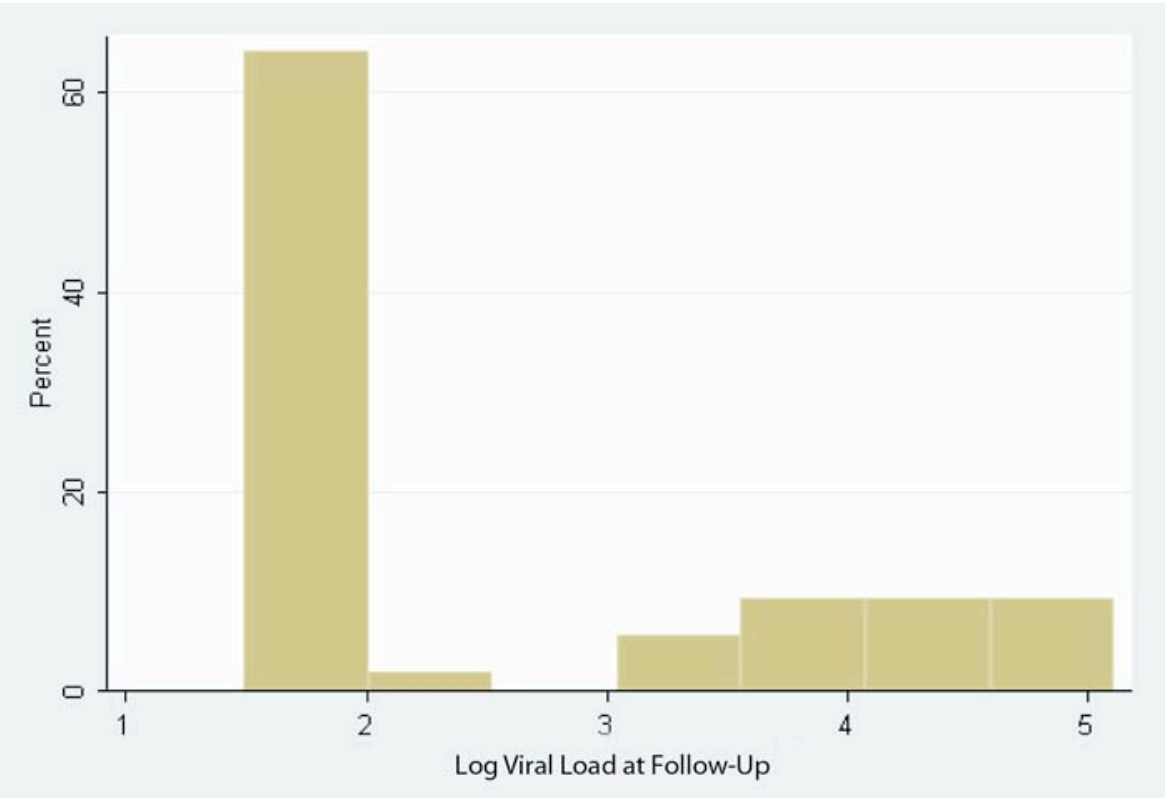

Figure 15: Viral load at follow up (log transformed to the base 10)

Displayed is a histogram of the log viral load with the x-axis showing the log viral load and the y-axis showing the percentage of children achieving the described viral load levels. A high percentage of children had a viral load of less than 50 copies of HIV RNA/mL, but levels higher than a log viral load of 3 were also measured.

\subsubsection{Categories of adherence}

In clinical practice, physicians usually group patients in adherence groups, to allow for a comparison between patients, and also to assess whether their risk for virological failure might be increased through being in a group with low adherence. To comply with this clinical practice, both adherence measures were modelled as dichotomous variables. The cut-off points were rates of over $95 \%$, over $90 \%$, over $80 \%$ and less than $60 \%$ based on mean MEMS and mean VAS adherence. VAS was included in this analysis to assess its usefulness as a categorical measure of adherence. Table 6 shows the proportion of children in each of these adherence categories. Adherences rates of over $95 \%$ (as recommended for long-term virological suppression) were achieved by $40 \%$ of caregivers $(n=29)$ as measured by MEMS. During the first month of monitoring, 
the number of caregivers rated in the three categories above $80 \%$ was higher than during the third month $\left(n=41\right.$ and $n=37$ respectively, $\left.\chi^{2}(1)=28.18, p<0.01\right)$. The number of caregivers with an adherence of less than $60 \%$ was significantly higher during the third month than during the first $\left(21 \%, \mathrm{n}=12\right.$, versus $\left.14 \%, \mathrm{n}=7 ; \chi^{2}(1)=30.52, p<0.01\right)$. As observed with the median adherence rates, the correct timing of doses seemed problematic and $40 \%$ of caregivers $(n=29)$ were in the poorest adherence category when MEMS adherence was adjusted for timing. Table 6 further illustrates that a much larger proportion of caregivers were in the highest adherence category based on their self-rating by VAS compared to MEMS-measured adherence. None of the caregivers reported very poor adherence. This sharply contrasts with the proportions in the MEMS-measured adherence categories. The distribution of children into these four adherence categories shows sharp contrasts between the adherence rates measured by MEMS and the adherence rates reported on the VAS. It further shows that even if doses were administered and thus MEMS adherence was high, these doses were not necessarily administered at the correct time and thus MEMS adherence adjusted for timing was lower.

Table 6: Distribution of adherence over the study period, by measure

\begin{tabular}{lllll}
\hline & $\mathbf{> 9 5 \%}$ adherent & $\mathbf{> 9 0 \%}$ adh. & $\mathbf{> 8 0 \%}$ adh. & $<6 \%$ adh. \\
\hline MEMS adherence overall $(\mathrm{n}=73)$ & $40 \%$ & $50 \%$ & $67 \%$ & $17 \%$ \\
MEMS adherence month 1 $(\mathrm{n}=73)$ & $36 \%$ & $48 \%$ & $68 \%$ & $14 \%$ \\
MEMS adherence month 3 $(\mathrm{n}=58)$ & $33 \%$ & $45 \%$ & $64 \%$ & $21 \%$ \\
MEMS timing adherence $(\mathrm{n}=72)$ & $26 \%$ & $33 \%$ & $49 \%$ & $40 \%$ \\
VAS adherence (n=65) & $91 \%$ & $92 \%$ & $100 \%$ & $0 \%$ \\
\hline
\end{tabular}

MEMS (Medication Event Monitoring System), VAS (Visual Analogue Scale)

\subsubsection{Categories of adherence and correlation with viral load}

To assess the relationships of the adherence categories of each measure with the virological outcome at follow-up, two-by-two tables were computed and tested for a significance on the level of $p<0.05$. To assess the impact of the correct timing of doses on the virological outcome, MEMS adherence adjusted for timing was added to the analyses 
as a third variable. Since virological data were only available for 69 children, the following analyses were performed for only this subgroup. Table 7 shows the number of children in each adherence category for the subgroup, stratified by the measures of MEMS adherence, MEMS adherence adjusted for correct timing as well as VAS adherence.

Table 7: Distribution of adherence for all children with available viral load at follow-up, by measure

\begin{tabular}{|c|c|c|c|c|}
\hline & $\begin{array}{l}>95 \% \text { adherent, } \\
\text { n (\%) }\end{array}$ & $\begin{array}{l}>90 \% \text { adh., } \\
\text { n }(\%)\end{array}$ & $\begin{array}{l}>80 \% \text { adh., } \\
\text { n }(\%)\end{array}$ & $\begin{array}{l}<60 \% \text { adh., } \\
\mathrm{n}(\%)\end{array}$ \\
\hline MEMS adherence $(\mathrm{N}=69)$ & $24(35)$ & $31(45)$ & $43(62)$ & $11(16)$ \\
\hline $\begin{array}{l}\text { MEMS adherence adjusted for } \\
\text { timing }(N=69)\end{array}$ & $17(25)$ & $22(32)$ & $32(46)$ & $27(39)$ \\
\hline VAS adherence $(\mathrm{N}=57)$ & $51(89)$ & $52(91)$ & $57(100)$ & 0 \\
\hline
\end{tabular}

MEMS (Medication Event Monitoring System), VAS (Visual Analogue Scale)

The number of children classified in each group was compared to the number of children who achieved virological suppression (defined as having <50 copies of HIV RNA/ mL; see Table 8). Both MEMS and VAS adherence categories thoroughly showed significant association with virological suppression. For the category of MEMS adherence adjusted for timing, the associations were less strong, but mostly also significant. Of 24 children with MEMS adherence levels greater than 95\%, 20 (83\%) had virological suppression, compared to only 2 of 11 children (18\%) with adherence levels lower than $60 \%$. 
Table 8: Number of children in each adherence category and association with virological suppression

\begin{tabular}{|c|c|c|c|c|}
\hline $\operatorname{MEMS}(\mathrm{N}=69)$ & VS & non-VS & $\chi^{2}(1)$ & $p$ \\
\hline adherence $>95 \%$ & 20 & 4 & \multirow[b]{2}{*}{6.32} & \multirow[b]{2}{*}{0.01} \\
\hline adherence $<95 \%$ & 22 & 20 & & \\
\hline adherence $>90 \%$ & 25 & 6 & \multirow[b]{2}{*}{7.31} & \multirow[b]{2}{*}{$<0.01$} \\
\hline adherence $<90 \%$ & 17 & 18 & & \\
\hline adherence $>80$ & 32 & 11 & \multirow[b]{2}{*}{6.20} & \multirow[b]{2}{*}{0.01} \\
\hline adherence $<80 \%$ & 10 & 13 & & \\
\hline adherence $>60 \%$ & 15 & 40 & \multirow{2}{*}{11.79} & \multirow{2}{*}{$<0.01$} \\
\hline adherence $<60 \%$ & 9 & 2 & & \\
\hline MEMS adjusted $(\mathrm{N}=69)$ & VS & non-VS & $\chi^{2}(1)$ & $p$ \\
\hline adherence $>95 \%$ & 15 & 2 & \multirow[b]{2}{*}{5.37} & \multirow[b]{2}{*}{0.02} \\
\hline adherence $<95 \%$ & 28 & 21 & & \\
\hline adherence $>90 \%$ & 17 & 5 & \multirow[b]{2}{*}{2.14} & \multirow[b]{2}{*}{0.14} \\
\hline adherence $<90 \%$ & 26 & 18 & & \\
\hline adherence $>80 \%$ & 25 & 7 & \multirow[b]{2}{*}{4.60} & \multirow[b]{2}{*}{0.03} \\
\hline adherence $<80 \%$ & 18 & 16 & & \\
\hline adherence $>60 \%$ & 29 & 10 & \multirow{2}{*}{3.56} & \multirow{2}{*}{0.06} \\
\hline adherence $<60 \%$ & 14 & 13 & & \\
\hline VAS $(\mathbf{N}=57)$ & VS & non-VS & $\chi^{2}(1)$ & $p$ \\
\hline adherence $>95 \%$ & 37 & 14 & \multirow[b]{2}{*}{7.54} & \multirow[b]{2}{*}{$<0.01$} \\
\hline adherence $<95 \%$ & 1 & 5 & & \\
\hline adherence $>90 \%$ & 38 & 14 & \multirow{2}{*}{10.96} & \multirow[b]{2}{*}{$<0.01$} \\
\hline adherence $<90 \%$ & 0 & 5 & & \\
\hline adherence $>80 \%$ & 38 & 19 & \multirow[b]{2}{*}{ - } & \multirow[b]{2}{*}{$-*$} \\
\hline adherence $<80 \%$ & 0 & 0 & & \\
\hline adherence $>60 \%$ & 38 & 19 & \multirow{2}{*}{-} & \multirow{2}{*}{$-*$} \\
\hline adherence $<60 \%$ & 0 & 0 & & \\
\hline
\end{tabular}

MEMS (Medication Event Monitoring System), VAS (Visual Analogue Scale), VS (Virological Suppression at follow-up; <50 copies of HIV RNA/mL), reporting chi-square tests.

* No chi-square test performed due to the non-variance in the sample 
In summary, these results do not clearly favour one measure over the other. High adherence levels by both MEMS and VAS are associated with virological suppression. However, the percentage of children with virological suppression is higher among the MEMS-measured groups of $>95 \%$ adherence ( $88 \%$ by adjusted MEMS and $83 \%$ by general MEMS) than among the VAS-measured group (73\% of children for VAS adherence $>95 \%$ ).

\subsubsection{Validation of binary adherence measures by virological outcome}

To further examine the usefulness of the categorical measures of adherence, logistic regression models were computed to explore which adherence cut-off point best predicts virological suppression at the follow-up visit. The model controlled for the viral load at study baseline and the length of antiretroviral treatment. The odds of patients achieving virological suppression decreased when they were classified into lower adherence categories. Adherence greater than $95 \%$ by MEMS adjusted for timing was highly predictive of virological suppression: children who reached this adherence category were 14.8 times more likely to achieve virological suppression at follow-up. Adherence greater than $95 \%$ by general MEMS was the only other category with a significant prediction of virological suppression (see Table 9).

Table 9: Odd's ratio for virological suppression, by adherence category

Patients who were classified as greater than 95\% adherent by MEMS adjusted for correct timing were 14.8 times more likely to achieve virological suppression at follow-up $(p<0.01)$.

\begin{tabular}{llll}
\hline Measure and cut-off point & Odd's ratio & 95\% CI & $\boldsymbol{p}$-value \\
\hline Timing-adjusted MEMS at 95\% adherence & 14.83 & $1.97-111.62$ & $<0.01$ \\
MEMS at 95\% adherence & 5.60 & $1.01-30.88$ & $<0.05$ \\
MEMS at 90\% adherence & 4.65 & $0.95-22.73$ & 0.06 \\
MEMS at 80\% adherence & 2.75 & $0.59-12.80$ & 0.20 \\
VAS at 95\% adherence & 2.79 & $0.17-44.88$ & 0.47 \\
\hline
\end{tabular}

MEMS (Medication Event Monitoring System), VAS (Visual Analogue Scale), 95\% CI (95\% Confidence Interval) 
In summary, the results of the analyses of adherence categories show that MEMS adherence is significantly associated with and predictive of virological suppression. This is even stronger when MEMS adherence is adjusted for the correct timing of the doses administered. Adjusting for the correct timing of doses, however, is very time consuming in clinical routine settings because the adjustment requires additional staff time and resources. Given the aim of this study to assess clinically practical methods, MEMS adherence adjusted for timing will not be included in the following analyses, which will be continued with general MEMS adherence.

\subsubsection{Analyses of sensitivity, specificity and positive predictive value for predicting virological suppression}

In line with the current international literature, the adherence categories for each measure were analysed for their sensitivity and specificity in predicting virological suppression. The aim of this analysis is to determine the most appropriate cut-off value for an adherence category that correctly predicts virological outcome. In Figure 16 the percentage of patients with reported adherence greater than $95 \%$ by MEMS and VAS is plotted against their virological outcome. Of all patients with virological suppression (log viral load <1.69; $\mathrm{n}=34), 56 \%$ had greater than $95 \%$ adherence by MEMS and $97 \%$ by VAS. Of all patients who were defined as failing their regimen (log viral load >4.69; $\mathrm{n}=5$ ), none had greater than 95\% adherence by MEMS, yet 67\% reported this adherence category by VAS. MEMS seemed to be more likely to detect non-adherence, resulting in an increase in viral load, since the proportions of patients with greater than $95 \%$ adherence decreases with increasing viral load. Caregivers of children with high viral loads still reported greater than $95 \%$ adherence by VAS. 


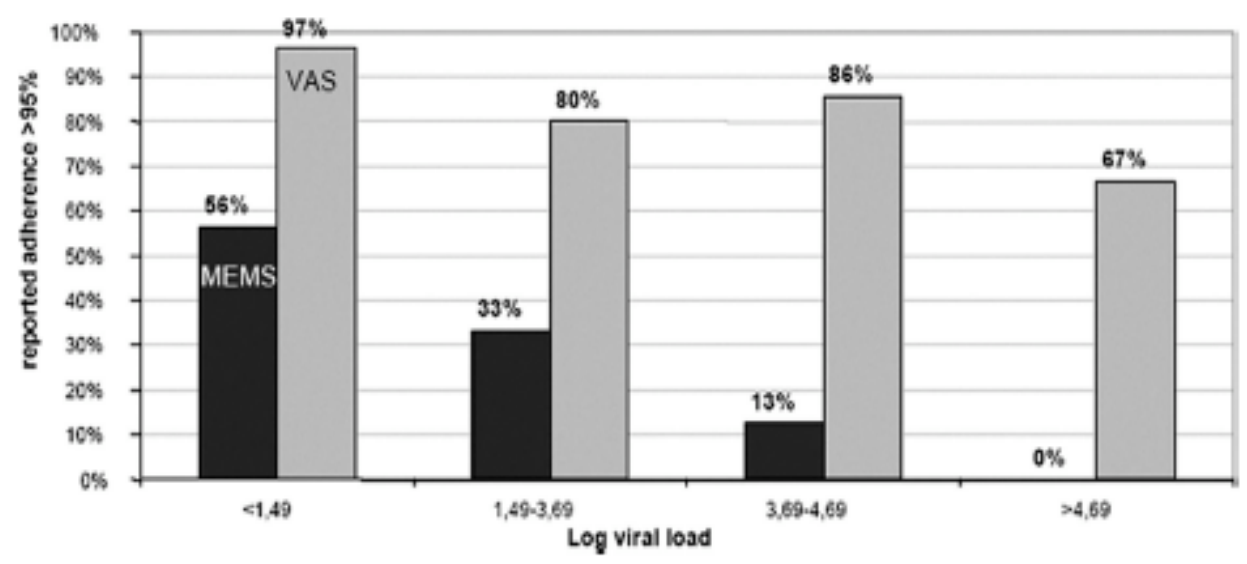

Figure 16: Virological outcome by adherence as measured by Medication Event Monitoring System (MEMS) and Visual Analogue Scale (VAS)

The bars are displaying the percentage of patients for whom each measure reported an adherence greater than $95 \%$, stratified by their virological outcome (viral load log transformed to the base 10). The percentage of high adherence (>95\%), reported by MEMS decreases with increasing viral load outcome. VAS reports high adherence even in patients with high viral loads.

However, $44 \%$ of all patients with suppressed viral loads were less than $95 \%$ adherent by MEMS. Greater than 95\% MEMS adherence had a sensitivity of $48 \%$ and a specificity of $83 \%$ of predicting virological suppression (95\% CI: $32-63$ and $62-95$, respectively; Table 10). When lowering the criteria for the classification as "adherent," sensitivity increased while specificity decreased. Adherence rates by VAS were more sensitive but less specific, therefore creating a large group of false positives.

Table 10: Sensitivity, specificity and positive predictive value for virological suppression

\begin{tabular}{lllll}
\hline Adherence measure and category & $\begin{array}{l}\text { Sensitivity } \\
(\boldsymbol{\%})\end{array}$ & $\begin{array}{l}\text { Specificity } \\
(\boldsymbol{\%})\end{array}$ & PPV $(\boldsymbol{\%})$ & $\boldsymbol{p}$-value \\
\hline MEMS adherence greater 95\% & 47.6 & 83.3 & 83.3 & $<0.01$ \\
MEMS adherence greater 90\% & 59.5 & 75 & 80.7 & $<0.01$ \\
MEMS adherence greater 80\% & 76.2 & 54.2 & 74.4 & $<0.01$ \\
VAS adherence greater 95\% & 97.4 & 26.3 & 72.6 & $---*$ \\
VAS adherence greater 90\% & 100 & 26.3 & 73.1 & -- - $^{*}$ \\
VAS adherence greater 80\% & 100 & 0 & 88.2 &.$--*$
\end{tabular}

MEMS (Medication Event Monitoring System), VAS (Visual Analogue Scale), PPV (Positive Predictive Value),

* no analyses performed due to lack of variance 
When analyzing the receiver-operating characteristic (ROC) curves, MEMS had a greater area under the curve $(\mathrm{AUC}=0.81)$ than VAS $(\mathrm{AUC}=0.61)$ and therefore better average performance when tested against virological outcome (Figures 17 and 18). The highest accuracy was produced at the ROC point $(0.0,0.3)$. MEMS therefore appeared to perform better at identifying likely positives (patients with virological suppression) than likely negatives (patients failing treatment).

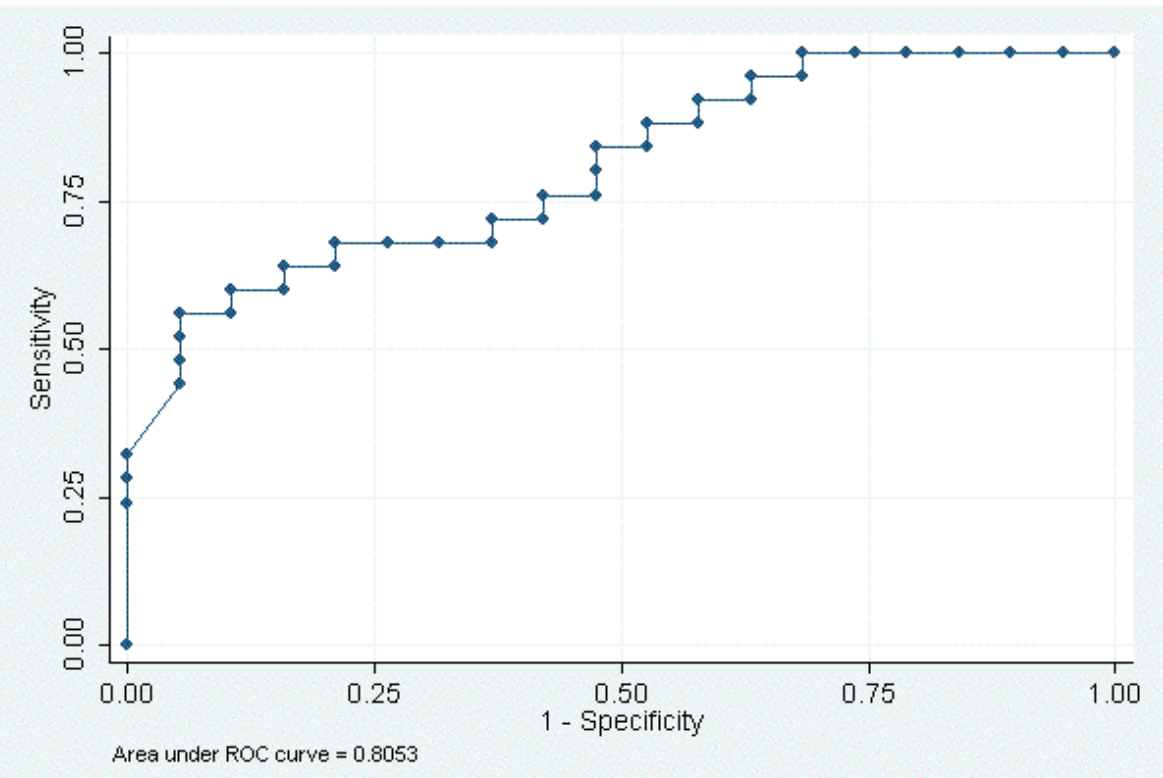

Figure 17: Receiver-Operating-Characteristic (ROC) curve in predicting virological suppression for mean adherence by Medication Event Monitoring System (MEMS)

Displayed is a ROC curve with the $\mathrm{x}$-axis showing the false-positive rate (1-specificity) and the $y$-axis showing the true-positive rate (sensitivity). The best possible prediction method would yield a point in the upper left quadrant, representing many true-positives (high sensitivity) and few false-positives (high specificity). MEMS has a tendency towards this quadrant, indicating improved discrimination between true and false positives. 


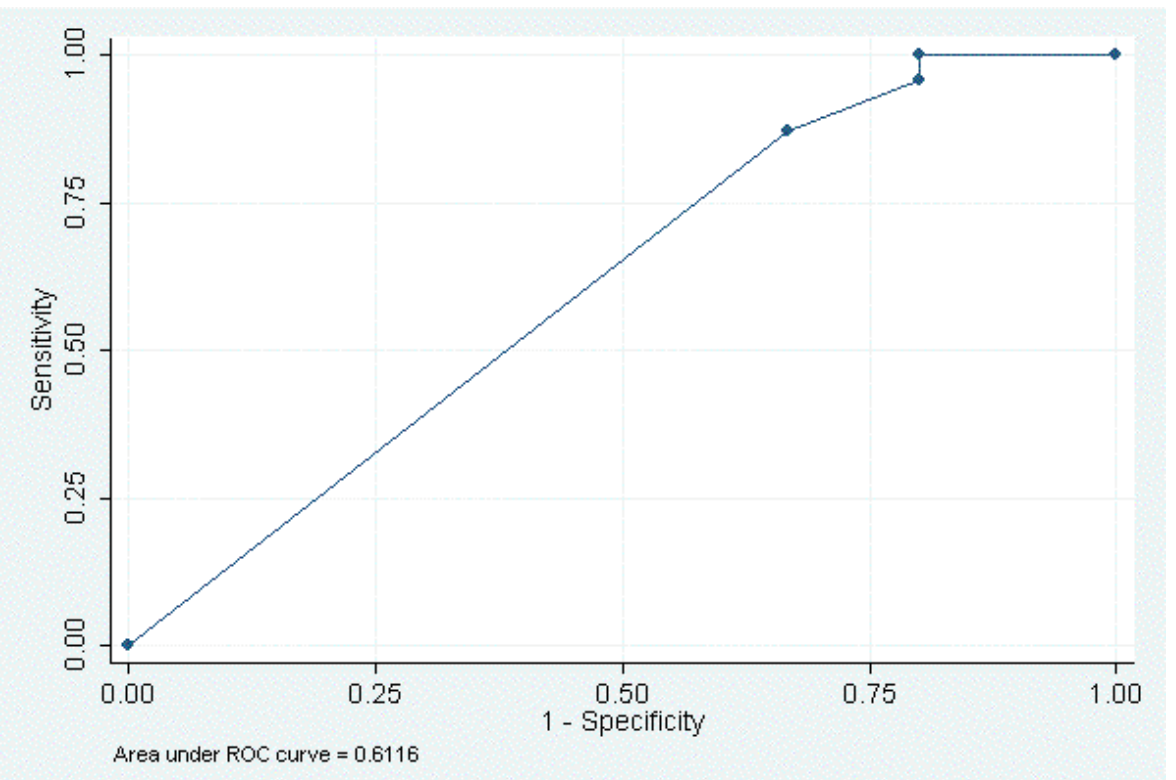

Figure 18: Receiver-Operating-Characteristics (ROC) curve in predicting virological suppression for mean adherence by Visual Analogue Scale (VAS)

Displayed is a ROC curve with the $\mathrm{x}$-axis showing the false-positive rate (1-specificity) and the $\mathrm{y}$-axis showing the true-positive rate (sensitivity). The best possible prediction method would yield a point in the upper left quadrant, representing many true-positives (high sensitivity) and few false-positives (high specificity). The VAS mostly follows the $45^{\circ}$ line of no discrimination, and therefore shows no accuracy beyond random chance.

In summary, all analyses performed thus far indicated that MEMS is a more valid measure of adherence than VAS both as a continuous and as a categorical measure. MEMS showed significant associations with virological outcome (for both continuous log viral load and the dichotomous variable of virological suppression). Its profile of sensitivity and specificity and its positive predictive value (for the adherence category $>95 \%$ ) is more favorable to the one of VAS. When analyzing their predictive value for virological suppression, however, both measures showed significant associations. Because MEMS has performed better than VAS in all previous analyses, its predictive value for virological outcome at follow-up, modeled as a continuous variable, will be examined in the final part of this paragraph. 


\subsubsection{Prediction of virological outcome by MEMS}

A multiple regression model was computed to assess the predictive value of MEMS adherence and other variables on the outcome log viral load. Other variables considered to be potentially influential based on clinical knowledge were as follows: the viral load at study baseline, the duration of antiretroviral treatment (ART), the CD4 percentage both at study baseline and at study outcome, the age of the child and the amount of additional prescribed drugs as an indicator for the presence of concurrent illnesses. For each of these variables, the association with virological outcome was analyzed using a stepwise linear regression (see Table 11).

Table 11: Linear regression coefficients for chosen variables on viral load outcome

\begin{tabular}{llll}
\hline STEP 1 & Adjusted R $^{2}$ & df & $\boldsymbol{p}$ \\
\hline Mean MEMS adherence & 0.28 & -0.54 & $<0.01$ \\
Duration of ART & 0.13 & 0.38 & $<0.01$ \\
Viral load at study baseline & 0.14 & 0.40 & $<0.01$ \\
Age of child & -0.01 & 0.12 & 0.40 \\
CD4+ percentage at study baseline & -0.02 & 0.02 & 0.86 \\
Amount of additional drugs & -0.02 & 0.02 & 0.86 \\
CD4+ percentage - outcome & -0.02 & 0.01 & 0.93 \\
\hline MEMS (Medication Event Monitoring System), ART (Antiretroviral Therapy), CD4+ (Cluster \\
of Differentiation-4 positive T-lymphocytes)
\end{tabular}

MEMS adherence, duration of ART, and baseline viral load significantly contributed to the regression. The MEMS regression line has previously been shown in Figure 12, the other two regression lines are displayed in Figures 19 and 20. 


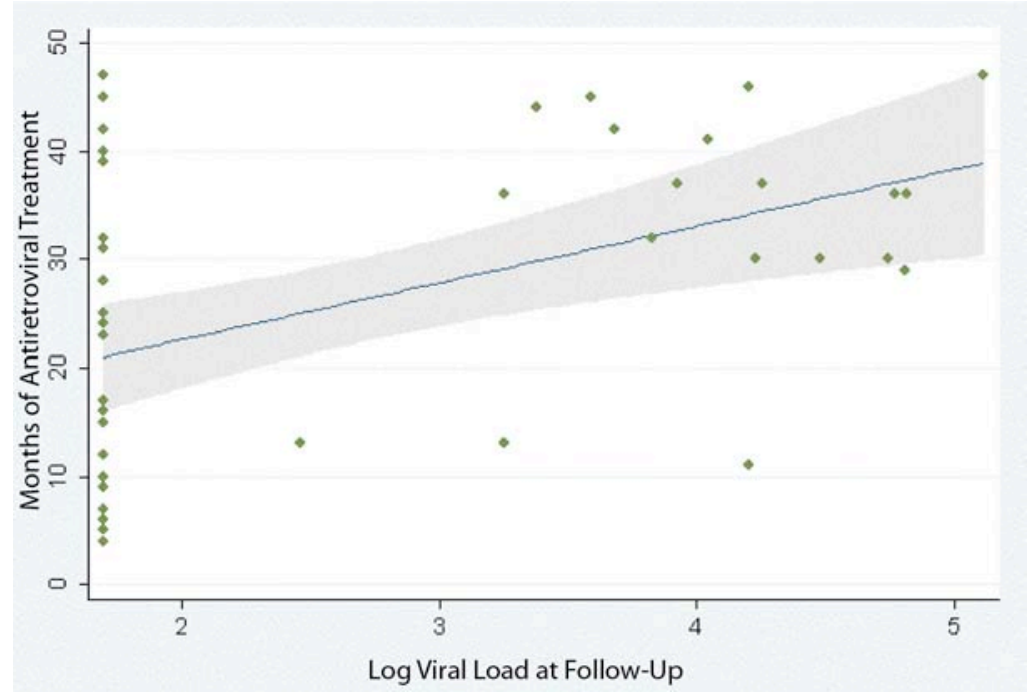

Figure 19: Association between viral load at follow-up and duration of treatment in months

The $\mathrm{x}$-axis shows the months of antiretroviral treatment (ART); the y-axis shows the viral load, log transformed to the base 10. Couples of data points are indicated by dots, the confidence interval of $25-75 \%$ is displayed as the grey area around the regression line. Both variables were positively correlated, indicating that a longer duration of ART was associated with a higher viral load.

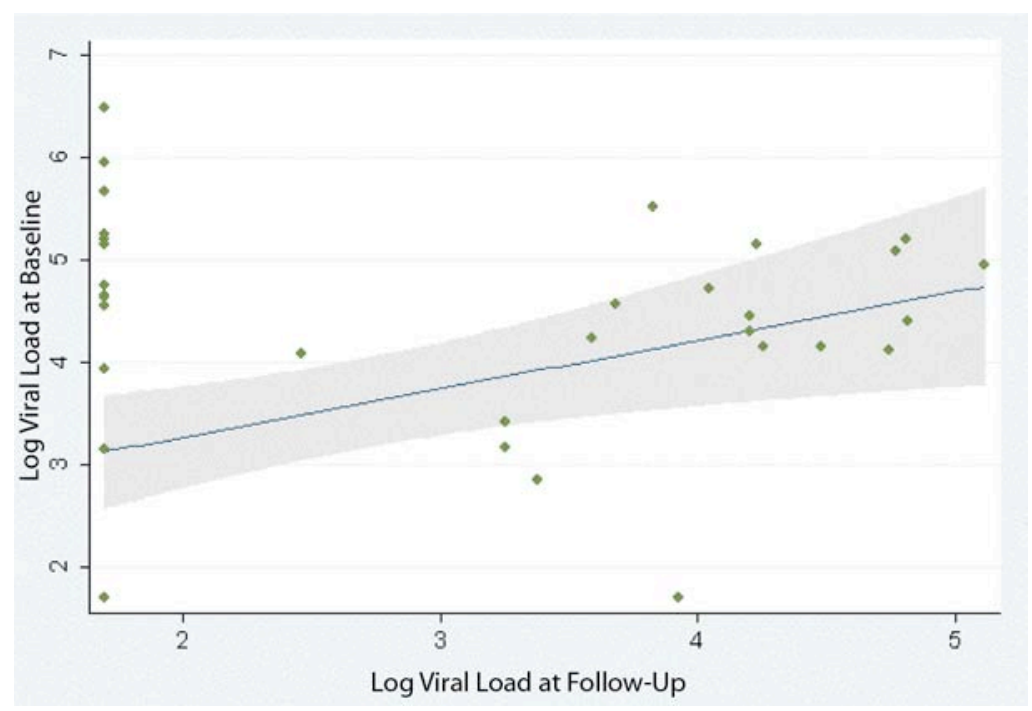

Figure 20: Association between viral load at study baseline and follow-up

The $\mathrm{x}$-axis shows viral load at study baseline, $\log$ transformed to the base 10; the y-axis shows the log viral load at follow-up. Couples of data points are indicated by dots, the confidence interval of $25-75 \%$ is displayed as the grey area around the regression line. A higher viral load at study baseline was associated with a higher viral load at follow-up. 
To examine which variable shows the highest explanation of variance, the three independent variables "mean MEMS adherence", "duration of ART" and "baseline viral load" were separately fitted into a new multiple regression model predicting virological outcome (log viral load). Because mean MEMS adherence was the variable with the highest $\mathrm{R}^{2}$-value, explaining the highest percentage of the variance, it was modeled as the first independent variable, and the other two variables were each separately added on.

Table 12: Linear regression - second step of forward selection

\begin{tabular}{llll}
\hline STEP 2 & $\begin{array}{l}\text { Adjusted } \\
\mathbf{R}^{\mathbf{2}}\end{array}$ & $\mathbf{d f}$ & $\boldsymbol{P}$ \\
& & & \\
\hline MEMS + Duration of ART & 0.36 & 2 & $<0.01$ \\
MEMS + viral load at study baseline & 0.34 & 2 & $<0.01$ \\
\hline MEMS (Medication Event Monitoring System), ART (Antiretroviral \\
Therapy)
\end{tabular}

In the third step, all three variables were fitted into one multiple linear regression model (Table 13). This model, which included mean MEMS adherence, the duration of ART and the log viral load at baseline, accounted for $46 \%$ of the variance of the virological outcome in log viral load.

Table 13: Linear regression - third step of forward selection

\begin{tabular}{llcc}
\hline STEP 3 & Adjusted R & df & $p$ \\
\hline MEMS + Duration of ART + viral load at & 0.46 & 3 & $<$ \\
baseline & & & 0.01 \\
\hline
\end{tabular}

MEMS (Medication Event Monitoring System), ART (Antiretroviral Therapy)

This analysis clarifies that MEMS adherence, together with the other two variables, acts as a significant predictor of virological outcome modeled as continuous log viral load. Considering the lack of variance in the VAS data and the resulting difficulties in modeling it in statistical models, and considering also the higher sensitivity and specificity of MEMS for predicting virological suppression, lead to the decision of solely using MEMS adherence in the subsequent analyses of factors that predict adherence. 


\subsection{Predictors of adherence}

To assess the impact of social determinants, cultural beliefs and quality of life on adherence and virological outcome, the results from the Assessment of Demographics and Socioeconomics questionnaire (ADS), from the Social Environment, Attitudes and Culture Assessment Scale (SACAS) as well as from the EUROHIS-QoL, were examined for their associations with MEMS adherence and virological outcome.

\subsubsection{Analysis of the Assessment of Demographics and Socioeconomics Questionnaire (ADS)}

Sixty-five caregivers returned the questionnaires; however only 57 were included in all additional analyses owing to missing data on adherence or virological outcome. Table 14 summarises the demographic and socioeconomic characteristics of the caregivers and children that were included in this analysis. The mean age of the children was 51 months (range, 9-128). MEMS data showed that 39\% of the children $(n=22)$ had adherence levels of $95 \%$ or above. Sixty-seven percent of the children $(n=38)$ achieved virological suppression at the follow-up protocol visit. As expected from the previous findings, MEMS adherence and log viral load at follow-up were significantly associated $(r=-0.47$; $p<0.001)$.

\subsubsection{Analysis of the Social Environment, Attitudes and Culture Assessment Scale (SACAS)}

The descriptive statistics of the SACAS are displayed in Table 18. Data from 57 caregivers were used in the analysis. Regarding the single scales of the SACAS questionnaire, on average only one caregiver did not finish each item (range 0-5). 
Table 14: Findings from the ADS questionnaire for children and caregivers

\begin{tabular}{|c|c|c|c|}
\hline & M (SD) & n & $\%$ \\
\hline \multicolumn{4}{|l|}{ Children } \\
\hline $\begin{array}{l}\text { Age in months } \\
\text { Female } \\
\text { Male } \\
\text { Months on treatment } \\
\text { Receiving second line regimen } \\
\text { Receiving TB treatment }\end{array}$ & $\begin{array}{l}51(25.6) \\
- \\
- \\
25(14.2) \\
- \\
-\end{array}$ & $\begin{array}{l}- \\
25 \\
32 \\
- \\
9 \\
7\end{array}$ & $\begin{array}{l}- \\
44 \\
56 \\
- \\
16 \\
12\end{array}$ \\
\hline $\begin{array}{l}\text { Caregivers (characteristics from ADS) } \\
\text { Age in years } \\
\text { Female } \\
\text { Male } \\
\text { Biological parent } \\
\text { Not employed } \\
\text { Years of education } \\
\text { No relationship or marriage } \\
\text { Primary language: Xhosa } \\
\text { Living in informal housing } \\
\text { No access to sanitation } \\
\text { No access to electricity } \\
\text { Disclosed own infection to household } \\
\text { Disclosed child's infection to household } \\
\text { AIDS-related death in family } \\
\text { Attending community support group } \\
\text { Monthly income < 10 Euro } \\
\text { Possession of watch/ cell phone } \\
\text { Number of people in household } \\
\text { Number of children cared for } \\
\text { Number of sick children cared for } \\
\text { Living with the child's father } \\
\text { Transport costs prevent clinic attendance } \\
\text { Trip to clinic is perceived as safe }\end{array}$ & $\begin{array}{l}34(9.9) \\
67 \\
0 \\
- \\
- \\
10(3.6) \\
- \\
- \\
- \\
- \\
- \\
- \\
- \\
- \\
- \\
- \\
- \\
5(2.9) \\
2.5(2.3) \\
1.1 \quad(0.3) \\
- \\
- \\
-\end{array}$ & $\begin{array}{l}- \\
- \\
- \\
45 \\
39 \\
- \\
36 \\
48 \\
41 \\
19 \\
16 \\
38 \\
46 \\
28 \\
17 \\
32 \\
47 \\
- \\
- \\
- \\
20 \\
17 \\
32\end{array}$ & $\begin{array}{l}- \\
- \\
- \\
80 \\
71 \\
- \\
65 \\
84 \\
72 \\
33 \\
28 \\
76 \\
81 \\
51 \\
30 \\
57 \\
82 \\
- \\
- \\
- \\
36 \\
30 \\
56\end{array}$ \\
\hline $\begin{array}{c}\text { Adherence children (MEMS) } \\
\text { Percentage of doses taken } \\
\text { Adherence }>95 \%\end{array}$ & $81(21.8)$ & - & $\begin{array}{l}- \\
39\end{array}$ \\
\hline $\begin{array}{c}\text { Viral load at enrolment children } \\
\text { Viral load (log) } \\
\text { Achieved VS }\end{array}$ & $\begin{array}{l}3.3(1.6) \\
-\end{array}$ & $\begin{array}{l}- \\
26\end{array}$ & $\begin{array}{l}- \\
46\end{array}$ \\
\hline $\begin{array}{c}\text { Viral load at follow-up children } \\
\text { Viral load (log) } \\
\text { Achieved VS }\end{array}$ & $\begin{array}{l}2.5(1.2) \\
-\end{array}$ & $\begin{array}{l}- \\
38\end{array}$ & $\begin{array}{l}- \\
67\end{array}$ \\
\hline
\end{tabular}

M (mean), SD (standard deviation), $\mathrm{n}$ (number of participants for which item is true), \% (percentage of participants for which item is true), ADS (Assessment of Demographics and Socioeconomics questionnaire), VS (virological suppression; cut-off at $<50$ copies of HIV RNA/mL blood), MEMS (Medication Event Monitoring System; adherence cut-off at >95\%), TB (tuberculosis treatment) 


\subsubsection{Quality of life by EUROHIS-QoL}

Fifty-nine caregivers returned the questionnaires assessing quality of life. For each subject, a mean score for the EUROHIS 8-item QOL (mQOL) was calculated. The values 1-5 were assigned to the possible answers for each item (answers were "very poor"=1, "poor"=2, "neither poor nor good"=3, "good"=4, "very good"=5). The values for all 8 items were added and the arithmetic mean was calculated for each subject. Overall mean quality of life was then calculated from the individual data and was 3.6 (SD, 0.8).

\subsubsection{Adherence by socioeconomic variables}

In a first step, the relationship between MEMS adherence and demographic as well as socio-economic factors was assessed by comparing the median adherence levels for patients with certain characteristics. The factors were chosen based on clinical experience and the current line of thought among HIV physicians, to establish whether they might be as influential as they are perceived. MEMS adherence was not significantly correlated with the age of the paediatric patient (Spearman's correlation: $r=-0.18, p=$ 0.14). The adherence of children whose HIV status had been disclosed to the household they lived in was only slightly different from children whose HIV status was not known to their environment ( $83 \%$ versus $81 \%$ respectively, Mann-Whitney-U-test: $z=-0.21, p=$ 0.83). Adherence was not significantly correlated to the caregiver's education, captured by the years of education $(r=0.10, p=0.45)$. Other variables with non-significant differences in adherence rates were as follows: whether or not the caregiver had experienced the death of a close person due to AIDS ( $82 \%$ versus $80 \% ; z=-1.32, p=0.19$ ) and whether or not the father of the child lived in the same household and supported the primary caregiver $(82 \%$ versus $81 \% ; z=-0.01, \mathrm{p}=0.99)$. A significant difference in adherence was found among children of caregivers who were employed and spent the day at work $(n=7)$ and children of caregivers who were either informally employed or unemployed $(n=50)$. Children with an employed caregiver showed lower adherence rates (69\% versus $83 \%$ respectively; $z=2.31, p=0.02$ ). Children whose caregivers possessed a watch or a cell phone to keep track of the time also had significantly higher adherence 
levels than children of caregivers without these (94\% versus $81 \%$ respectively, $z=2.32$, $p=0.02$ ). Table 15 and 16 show the associations of the ADS items with adherence.

Table 15: Correlation analyses for adherence and ADS items

\begin{tabular}{lll}
\hline ADS item & $\begin{array}{l}\text { Correlation } \\
\text { adherence }(\boldsymbol{r})\end{array}$ & $\boldsymbol{w}$ \\
\hline Years of CG education & 0.10 & 0.45 \\
Number of people in household & -0.12 & 0.36 \\
Number of children cared for & -0.17 & 0.20 \\
Number of sick children cared for & 0 & 1 \\
Age of the HIV+ child & -0.18 & 0.14 \\
\hline
\end{tabular}

ADS (Assessment of Demographics and Socioeconomics questionnaire), CG (Caregiver), HIV+ (infected with the Human Immunodeficiency Virus), $r$ and $p$ for Spearman's correlations

Table 16: Adherence rates by ADS questionnaire item

\begin{tabular}{lllll}
\hline ADS item & $\begin{array}{l}\text { Adherence if } \\
\text { correct }\end{array}$ & $\begin{array}{l}\text { Adherence if not } \\
\text { correct (\%) }\end{array}$ & $\boldsymbol{z}$ & $\boldsymbol{p}$ \\
\hline CG is biological parent & 92 & 80 & -0.96 & 0.34 \\
CG is employed & 69 & 83 & 2.31 & 0.02 \\
CG does not have relationship/ marriage & 91 & 90 & -0.23 & 0.82 \\
CG lives together with child's father & 82 & 81 & -0.01 & 0.99 \\
CG home language is Xhosa & 91 & 85 & 0.01 & 0.99 \\
CG lives in informal housing & 90 & 90 & 1.00 & 0.32 \\
CG has access to sanitation & 90 & 89 & -0.89 & 0.37 \\
CG has access to electricity & 88 & 94 & 0.16 & 0.87 \\
CG disclosed own infection to household & 94 & 90 & 0.19 & 0.85 \\
CG disclosed child's infection to household & 83 & 81 & -0.21 & 0.83 \\
CG experienced AIDS-related death & 82 & 80 & -1.32 & 0.19 \\
CG attends support group & 90 & 92 & 0.38 & 0.71 \\
CG earns less than 10 Euro/month & 90 & 91 & 0.28 & 0.78 \\
CG owns watch/ cell phone & 94 & 81 & 2.32 & 0.02 \\
CG feels that transport cost prevents clinic attendance & 92 & 83 & -1.52 & 0.13 \\
CG perceives transport to clinic as safe & 90 & 90 & 0.25 & 0.80 \\
\hline
\end{tabular}

ADS (Assessment of Demographics and Socioeconomics questionnaire), CG (Caregiver), AIDS (Acquired Immunodeficiency Syndrome), $z$ and $p$ for Mann-Whitney-U tests 
In summary, these analyses showed differences in adherence for children of caregivers who were and were not able to manage time and fit adherence behaviour into their daily routine. To investigate the associations of the socially determined factors (including quality of life) and adherence in more detail, the adherence variable was dichotomised. The cut-off point for the definition of "adherent" versus "non-adherent" was set at $95 \%$, as suggested by previous studies and used in clinical practice. This was also the cut-off value that had the highest positive predictive value in predicting virological suppression in the previous analyses. Virological outcome was added to the analyses as an additional dichotomous variable, based on whether or not a child achieved virological suppression. The aim was to test for associations between social determinants and virological outcome that might not necessarily be linked to adherence.

\subsubsection{ADS items - correlations to adherence and virological outcome}

Depending on the level of measurement, Spearman's correlation analyses and $\chi^{2}$ tests were used to investigate the relationship of the socio-demographic variables with adherence (as adherent vs. non-adherent, cut-off at 95\% adherence) and virological suppression (at a cut-off of less than 50 copies of HIV RNA/ mL). The sociodemographic variables included age and sex of the child; the age of the caregiver, caregiver education, the caregiver's primary language; structure and availability of housing, sanitation and electricity; disclosure to the child and the household in which the child lived;, and the experience of a death related to AIDS in the family (for a full list of items of the ADS, see Table 14). The only item that was significantly associated with adherence was the existence of a cell phone or watch at home $\left[\chi^{2}(1)=6.71 ; p<0.01\right]$. Caregivers who possessed a cell phone or watch showed higher adherence. While none of the other listed associations was significant, a tendency of non-significance could be observed for the items, "Does transport cost keep you from coming to the clinic?" $\left[\chi^{2}(1)\right.$ $=3.23 ; p=0.07]$, indicating that financial problems might be associated with lower adherence. The age of the child was slightly negatively correlated with adherence $(r=-$ $.24 ; p=0.08$ ), showing a trend of better adherence with higher age. Additionally, the number of people living in the household also showed a trend towards being negatively 
correlated $(r=-.25 ; p=0.09)$, indicating that a higher number of people living in the household was associated with poorer adherence (for detailed results, see Table 17).

Table 17: Associations between socio-demographic variables (ADS) with adherence and virological suppression (VS)

\begin{tabular}{|c|c|c|c|c|c|c|c|c|}
\hline \multirow[b]{2}{*}{ ADS Items } & \multicolumn{4}{|c|}{ Adherence $>95 \%$} & \multicolumn{4}{|c|}{ Virological suppression } \\
\hline & $r$ & $\chi^{2}$ & $d f$ & $p$ & $r$ & $\chi^{2}$ & $d f$ & $p$ \\
\hline Age caregiver & -.13 & & & .34 & -.05 & & & .75 \\
\hline Age child & -.24 & & & .08 & -.07 & & & .60 \\
\hline Sex child & & 0.55 & 1 & .46 & & 6.02 & 1 & .01 \\
\hline Years of education caregiver & .09 & & & .53 & .10 & & & .48 \\
\hline Monthly income $(\dagger)$ & -.10 & & & .44 & -.06 & & & .66 \\
\hline Home language & & 1.53 & 4 & .82 & & 3.36 & 4 & .50 \\
\hline Existence of a tap at home & & 0.31 & 1 & .58 & & 1.46 & 1 & .23 \\
\hline Existence of electricity at home & & 1.87 & 1 & .17 & & 3.66 & 1 & .06 \\
\hline Possession of watch or cell phone & & 6.72 & 1 & .01 & & 2.38 & 1 & .12 \\
\hline Number of people in household & -.25 & & & .09 & .21 & & & .13 \\
\hline Number of children cared for & -.12 & & & .37 & .14 & & & .33 \\
\hline Number of sick children cared for & -.08 & & & .58 & .03 & & & .81 \\
\hline Living with child's father & & 0.54 & 1 & .82 & & 0.22 & 1 & .64 \\
\hline Disclosure of child's infection & & 1.77 & 1 & .18 & & 2.97 & 1 & .09 \\
\hline Disclosure of caregiver's infection & & 1.08 & 1 & .30 & & 3.09 & 1 & .08 \\
\hline AIDS-related death in surrounding & & 0.88 & 1 & .35 & & 3.31 & 1 & .07 \\
\hline Transport cost prevent clinic attendance & & 3.24 & 1 & .07 & & 0.55 & 1 & .46 \\
\hline Trip to clinic perceived as safe & & 1.09 & 1 & .58 & & 0.86 & 1 & .65 \\
\hline Participation in community support group & & 1.44 & 1 & .23 & & $\S$ & & \\
\hline
\end{tabular}

All statistics refer to the full sample of $\mathrm{N}=57$. ADS (Assessment of Demographics and Socioeconomics questionnaire), Virological suppression (cut-off at <50 copies of HIV RNA/ mL blood; 1: suppressed, 0: not suppressed); Adherence cut-off at $>95 \%(1=$ adherent, $0=$ non-adherent $)$; Associations between dichotomous variables were computed using ChiSquare-Tests $\left(\chi^{2}\right)$; associations between adherence/virologic suppression and rank $(\dagger)$ or metric variables were calculated using correlation coefficients (Spearman's $r$ or point-biserial $r$, respectively). In the questionnaire for yes/no questions, "yes" was labeled with 1 and "no" was labeled with 0 ; $§$ insufficient number of cases in one cell. 
Virological suppression (VS) was associated with the child's sex $\left[\chi^{2}(1)=6.02 ; p<\right.$ 0.01] indicating relatively fewer boys than girls with virological suppression. Additionally, some associations just missed the statistical threshold, but could nevertheless be considered as clinically significant. These items were as follows: the disclosure of the caregiver $\left[\chi^{2}(1)=3.09 ; p=0.08\right]$, the disclosure of the child $\left[\chi^{2}(1)=\right.$ $2.97 ; p=0.09]$, access to electricity $\left[\chi^{2}(1)=3.66 ; p=0.06\right]$ and experience of an AIDSrelated death in one's close surrounding $\left[\chi^{2}(1)=3.31 ; p=0.07\right.$; with relatively more VS in children without experience of death in surrounding].

\subsubsection{SACAS items - correlations to adherence and virological outcome}

Descriptive statistics of the SACAS are displayed in Table 18. Correlation analyses were calculated to investigate the relationship of the single item scores with adherence and virological outcome (for all results see Table 17). Adherence was significantly correlated with the following items: "When my child is better it is not necessary to give all the antiretrovirals anymore" $(r=-0.31 ; p<0.01)$, "The side effects of my child's antiretrovirals are strong" $(r=-0.30 ; p=0.03)$ and "People treat me differently because of my child's HIV infection" ( $r=-0.29 ; p=0.04)$. A higher agreement to these items was correlated with poorer adherence.

For virological suppression, the following items were significantly positively associated: "I enjoy the time I can spend with my child" ( $r=0.42 ; p<0.01)$, "My HIV infected child is in a good health state" $(r=0.40 ; p<0.01)$, "I am confident in speaking English when speaking with the doctor" $(r=0.34 ; p<0.01)$, "My child is now in a better condition than before the antiretrovirals" $(r=0.32 ; p=0.01)$, "The doctor spends enough time with me and my child" ( $r=0.38 ; p<0.01)$, "Modern European medicine works better than traditional medicine" $(r=0.28 ; p<0.05)$ and "I have enough time to look after my own health" $(r=0.33 ; p=0.01)$. An agreement to the following items correlated negatively with virological suppression: "When my child is better it is not necessary to give all the antiretrovirals anymore" $(r=-0.28 ; p=0.03)$, "Traditional healers know more

about HIV than doctors" ( $r=-0.33 ; p=0.01)$ and "People treat me differently because of my child's HIV infection" $(r=-0.38 ; p<0.01)$. 
Table 18: Results from the SACAS and correlations with adherence and virological outcome

\begin{tabular}{|c|c|c|c|c|c|c|c|c|}
\hline No. & SACAS Item & $\mathbf{n}$ & $\mathbf{M}$ & SD & $\begin{array}{c}\text { Adhere } \\
(r)\end{array}$ & & $\begin{array}{l}\mathrm{V} \\
(\boldsymbol{r}\end{array}$ & \\
\hline 1 & I enjoy the time I can spend with my child & 56 & 3.55 & 0.50 & -.01 & & .42 & *** \\
\hline 2 & $\begin{array}{l}\text { My HIV infected child is in a good health } \\
\text { state }\end{array}$ & 57 & 3.49 & 0.50 & -.13 & & .40 & $* *$ \\
\hline 3 & $\begin{array}{l}\text { When my child is better it is not necessary } \\
\text { to give all the ARV's anymore }\end{array}$ & 55 & 1.60 & 0.63 & -.31 & $*$ & -.28 & $*$ \\
\hline 4 & $\begin{array}{l}\text { I am confident in speaking English when } \\
\text { speaking with the doctor }\end{array}$ & 57 & 2.74 & 0.88 & .12 & & .34 & $* *$ \\
\hline 5 & I have difficulties in reading & 53 & 2.02 & 0.80 & -.22 & & -.24 & \\
\hline 6 & Antiretrovirals are efficient against HIV & 55 & 3.47 & 0.60 & -.09 & & .19 & \\
\hline 7 & My everyday life does not stress me & 54 & 3.09 & 0.92 & .17 & & .16 & \\
\hline 8 & $\begin{array}{l}\text { I am ashamed of asking the doctor something } \\
\text { I have not understood }\end{array}$ & 57 & 2.02 & 0.88 & -.02 & & .01 & \\
\hline 9 & I know how antiretrovirals work in the body & 52 & 3.27 & 0.66 & -.10 & & .22 & \\
\hline 10 & $\begin{array}{l}\text { It is difficult to remember the names of the } \\
\text { antiretrovirals my child takes }\end{array}$ & 55 & 2.13 & 0.98 & .05 & & -.10 & \\
\hline 11 & $\begin{array}{l}\text { My child's doctor knows a lot about HIV and } \\
\text { treatment possibilities }\end{array}$ & 57 & 3.49 & 0.57 & .01 & & .22 & \\
\hline 12 & $\begin{array}{l}\text { I know how to administer my child's } \\
\text { antiretrovirals correctly }\end{array}$ & 57 & 3.39 & 0.62 & -.09 & & .20 & \\
\hline 13 & $\begin{array}{l}\text { It is difficult to remember giving antiretrovirals } \\
\text { at certain times }\end{array}$ & 57 & 1.91 & 0.85 & -.05 & & -.21 & \\
\hline 14 & It is good to take traditional medicine as well & 56 & 1.70 & 0.71 & -.22 & & -.20 & \\
\hline 15 & $\begin{array}{l}\text { Traditional healers know more about HIV } \\
\text { than doctors }\end{array}$ & 57 & 1.51 & 0.60 & -.07 & & -.33 & $*$ \\
\hline 16 & $\begin{array}{l}\text { My child is now in a better condition than } \\
\text { before the antiretrovirals }\end{array}$ & 57 & 3.46 & 0.66 & .11 & & .32 & $*$ \\
\hline 17 & The doctor does not understand my problems & 52 & 2.25 & 0.95 & -.13 & & .01 & \\
\hline 18 & $\begin{array}{l}\text { The doctor spends enough time with me and } \\
\text { my child }\end{array}$ & 56 & 3.46 & 0.54 & .05 & & .38 & ** \\
\hline 19 & $\begin{array}{l}\text { The doctor's advice concerning my child is } \\
\text { important for me }\end{array}$ & 54 & 3.52 & 0.50 & -.12 & & .26 & \\
\hline 20 & $\begin{array}{l}\text { Modern European medicine works better than } \\
\text { traditional medicine }\end{array}$ & 55 & 3.51 & 0.57 & -.05 & & .28 & \\
\hline 21 & $\begin{array}{l}\text { The side effects of my child's antiretrovirals } \\
\text { are strong }\end{array}$ & 55 & 2.07 & 0.84 & -.30 & $*$ & -.22 & \\
\hline 22 & $\begin{array}{l}\text { It is better to reduce my child's antiretrovirals } \\
\text { if the side effects are too strong, even before } \\
\text { consulting the doctor }\end{array}$ & 55 & 1.76 & 0.86 & .05 & & -.02 & \\
\hline 23 & To get to the clinic is no big effort for me & 57 & 2.74 & 0.99 & -.01 & & .11 & \\
\hline 24 & Time spent at the clinic causes problems at work & 56 & 1.89 & 0.78 & -.13 & & -.05 & \\
\hline 25 & $\begin{array}{l}\text { It is difficult to organise my household when } \\
\text { I go to the clinic with my child }\end{array}$ & 56 & 2.48 & 0.93 & -.14 & & -.20 & \\
\hline 26 & I have enough time to look after my own health & 56 & 3.30 & 0.66 & .09 & & .33 & $*$ \\
\hline 27 & Antiretroviral treatment is good for my child & 57 & 3.53 & 0.50 & -.04 & & .22 & \\
\hline 28 & $\begin{array}{l}\text { People treat me differently because of my } \\
\text { child's HIV infection }\end{array}$ & 54 & 2.04 & 0.78 & -.29 & $*$ & -.38 & $* *$ \\
\hline
\end{tabular}




\begin{tabular}{|c|c|c|c|c|c|c|}
\hline No. & SACAS Item & $\bar{n}$ & $\mathbf{M}$ & SD & $\begin{array}{l}\text { Adherence } \\
(r)\end{array}$ & $\begin{array}{l}\mathrm{VS} \\
(r)\end{array}$ \\
\hline 29 & $\begin{array}{l}\text { I would like to always see the same doctor, } \\
\text { even if it means that I have to wait longer }\end{array}$ & 56 & 2.66 & 1.05 & -.02 & .07 \\
\hline 30 & $\begin{array}{l}\text { Sometimes I don't have enough food and } \\
\text { can't give antiretrovirals to my child }\end{array}$ & 57 & 2.00 & 0.82 & -.22 & -.18 \\
\hline 31 & $\begin{array}{l}\text { A traditional healer can be a good addition } \\
\text { to the treatment received at the clinic }\end{array}$ & 57 & 1.47 & 0.50 & -.18 & -.15 \\
\hline 32 & $\begin{array}{l}\text { I would feel comfortable if there was } \\
\text { a traditional healer at the clinic }\end{array}$ & 57 & 1.56 & 0.60 & -.08 & -.08 \\
\hline 33 & $\begin{array}{l}\text { If I am not sure about something concerning } \\
\text { my child's medication, I first ask friends or } \\
\text { neighbours and then I ask the doctor }\end{array}$ & 57 & 1.65 & 0.61 & -.25 & -.23 \\
\hline 34 & I trust the doctor & 56 & 3.39 & 0.78 & .04 & .07 \\
\hline 35 & $\begin{array}{l}\text { There is a person who I trust and who I } \\
\text { can turn to for advice }\end{array}$ & 56 & 2.55 & 0.97 & .07 & .10 \\
\hline 36 & $\begin{array}{l}\text { I get enough support from my family } \\
\text { and friends }\end{array}$ & 55 & 2.95 & 0.91 & .13 & .00 \\
\hline
\end{tabular}

SACAS (Social environment Attitude and Culture Assessment Scale), MEMS (Medication Event Monitoring System), VS (Virological suppression; cut-off at less than 50 copies of HIV RNA/ mL blood; 1: suppressed, 0: not suppressed), Adherence cut-off at >95\% (1: adherent, 0: non-adherent); $\mathrm{n}$ (number of participants completing the item; full sample $\mathrm{N}=57$ ), $\mathrm{M}$ (mean), SD (standard deviation), $r$ (point-biserial correlation coefficient), $* p<0.05, * * p<0.01$;

\subsubsection{Superordinate structure of SACAS items}

Because there was a possibility that the findings of the correlation analyses on the item level might be chance results, the SACAS questionnaire was examined to assess whether a simplified superordinate factor structure could be established. An exploratory principal components analysis and an additional varimax rotation revealed three distinct factors (eigenvalue >2) that explained $46.33 \%$ of the total variance (see Table 19). Inspection of the eigenvalues and the screeplot showed a drop in eigenvalues between the third (2.4) and the fourth factor (1.8). All items loaded above 0.30 on one of the three factors and most of them could clearly be classified as belonging to a single factor with the exception of items 13 and 25 ("It is difficult to remember giving antiretrovirals at certain times", "It is difficult to organise my household when I go to the clinic with my child"). Because the SACAS was constructed only for the specific setting of the presented study, no former steps in validation were performed and all items were assigned to the factor on which they loaded highest. The semantic label of each factor resulted from inspection of the assigned items. The first factor included statements concerning caregiver coping skills, a good relationship to and trust in the physician, biomedicine and ART. 
Therefore, the first factor was named coping \& trust (factor 1). The second factor consisted of items dealing with drug side-effects, readiness to follow the physician's instructions as well as a positive attitude towards African traditional medicine and was named side-effects \& compliance (factor 2). Items belonging to the third factor deal with difficulties in English literacy as well as the knowledge and understanding of ART procedures and underlying principles. Hence, it was termed literacy \& knowledge (factor 3).

Considering the different loading of the items, the factor scores of each participant were calculated for each factor. The factor scores were then applied to correlation analyses with the measures of adherence and virological outcome. Only the first factor, coping \& trust, correlated significantly with virological suppression $(r=0.34 ; p<0.01$, Table 19), revealing a link between good virological outcome and a trusting relationship with the doctor as well as positive attitudes towards antiretroviral treatment. The other factors did not show substantial correlations to virological outcome (factor 2: $r=-0.13, p$ $=0.34$; factor $3: r=-0.22, p=0.11)$. None of the factors was substantially correlated with adherence (factor 1: $r=-0.02, p=0.06$; factor 2: $r=-0.17, p=0.07$; factor $3: r=-0.16, p$ $=0.88)$.

\subsubsection{EUROHIS-QoL - correlations to adherence and virological outcome}

Taking into account the one factor structure of the EUROHIS-QOL, a simple score of overall quality of life was computed by using the mean score across all items. The associations between the caregiver's mean quality of life (mQOL) and adherence (defined as adherence >95\%; $r=-0.05, p=0.69)$ and virological suppression $(r=-0.03, p$ $=0.88$ ) did not reach statistical significance. Mean caregiver-reported QOL correlated significantly with the SACAS factor coping \& trust $(r=0.42, p<0.01)$, again suggesting that this factor in some parts reflects life- as well as health situation. No correlations were found between mQOL and SACAS side-effects \& compliance (factor 2; $r=0.10, p=$ 0.47 ) or SACAS literacy \& knowledge (factor 3; $r=-0.01, p=0.94$ ). 
Table 19: Exploratory Principal-Components Analysis: varimax rotated factor matrix

\begin{tabular}{|c|c|c|c|c|}
\hline SACAS item & factor1 & factor2 & faktor3 & $\mathbf{h}^{2}$ \\
\hline 1 & .71 & -.18 & .03 & .53 \\
\hline 2 & .74 & -.06 & .12 & .56 \\
\hline 3 & -.01 & .55 & .42 & .48 \\
\hline 4 & .41 & -.05 & -.52 & .44 \\
\hline 5 & .09 & .16 & .72 & .55 \\
\hline 6 & .78 & .01 & -.07 & .61 \\
\hline 7 & .52 & .03 & .21 & .32 \\
\hline 8 & .32 & .26 & .60 & .53 \\
\hline 9 & .45 & .16 & -.23 & .28 \\
\hline 10 & .02 & .36 & .52 & .39 \\
\hline 11 & .75 & -.08 & -.17 & .59 \\
\hline 12 & .87 & -.06 & -.13 & .77 \\
\hline 13 & -.29 & .17 & .30 & .20 \\
\hline 14 & -.44 & .55 & -.07 & .51 \\
\hline 15 & -.61 & .55 & .06 & .68 \\
\hline 16 & .78 & -.17 & .00 & .64 \\
\hline 17 & -.07 & .01 & .60 & .36 \\
\hline 18 & .78 & -.15 & -.05 & .64 \\
\hline 19 & .85 & -.13 & -.17 & .77 \\
\hline 20 & .75 & -.13 & -.00 & .58 \\
\hline 21 & .11 & .46 & .24 & .28 \\
\hline 22 & .10 & .60 & .29 & .45 \\
\hline 23 & .34 & .22 & -.18 & .20 \\
\hline 24 & -.07 & .68 & .04 & .48 \\
\hline 25 & -.08 & -.03 & .19 & .04 \\
\hline 26 & .69 & .05 & -.17 & .51 \\
\hline 27 & .83 & -.09 & -.07 & .71 \\
\hline 28 & -.13 & .50 & .28 & .35 \\
\hline 29 & .18 & .56 & -.07 & .35 \\
\hline 30 & -.05 & .56 & .25 & .38 \\
\hline 31 & -.21 & .57 & .13 & .38 \\
\hline 32 & -.15 & .68 & -.05 & .48 \\
\hline 33 & -.28 & .38 & .59 & .57 \\
\hline 34 & .54 & .00 & -.13 & .31 \\
\hline 35 & -.01 & .63 & -.43 & .57 \\
\hline 36 & .42 & .13 & .07 & .20 \\
\hline Eigenvalue & 8.86 & 4.62 & 3.20 & 16.68 \\
\hline $\begin{array}{l}\text { variance } \\
\text { explained [\%] }\end{array}$ & 24.61 & 12.82 & 8.90 & 46.33 \\
\hline
\end{tabular}

SACAS (Social Environment Attitude And Culture Assessment Scale), items see Table 17 , factor $1-3$ refer to resulting primary factors, $\mathrm{h}^{2}=$ communalities 
Table 20: Descriptive statistics and Pearson's correlations of superordinate SACAS factors with virological outcome and MEMS adherence

\begin{tabular}{l|l|l|c|c|c}
\hline factor & factor meaning & $\begin{array}{l}\text { M factor } \\
\text { values }\end{array}$ & $\begin{array}{l}\text { SD } \\
\text { factor } \\
\text { values }\end{array}$ & $\begin{array}{c}\text { correl. (r) } \\
\text { Adherence }\end{array}$ & $\begin{array}{c}\text { correl (r) } \\
\text { VS }\end{array}$ \\
\hline $\mathbf{1}$ & coping \& trust & -0.04 & 1.09 & -0.02 & $0.34 * *$ \\
$\mathbf{2}$ & side-effects \& compliance & -0.04 & 1.15 & -0.17 & -0.13 \\
$\mathbf{3}$ & literacy \& knowledge & -0.00 & 1.10 & -0.16 & -0.22
\end{tabular}

M (mean), SD (Standard Deviation), VS (Virological suppression; cut-off at less than 50 copies of HIV RNA/ mL blood; 1: suppressed, 0: not suppressed), Adherence cut-off at >95\% (1: adherent, 0: nonadherent), $r$ (point-biserial correlation coefficient), $* * p<0.01$;

\subsubsection{Items predictive of adherence and virological outcome}

The ADS and SACAS items that showed significant or close to significant $(p<$ $0.10)$ associations were included as predictors in a stepwise logistic regression analysis to predict adherence (cut-off $>95 \%$ ). A threshold of $p<0.05$ was used for including a new variable. Variables were incorporated as categorical variables if necessary. In three steps, the analysis included the following items as predictors: In step one "Existence of a watch/cell phone" was included $\left[\chi^{2}(1)=9.99 ; p<0.01\right.$; adjusted $\left.R^{2}{ }_{\text {logit }}=0.23\right]$. The second step added "Age of child" $\left[\chi^{2}(1)=6.42 ; p<0.05\right.$; adjusted $\left.R^{2}{ }_{\text {logit }}=0.36\right]$. In the final step, the SACAS item "When my child is better it is not necessary to give all the antiretrovirals anymore" was additionally included $\left[\chi^{2}(1)=6.52 ; p<0.05\right.$; adjusted $R_{\text {logit }}^{2}$ $=0.47]$ (for details see Table 21).

To predict virological suppression, a similar independent stepwise logistic regression model was computed with the ADS and SACAS items that were significantly correlated (or were close to being significantly correlated, $p<0.10$ ). Four items were included in separate steps, enhancing the quality of the prediction (see Table 20 for details). The first item was "People treat me differently because of my child's HIV infection" $\left[\chi^{2}(1)=13.0 ; p<0.001\right.$; adjusted $\left.R_{\text {logit }}^{2}=0.34\right]$. In the second step, the item "My HIV infected child is in a good health state" was added, listed even preceding the first item $\left[\chi^{2}(1)=22.88 ; p<0.001\right.$; adjusted $\left.R_{\text {logit }}^{2}=0.75\right]$. In the third step, the item "I am confident in speaking English when speaking with the doctor" was included in second 
position $\left[\chi^{2}(1)=10.62 ; p<0.01\right.$; adjusted $\left.R_{\text {logit }}^{2}=0.89\right]$. Finally, "disclosure of caregiver" was added as the last item $\left[\chi^{2}(1)=5.72 ; p<0.05\right.$; adjusted $\left.R_{\text {logit }}^{2}=0.95\right]$. This model accounted for $95 \%$ of the variance (Nagelkerke's $\mathrm{R}^{2}=0.95$ ).

Table 21: Stepwise binary logistic regression predicting adherence and virological suppression by correlated socio-demographic and SACAS items

\begin{tabular}{|c|c|c|c|c|c|}
\hline Step & Included Items & $\begin{array}{c}\text { Nagelkerke } \\
R_{\text {logit }}^{2} \\
\end{array}$ & $\begin{array}{c}\text { Model } \\
\chi^{2}\end{array}$ & $\begin{array}{c}\text { Model } \\
\quad d f\end{array}$ & $\begin{array}{c}\text { Model } \\
p \\
\end{array}$ \\
\hline \multicolumn{6}{|c|}{ Adherence } \\
\hline 1 & Existence of a watch/cell phone & .23 & 9.99 & 1 & $<.01$ \\
\hline 2 & $\begin{array}{l}\text { Existence of a watch/cell phone } \\
\text { Age of child }\end{array}$ & .36 & 6.42 & 1 & $<.05$ \\
\hline 3 & $\begin{array}{l}\text { Existence of a watch/cell phone } \\
\text { Age of child } \\
\text { When my child is better it is not } \\
\text { necessary to give all the } \\
\text { antiretrovirals anymore }\end{array}$ & .47 & 6.52 & 1 & $<.05$ \\
\hline \multicolumn{6}{|c|}{ Virologic suppression } \\
\hline 1 & $\begin{array}{l}\text { People treat me differently because of } \\
\text { my child's HIV infection }\end{array}$ & .34 & 13.0 & 1 & $<.001$ \\
\hline 2 & $\begin{array}{l}\text { People treat me differently because of } \\
\text { my child's HIV infection } \\
\text { My HIV infected child is in a good } \\
\text { health state }\end{array}$ & .75 & 22.88 & 1 & $<.001$ \\
\hline 3 & $\begin{array}{l}\text { People treat me differently because of } \\
\text { my child's HIV infection } \\
\text { My HIV infected child is in a good } \\
\text { health state } \\
\text { I am confident in speaking English } \\
\text { when speaking with the doctor }\end{array}$ & .89 & 10.62 & 1 & $<.01$ \\
\hline 4 & $\begin{array}{l}\text { People treat me differently because of } \\
\text { my child's HIV infection } \\
\text { My HIV infected child is in a good } \\
\text { health state } \\
\text { I am confident in speaking English } \\
\text { when speaking with the doctor } \\
\text { Disclosure of caregiver }\end{array}$ & .95 & 5.72 & 1 & $<.05$ \\
\hline
\end{tabular}

Model $\chi^{2}$ : statistical test for the change of variance explanation achieved by including the independent variables in each step. $R_{\text {logit }}^{2}$ indicates the proportion of explained variance (Nagelkerke's $R_{\text {logit }}^{2}$ adjusts $R_{\text {logit }}^{2}$ between 0 and 1 ). The order of included items did not change during the three steps. 


\section{Discussion}

This study assessed the levels of adherence among HIV-infected children in a resource-limited setting. It evaluated the feasibility of Medication Event Monitoring System (MEMS) and caregiver-report by a Visual Analogue Scale (VAS) to measure adherence and compared the results of these two methods to virological outcomes. In addition, this study examined the socio-economic situation, the cultural background and the subjectively-rated quality of life of the HIV-infected children's caregivers and tested these factors for their predictive value for adherence. It was designed as a prospective investigation over a three month period that included 78 children and caregivers at a paediatric HIV outpatient service in a tertiary care institution in Cape Town, South Africa. The main findings were that adherence levels assessed by both measures were relatively high, yet much higher when measured by caregiver-report on the VAS. The VAS adherence levels were not significantly correlated to virological outcome. This finding is in sharp contrast to MEMS which showed close associations. MEMS seemed to be the more appropriate measure by analyses of sensitivity and specificity. Caregivers' beliefs in the efficacy of antiretroviral treatment and higher knowledge thereof were linked to higher adherence levels. Social stigma, on the other hand, was associated with lower adherence levels. Poor socio-economic status was not predictive of adherence; but children who lived in poor living conditions were more likely to fail therapy, even with good adherence levels.

This paediatric adherence study is the first study to focus on the age group of young infants, aged 0-4 years, who are treated with liquid medications. To date, it is the only study world-wide to evaluate the use of electronic monitoring devices with these liquid medications. Therefore, this study presents the first objectively measured adherence levels from children in a resource-limited setting as well as the first investigation to identify predictors of objectively measured adherence in these settings.

The adherence measures MEMS and VAS reported unequal levels of adherence. Each measure will therefore be discussed individually before focusing on the adherence levels themselves. 


\subsection{Medication Event Monitoring System}

In resource-limited settings, Medication Event Monitoring System (MEMS) has not yet been used for the investigation of paediatric adherence levels. Indeed, there have only been two studies world-wide that have used MEMS in the paediatric HIV adherence context, and both have been conducted in the United States (FARLEY et al. 2003; STEELE et al. 2001). FARLEY et al. assessed the utility of MEMS in a cohort of 26 children and their caregivers and compared the adherence levels to virological outcome after 6 months of observation. STEELE et al. gave MEMS to 8 of 30 children in an adherence study, to compare adherence to the caregivers' health beliefs. Both studies showed wide ranges in adherence, which are consistent with the width of range in this study.

Adherence in the presented investigation was significantly correlated with virological outcome, suggesting that the levels of adherence measured by MEMS were correct. This is somewhat conflicting with the findings of the two other studies: FARLEY reported that adherence was significantly correlated to virological outcome (log viral load) at the end of the observation period; STEELE however reported no significant association. Although the methodology was identical, the sample sises of this study and the two previous studies show remarkable differences: the present study included 73 children; STEELE included only 8 and FARLEY included 26 children. The larger sample size supports the validity of the correlation between viral load and adherence in this study. This correlation, however, is weaker than the one reported by FARLEY and his colleagues. For adherence levels of $>90 \%$, which are the only levels that they reported on, the cohort of the current study showed a less strong prediction of virological suppression based on the analyses of sensitivity and specificity. This is not necessarily due to an incorrect measure of adherence, but might, rather, be due to variations in virological response that occur in individual patients despite similar adherence levels. The cohort investigated here was younger (the mean age of FARLEY's cohort was 6.9 years), and thus less likely to contain children with a fully mature immune system. This might affect the viral load response to ART and, thus, increases the risk of incomplete viral suppression even with full adherence. It should also be considered that the cohort in this study used MEMS with 
syrups, where the administration of precise doses is more difficult to achieve - unlike FARLEY'S cohort, which used MEMS to monitor tablets that allow precise dosing to the milligram. The consequence would be that drug plasma levels might differ despite the correct administration of drug doses, leading to variations in virological outcome.

There are a few other possible reasons why virological responses can differ between patients with similar adherence levels. A few of the children had received a single dose of nevirapine postnatally as prevention of mother to child transmission (PMTCT). Almost 50\% of infected infants from a Ugandan study (HIVNET012) had nevirapine-resistant viruses after single-dose nevirapine for PMTCT, although the resistant populations decreased over time (ESHLEMAN et al. 2001). A clinical trial in Botswana showed that infants who failed PMTCT with single-dose nevirapine in addition to antenatal zidovudine were nine times more likely to have consistently increased viral loads, although the number of infected children in this study was small (LOCKMAN et al. 2007). However, the standard treatment for PMTCT in South Africa since 2004 was zidovudine given only to the newborn infant, which appears to decrease the rate of resistance (ESHLEMAN et al. 2006). The fact that all children in our cohort had been on their first line regimen, without periods of consistently increased viral loads before the enrolment into the study, also makes resistance acquired through PMTCT more unlikely.

Adherence in this study was only monitored for 3 months during an on-going antiretroviral treatment regimen, and it is possible that children had periods of insufficient adherence before the observation period. This could have resulted in a rise of viral load or the emergence of a resistant viral strain, leading to a situation where viral load could increase despite good adherence. Given the fact that the mean duration of antiretroviral treatment in the cohort presented here was longer than in FARLEY's cohort (26 months versus 22 months), there was more time for such episodes of poor adherence that might have led to viral resistance and ineffective viral response to treatment in a few of the cohort's patients. As a consequence, even though MEMS had correctly measured adherence for these patients, the correlation between adherence and virological outcome for the entire cohort would be less strong. This seems the most probable explanation for the slightly weaker correlation that this cohort showed in comparison to FARLEY's cohort. Another explanation could be that there might have been less room for adherence changes 
and changes in virological suppression because the cohort presented here had a longer pre-study treatment period than FARLEY's cohort.

There have been concerns that, because adherence is monitored by MEMS, caps could influence adherence behavior in itself. FENNIE et al. (2006) postulated that what MEMS really measures is the willingness to be monitored rather than actual adherence. Thus far, the only study to compare patients' perceptions of and attitudes towards MEMS to actual adherence behavior showed that patients who were comfortable with the use of MEMS had better adherence than patients who expressed difficulties or experienced the use of MEMS as inconvenient (SCHOENTHALER and OGEDEGBE 2008). In the same study, $59 \%$ of the participants stated that MEMS helped them remember to take their medication. We would expect this effect to be stronger at the beginning of a monitoring period, when the MEMS cap is still perceived as new and therefore has more of a reminding capacity. In our population, however, adherence dropped only slightly from $89 \%$ in month one to $88 \%$ in month three, and thus did not change much during the monitoring period. Assuming that maintaining high adherence levels over this long period of time is unlikely if there had not been a familiar routine in place beforehand, this suggests that MEMS monitoring itself had only little or no influence at all on the adherence behavior of our caregiver population. On the other hand, the Hawthorne effect is well known and researched and may have influenced the adherence behavior from the first day onwards. In this case, the knowledge of being part of an investigation would have improved adherence. This effect, however, is not specific for MEMS and will be encountered with the use of all adherence measures.

More specific for MEMS is the concern that the exclusive monitoring of lamivudine and abacavir for logistical reasons might also lead to overestimation of adherence. Protease inhibitors, which form the third pillar of antiretroviral treatment and need to be taken simultaneously, are known for their poor palatability and more difficult administration, thus posing more challenges to adherence (VAN DYKE et al. 2002). None of the published MEMS studies have considered this fact, and it is not specified if protease inhibitors were monitored in their study cohorts. However, the protease inhibitor is the most potent drug of the regimen (GIAQUINTO et al. 2008), and deteriorations in virological outcome are a sensitive predictor of non-adherence. While a bias based on the 
described concern cannot be excluded, it seems rather unlikely given the high rates of successful virological outcome in the cohort.

There are a few other possible ways in which MEMS can over-report adherence. As the actual intake of doses is not monitored, caregivers might pretend to simply open the cap without administering a dose. This has been described by BovA et al. (2005) for a cohort of adult patients, in which $26 \%$ reported opening the MEMS container without taking the medication. However, this is unlikely to have happened in the cohort of this study because the mechanism through which MEMS measured adherence was not revealed to the caregivers. During the information session before enrolment, all caregivers were informed that adherence would be monitored with the "MEMS bottle" - it was not specified, however, that opening of the cap led to the registration of time and date. The decision to withhold the information about the exact mechanism from the caregivers was deliberately taken in order to avoid the situation described by BovA et al. Moreover, it was approved by the Research Ethics Committee prior to the study.

It is a well-known fact that children might not swallow their medication but rather spit it out, mainly due to poor taste (WHO 2009). This cannot be excluded in this study cohort, and is a common bias for all methods, which leads to over-estimation of adherence. Except for directly-observed therapy, there is no way of ensuring the actual ingestion of the medication.

BANGSBERG et al. (2000) have reported concerns that MEMS might underestimate adherence by not registering so-called "pocket doses" - doses that are taken out of the bottle together with a previous dose, but then stored for later administration. Their adult cohort received antiretroviral tablets, which can easily be stored elsewhere but in the pill container. Storing extra doses separately seems more complicated for liquid medication they would have to be drawn up in a feeding syringe and then be stored upside-down in a secure place. This elaborate procedure makes it unlikely for caregivers to store extra doses aside. To minimise the "pocket-dosing" bias, all caregivers answered a questionnaire on their administrative behaviour when returning the MEMS cap. Three caregivers reported "pocket-dosing" and were subsequently excluded from the analyses. 
Previously, the consensus opinion on electronic monitoring devices and paediatric liquid medication stated that it was not feasible to use MEMS with drugs in syrup formulations: SHELLMER and ZELIKOVSKY (2007) reported that of 59 paediatric patients on immunosuppressant therapy, 19 were unable to participate in a MEMS adherence study due to their liquid medication and FARLEY et al. (2003) reported the same impediment for a study on adherence to antiretroviral therapy. The findings from this study contradict their reports in providing MEMS-measured adherence data for children who were treated with antiretroviral syrups. There were, however, several practical challenges that were encountered in introducing MEMS in the use with liquid medication. The MEMS bottle was not equipped with a leak-proof screw bottleneck, and when turning the bottle or placing it sideways, some of the liquid medication leaked. This made the handling more difficult for both caregivers and researchers, and reduced the amount of medication in the bottle slightly. As the study progressed, it was noticed that left-over syrup started to crystallise at the screw of the bottle neck and the cap. The crystallization increased over time, and impeded the opening and closing of the MEMS cap. This might be an important limitation for the length of future studies. Even though all caregivers received written and oral instructions about the proper handling of the MEMS, three participants had to be excluded because they later reported not using the MEMS in accordance with the instructions: they had opened the bottle once a day but taken out an additional dose to store separately for later administration, as described in the previous paragraph on "pocket-dosing". None of the other paediatric adherence studies using MEMS in the developed world reported that caregivers had used the devices incorrectly (FArley et al. 2003; Shellmer and Zelikovsky 2007; Steele et al. 2001); however, none of these studies reported to have questioned the caregivers about the correct usage of MEMS as this study did. Considering the fact that the administration out of a MEMS bottle is only slightly different to the use of regular medication bottles, this illustrates the various ways that caregivers have developed in their medication administering behaviour. It has often been adapted to their daily routines and to the need to fit the medication into their schedule, for example when taking out an additional dose to give to a second caregiver for later administration. In this study, caregivers and children with such routines 
are excluded, and MEMS adherence reflects only the adherence of children whose caregivers comply exactly with the treatment protocol.

One MEMS cap had to be excluded from the analysis after the entry of syrup into the cap, which resulted in the data not being readable. If this is added to the three caps with incorrect usage, the drop-out rate of MEMS caps was 5\%, which is much smaller than the findings by STEELE et al. (2001) who reported that $27 \%$ of caregivers did not return the MEMS cap as requested. It also seemed that the caregivers in the study cohort described here were less reluctant to participate in an adherence monitoring study with MEMS caps than caregivers in the United States. Only two out of 80 caregivers declined consent in our study. SHELLMER and ZELIKOVSKY (2007) reported that out of 59 eligible participants, 9 caregivers declined participation based on a rejection to be monitored with MEMS. An additional 9 caregivers subsequently dropped out after the first monitoring period stating that they did not want to use MEMS. Similarly, in the cohort of FARLEY et al. (2003), 11 of 42 caregivers denied participation. These findings suggest that the acceptance of research on adherence is high among patients in resource-limited settings, and that even elaborate and more complicated methods are well tolerated and respected by the study participants.

Another consideration of this issue could be that most patients who receive medication in tablets use pillboxes as a reminder as well as to help them administer their doses. For these patients, using MEMS caps represents a change of routine, as they would have to discontinue using their pillboxes. This was found to one of the major barriers to using MEMS caps in a study by BovA et al. (2005), where $26 \%$ of participants reported to have forgotten the MEMS cap because of their pillbox. Similarly, 13\% of participants who usually used pillboxes in the United States reported that using the MEMS cap made adherence more challenging (WENDEL et al. 2001). For liquid medications, there is no difference in the administration of the medication when caregivers use MEMS caps - they still have to open the bottle with the liquid drug, draw it up in a plastic feeding syringe and then administer it to the child. MEMS caps do not change this routine, and it might be possible that adherence behaviour is therefore reflected more realistically.

Although there were no major difficulties in utilizing MEMS in the setting of this study, an important limitation for the future implementation of MEMS in resource-limited 
settings will be its cost. The system is priced at about 80 US dollars for a cap and a bottle, with an additive one-off cost of 400 US dollars for the hard- and software. Each cap has a maximum battery time of 3 years and needs to be replaced thereafter. Additional costs include the training and employment of staff responsible for the management of the MEMS. This is way beyond the financial capacities of most health care systems, and MEMS should be used, rather, in research-driven clinical settings with access to funding. It would be desirable to have MEMS provided at a lower price so that the settings with the biggest need and the largest patient populations can benefit from its technology.

In summary, the findings of this study suggest that MEMS is a valid measure for adherence in resource-limited settings. It can be used to measure adherence in children who receive liquid medications. Its feasibility in resource-limited settings depends on the financial situation, and it might be advantageous to assess cheaper adherence measures for their performance compared to MEMS.

\subsection{Caregiver report by Visual Analogue Scale}

One of these cheaper adherence measures might be a Visual Analogue Scale (VAS), and this study was the first to introduce it as a means of caregiver report in a resource-limited setting. OYUGI et al. (2004) had introduced VAS for adult self-report in Uganda and found it to be closely correlated with MEMS adherence and virological outcome. It was thus recommended for self-reported adherence assessment in resourcelimited settings. However, in the setting of the study described here, the discrepancy between VAS and MEMS adherence was large and the absence of variability in the VAS data made further analyses of correlations impossible. Sixty-seven percent of caregivers, whose children had very high viral load levels and thus were failing their treatment, still reported adherence greater than $95 \%$ on the VAS. None of these children had such high adherence measured by MEMS. Studies from the developed world confirm that measures based on caregiver report overestimate paediatric adherence (MELLINS et al. 2004; NAARKING et al. 2005; STEele et al. 2001). For example, SteEle et al. showed that MEMS caps confirmed adequate adherence in only $25 \%$ of caregivers that had reported it. The discrepancy between caregiver-reported VAS and objectively-measured MEMS 
adherence in this study is in line with observations from adult HIV-infected patients (ARnStEn et al. 2001; BANGSBERG et al. 2000). These observations reinforce the objections raised against caregiver reported adherence and highlight that the results from these measures should be interpreted with care and in consideration of the context in which they were obtained.

There are several factors that might play a role in explaining the poor performance of VAS in this context. First, unlike Uganda, a country with a high rate of literacy, South Africa still has a large population that is barely or not at all literate. The concept of rating one self's adherence in a percentage requires a basic arithmetic understanding; the lack hereof might result in an overestimation of adherence. Patients from Malawi, interviewed on potential limitations of adherence measures, raised concerns that poor literacy might skew results from caregiver reports (SAFREN et al. 2006). In the current study, the explanation of the VAS was performed in the caregivers' home language rather than English to enhance comprehensibility. However, the issue of literacy might be an important factor in explaining the indistinctive VAS adherence results.

Second, caregiver-reported adherence measures are prone to over-reporting of adherence owing to answers oriented on social desirability (SIMONI et al. 2007). Caregivers might feel compelled to report good adherence despite actual adherence failures out of fearing negative consequences in the treatment by the health care providers (SAFREN et al. 2006). This seems even more plausible in a setting like South Africa where language barriers between caregivers and health care providers impede a trustful patientphysician relationship. In this study, however, a research assistant who was not part of the medical team administered the VAS, and caregivers were informed that the research team was not linked to the team of health care providers. In choosing the research assistant, special attention was placed on gender, language skills and cultural background. The area where caregivers were interviewed and then reported their adherence on the VAS was separated from the consultation and procedure rooms. Despite all the precautions taken to reduce the bias of social desirability, the fact that caregivers still reported much higher adherence than measured by MEMS suggests that the impact of social desirability in a paediatric setting might be higher than expected. 
Third, recall bias is another issue that might make VAS caregiver reports less accurate and could explain the overestimation of adherence by VAS. When trying to remember the administering of doses over a long period of time, caregivers might overestimate their adherence (SIMONI et al. 2006). However, a recent study by LU et al. (2008), determining the most accurate time frame for self-report measures, found that over-reporting of adherence was significantly less for a 1-month period than for shorter periods. Thus, the overestimation of VAS adherence in this cohort, for which the recall period was one month, seems not to be caused by recall bias.

VAS is increasingly being used to assess paediatric adherence in the developed world, not only for HIV-infected children, but also in other medical disciplines. FELDMAN et al. (2007) used it during a one-year observation period in children treated for juvenile idiopathic arthritis in Canada, while IVANOvA et al. (2008) measured adherence in a cohort of children and adults receiving inhaled corticosteroid therapy. VAS is costeffective and quick to administer and would thus seem like an ideal measure to be implemented in resource-limited settings. However, the findings from this study strongly suggest that it is not an accurate measure and should not be recommended as such.

An alternative to the resource-intensive MEMS was recently used by KIBONEKA et al. (2008) in Uganda. In order to avoid dependency solely on overestimated, caregiverreported adherence levels, they used a combination of objective and subjective adherence measures, namely pharmacy refill measures, pill count and caregiver report of missed doses during the previous three days. Only children that showed high levels of adherence by all three measures were then classified as adherent. The measures have been described in previous study designs where they were used as single measures (FARLEY et al. 2003; Hammami et al. 2004; Hansudewechakul et al. 2006; NABUKeERA-BARUnGi et al. 2007; STEELE et al. 2001; TEMPLE et al. 2001; WATSON and FARLEY 1999; WiLLIAMS et al. 2006) and were described in more detail in the introduction. This seems like a promising approach, but it needs to be validated against virological outcome. Pill count, important and cost-effective, is not feasible for young children receiving drugs as syrups. However, DAVIES et al. (2008) have demonstrated that measuring the amount of returned syrups and calculating proportional use in comparison to the prescribed amount is a valid concept for this young age group. 
When developing improved adherence measures, more attention should be focused on the time when doses are administered. In this study, adherence levels by MEMS were significantly lower (median level 79\%) when doses that were administered too early or too late were excluded from the individual datasets. These adherence levels were more predictive of virological outcome than the adherence levels based on the inclusion of all doses taken regardless of the time of their administration. However, with the exception of MEMS none of the currently available adherence measures takes the timing of doses into account, as KERR et al. (2005) have remarked in a recent review. Including information on the timing of doses is easier for measures that are based on the recall of single doses missed or administered. These can be complemented by asking about the time of each dose. An example which could easily be modified is the Pediatric AIDS Clinical Trials Group (PACTG) questionnaire as used by WiLLIAMS et al. (2006).

The findings of this study underline the limitations of subjective adherence measures, which can be unreliable. It highlights that single adherence measures may be unreliable too. The improvement of the accuracy of these measures is vital for the ongoing monitoring of antiretroviral therapy. MEMS is a method that has proven to work in paediatric patient collectives and should be used as the gold-standard against which other measures are compared to. For resource-limited settings that cannot afford the MEMS system, cheaper combination measures should first be evaluated against MEMS in a research environment, to avoid unreliable adherence results.

\subsection{Adherence levels}

There are thirteen studies on paediatric adherence to antiretroviral therapy in resource-limited settings in the medical literature (BIADGILIGN et al. 2008; BIKAAKOKAJURA et al. 2006; DAVIES et al. 2008; Elise et al. 2005; FASSINOU et al. 2004; Hansudewechakul et al. 2006; Kiboneka et al. 2008; Mukhtar-Yola et al. 2006; NABUKeERA-BARUngi et al. 2007; NATU and DAGA 2007; NyANDiKo et al. 2006; ReDDi et al. 2007; SAFREED-HARMON et al. 2007). Of these, only one has reported on adherence levels of very young infants treated with liquid medication (DAVIES et al. 2008), an age group highly affected by HIV in these settings (VREEMAN et al. 2008). Across the 
literature, there is a wide array of measures and definitions of adherent children, with most studies being based on caregiver report. For example, BIKAAKO-KAJURA et al. (2006) described that $29 \%$ of caregivers reported not to have missed any dose without specifying the observation period. In the cohort from ELISE et al. (2005), 67\% of caregivers reported no missed doses for the past month. Psychologists in Côte d'Ivoire rated adherence as "globally good" (FASSINOU et al. 2004); 80\% of caregivers in Nigeria reported greater than 95\% adherence (MUKHTAR-YOLA et al. 2006). NYANDIKO et al. (2006) described that $75 \%$ of caregivers said they hadn't missed a dose in the previous month. REDDI et al. (2007) reported on South African caregivers among whom $89 \%$ had only missed less than 2 doses in the previous month. This diversity and inconsistency of measures makes a comparison very difficult. The discussion will thus be based on the studies that have used objective adherence measures.

No other study has reported adherence measures by MEMS yet. The median MEMS adherence rate of $88 \%$ in our studied population is similar to adherence rates evaluated by the objective method of the keeping of clinic appointments in Nigeria (88\%; MuKhtAR-Yola et al. 2006). DAVIES et al. (2008) reported that $73 \%$ of all children had greater than $95 \%$ adherence by the measurement of returned liquid medication, the analogue to pill count for children on syrups. This is substantially higher than the $40 \%$ of the children in this cohort. All other studies using objective measures also found higher adherence: in a cohort from Uganda, adherence rates were $97 \%$ by pill count at the clinic, and $94 \%$ if the pill count was conducted without announcement at the patient's home (NABUKEERA-BARUngi et al. 2007). Similarly, SAFREED-HARMON et al. (2007) measured 98\% and $99 \%$ adherence by pill count in Thailand for children without and with the care of their biological parents respectively. KIBONEKA et al. (2008) reported that $95 \%$ of children achieved adherence levels greater than $95 \%$ evaluated by a combination of pharmacy refill, pill count and caregiver interviews. In India, children showed adherence levels of $95 \%$ when evaluated by the attendance of their follow-up visits (NATU and DAGA 2007).

It may be hypothesised that MEMS measures more accurate levels of adherence than other objective measures because it is the only direct method that accounts for each administered dose. The fact that all other objective measures are indirect, i.e. 
reconstructing adherence behavior based on the return of unused medication (pill count) or dispensed medication (pharmacy refill) leaves more possibilities for bias in these methods. For example, a caregiver might discard tablets, which will alter the adherence result of pill counts. STEELE et al. (2001) reported that adherence by pill count was $90 \%$, yet MEMS measured only $44 \%$ in the same paediatric cohort. Across all medical disciplines, seven studies have used MEMS to assess adherence to chronic medication in children, and all found adherence levels that were often below 80\% adherence (FARLEY et al. 2003; Gerson et al. 2004; LAU et al. 1998; MAIKRANZ et al. 2007; SHELLMER and Zelikovsky 2007; SHemesh 2004; STEELE et al. 2001). The discrepancy between the median adherence levels of the cohort here and the other cohorts from resource-limited settings ranges from $6-9 \%$, which might be due to different indirect adherence measures.

The objective adherence studies from other resource-limited settings show great variation in setting and culture: MUKHTAR-YOLA et al. (2006) reported from Nigeria in West Africa, Nabukeera-Barungi et al. (2007) from the East African Uganda, SAFREED-HARMON et al. (2007) from Thailand and NATU and DAGA (2007) from India. Each of these settings has unique health care structures, societies and challenges, which can influence adherence. The setting in this study is, however, different: an urban South African tertiary care clinic. These different settings and premises might cause the discrepancies in the adherence between this cohort and the others.

The percentage of children with greater than $95 \%$ adherence was lower than in the South African cohort described by DAvies et al. (2008). The setting of the two investigations was very similar - DAVIES investigated at another tertiary care clinic in Cape Town. In this case, there were almost no differences in culture, social environments or economic factors between the cohorts. The characteristics of children and caregivers were similar. There was a difference, however, in the criteria for starting antiretroviral therapy. Contrary to DAVIES' cohort, the cohort in this study was composed of caregivers who were enrolled into the antiretroviral treatment program based on the South African National Guidelines from 2004 (South African Department of Health 2004). Following these guidelines, the decision to start children on treatment is based on the immunological and virological status of the patient, and thus not related to social factors. Many children in DAVIES' cohort were selected for antiretroviral treatment based on 
social criteria, which may have led to a pre-selection of particularly adherent caregivers. This suggests that the adherence results from the cohort described here are more representative of all South African HIV-infected children and their caregivers.

The median levels of adherence in this cohort are higher than in cohorts from the United States. STEELE et al. (2001) reported 44\% adherence measured by MEMS, FARLEY et al. (2003) reported $81 \%$ adherence - these are the only paediatric HIV adherence studies using MEMS. The high rates of adherence are even more remarkable considering the fact that the children had been treated for a longer period than the US cohorts. This finding rejects former concerns about poor adherence in resource-limited settings (POPP and Fisher 2002). It confirms for children what MiLls et al. (2006) have already established for adult cohorts: that adherence to antiretroviral treatment in resource-limited settings is not worse and often even better than in developed countries.

\subsection{Predictors of adherence}

The results from the Assessment of Demographics and Socio-economics Questionnaire (ADS), the Social Environment Attitude and Culture Assessment Scale (SACAS) as well as the EUROHIS Quality of Life (QoL) were assessed for their predictive value for adherence and virological suppression. Adherence was defined as taking more than $95 \%$ of the prescribed medication and virological suppression was achieved when less than 50 copies of HIV RNA/mL blood were detectable.

Neither adherence nor virological suppression was significantly correlated with most social determinants. Except for the existence of a watch or cell phone to keep track of time, none of the socio-economic variables predicted adherence or virological outcome. When reported by the caregiver, stigmatization as a result of the child's HIV infection was linked to non-adherence and virological failure. Virological suppression was further correlated with a superordinate factor that represented a feeling of trust and confidence in the physician and the treatment by the caregiver, which resulted from the principal component analysis of the SACAS. Variables relating to the caregiver's social stigmatization, the disclosure of the caregiver's HIV status as well as a good caregiverphysician relationship emerged predictive of virological suppression. 
Even though many children and caregivers lived in poverty, the findings from this cohort suggest that these disadvantages did not have a strong influence on adherence. The difference of adherence and virological suppression in these factors, however, suggests that virological outcome may be rather influenced by poor socio-economic circumstances, even with good adherence. Most notably, virological outcome seems to deteriorate in environments of poor hygiene and sanitation. The fact that virological outcome seems related to socio-economic circumstances should be a reminder that successful antiretroviral treatment cannot be seen in the clinical setting only. Although funding for medication is increasingly available, and adherence support is beginning to be recognised in its importance, the change of infrastructural factors is just as important to reduce inequities that result in poor health outcomes (MARAIS et al. 2008).

Findings by MuKHTAR-YolA et al. (2006) demonstrate that social circumstances can indeed be a barrier to adherence. In their Nigerian setting, the cost of antiretroviral treatment was reported as the most substantial barrier. Similarly, WEISER et al. (2003) identified the cost of ART as the main barrier for adult patients in Botswana. The fact that financial constraints were not correlated to adherence in this cohort, which had free access to treatment, underscores the importance of the provision of free antiretroviral treatment in the public sector.

Poor adherence was significantly associated with stigma, as reported by the caregivers. $21 \%$ of all caregivers agreed that they were being treated differently as a result of their child's HIV infection. This is similar to findings by REDDINGTON et al. (2000), in whose cohort non-adherent caregivers were more likely to express concerns about the child's teacher or friends finding out about the HIV-infection. In participants of the study described here, disclosure of the HIV status of the caregiver as well as of the child to the household they were staying in was associated with higher rates of virological suppression. The logistic regression model that included disclosure of the caregiver as well as reported stigma among others was highly predictive of virological outcome (34\% explained variance by stigma). Two other studies from developing countries support these results (BIKAAKO-KAJURA et al. 2006; NABUKEERA-BARUNGI et al. 2007). The consequences that fear of stigma and actual stigmatization can have on adherence behavior are not too difficult to foresee: a caregiver might feel compelled to hide 
medications to avoid disclosure, thus the child might miss doses at times where the administration thereof could attract unwanted attention. Stigma - and non-disclosure as its consequence - can also have an impact on the child's motivation to take medication and make administration more difficult if children do not know about the rational necessity of treatment. Where HIV positive patients still perceive stigma to be high in their communities, it is imperative that physicians and other medical staff inform and educate this community.

In a recent editorial, HAWKINS and MURPHY (2007) state that a steady and reliable access to antiretroviral treatment may well be the most important intervention to assure good adherence in resource-limited settings and would be more important than other interventions directed at improving individual adherence behavior or reducing social stigma. According to their opinion, individual behavior and stigma are typical barriers of developed countries. The findings of this study, however, demonstrate that these barriers are also found in resource-limited settings when the financial barriers are removed. Programs of adherence interventions thus always need to address these barriers as they are concomitant to and not foregone by financial factors.

A logistic regression model including variables about perceived stigma, the child's health status, ability to communicate in English and caregiver disclosure accounted for $95 \%$ of the variance in virological suppression. A large part of the explanation in variance was due to a statement that assessed caregivers' impression of their child's health status and thus seems intuitively linked to virological outcome. Obviously, this model cannot replace laboratory measurements for viral load status. It emphasises again, however, the important role of social relations and should be taken into account for further assessment of influential factors. The ability to communicate in English seems to point towards the importance of education. However, adherence was not correlated with caregiver education per se, but rather with specific treatment knowledge and the understanding thereof. While CuPSA et al. (2000) identified a low educational background as predictor of adherence in Brazil, our results suggest that it is rather the understanding of the concept of antiretroviral therapy that affects adherence. Agreements to statements that were not in line with the physician's recommendations were associated with poorer adherence and non-suppressed viral load. The level of education does not seem to influence the ability to 
understand these recommendations, but it can be hypothesised that language does children of caregivers who reported confidence in communicating in English, the language of most health care-related communication, showed higher rates of virological suppression ( $75 \%$ versus $52 \%$ respectively). Other studies have not reported on this (BIKAAKO-KaJura et al. 2006; CUPSA et al. 2000; FASSINOU et al. 2004; MuKHTAR-YolA et al. 2006; NABUKEERA-BARUNGI et al. 2007; NyANDIKO et al. 2006; SAFREED-HARMON et al. 2007), which might be a phenomenon that is more prevalent in South Africa, a multilingual country. However, it is also relevant for other countries where health care professionals communicate in a language different from the one spoken by patients. These results emphasise the need for patient-friendly health services that are offered in the local languages. In clinical practice, this might be achieved by employing specially trained translators for physicians who cannot communicate with patients and caregivers, or peer treatment advisors to train caregivers on adherence-specific issues.

Trust in the biomedical treatment model rather than in traditional medicine was positively correlated with virological outcome but not with adherence, as shown by the significant high correlation of the SACAS factor coping \& trust with virological outcome. It can be hypothesised that there might be influences on virological outcome that are beyond medication-administration adherence and are more related to lifestyle and general health behavior. This corresponds with the comprehensive model of adherence as postulated by the World Health Organization: adherence as the extent to which a person's behaviour - taking medication, following a diet, and/or executing lifestyle changes, corresponds with agreed recommendations from a health care provider (WHO 2003). Although currently available methods only measure the administration of medication, the influence of the other recommendations might be higher than previously thought. HUBLEY and ZUMBo (1996) have recognised this inadequacy of measures as one of two major threats to validity, more specifically, as "construct under-representation", that is, the measure fails to include important dimensions of the construct - such as the following of dietary guidelines in the adherence assessment. This under-representation of the behavioural dimensions of adherence extends into many fields of HIV medicine. The results from this study suggest that traditional adherence measures, (focusing on medication-administration) in conjunction with the assessment of caregivers' knowledge 
and attitudes, can lead to an improved prediction of virological outcome. This has practical implications for clinical settings - while it re-enforces the necessity of monitoring medication-administration adherence, it also calls for broader assessment methods to account for the underrepresented dimensions of the term "adherence."

\subsection{Limitations and critical considerations}

This study is subject to a number of important limitations. First, owing to the relatively small sample size, the statistical power to detect associations is limited. Furthermore, the cohort only showed limited variation in some of the socioeconomic variables, and this might limit the statistical analyses and significance. Therefore, the absence of associations should be interpreted with caution, and studies with larger sample sizes are necessary to further assess the presented findings.

The caregivers in the study's cohort were treated at an academic hospital rather than in their own community. This might represent a selection bias because it excludes caregivers and patients who are unable to travel the larger distance because of socioeconomic or family-related constraints and who would rather seek treatment at community clinics and primary health institutions. The generalisability of the findings for other settings is thus limited, because challenges and barriers might be different from the ones describes here.

The results from the caregiver-reported questionnaires and adherence measures may have been influenced by the perceived need of social desirability, as described by Chesney et al. (1999). However, as discussed in a previous paragraph, manifold precautions have been taken to avoid that caregivers feel pressured to give socially desired answers: the availability of all research-related material in their preferred language, the distinct separation of the researchers from the medical team as well as the research assistant who came from a similar background and culture.

Adherence by MEMS could have been overestimated when non-adherent caregivers denied participation in the study. However, only 2 out of 80 caregivers who were approached refused to be monitored. Although all other 78 caregivers agreed to participate, not all of them were monitored for the full period of 3 months. The reason for 
an earlier stop of the monitoring period was never the caregiver's wish to do so, but rather due to external factors such as a change in treatment regimen or the child's referral to another treatment center. So it seems unlikely that it was mostly poorly adherent caregivers who dropped out during the monitoring period. Adherence could further have been overestimated by the Hawthorne effect, leading to higher adherence levels during the monitoring situation than at other times. The possible influences of this effect are inherent to all monitored adherence studies, so that it cannot be excluded as a bias.

Despite all listed limitations, the results of this study constitute important observations that are of high relevance for both clinical practice and adherence research.

\subsection{Conclusion}

In conclusion, the findings of this study show that children in resource-limited settings can achieve good adherence and virological outcome regardless of the socioeconomic background of their caregivers. MEMS caps may be a more accurate estimate of pediatric antiretroviral adherence to syrups than self-report by caregivers on a VAS - this has been shown by a strong association of MEMS and virological outcome, and a strong positive bias of the VAS. MEMS can be used as a measure for paediatric adherence both in resource-limited settings and for liquid drug formulations.

Caregivers' attitudes towards treatment as well as knowledge and understanding hereof seem to be of much greater importance, and this should be considered even more in settings with diverse cultural and traditional backgrounds. Factors related to the personal relationship between caregiver and child, as well as between caregiver and physician have a direct influence on virological outcome, suggesting other important ways of influence than medication-administration adherence. The assessed broader concept of adherence, which acknowledges and measures knowledge and attitude about and towards antiretroviral therapy, has proven to be more appropriate for satisfying the requirements of clinical settings. 


\section{Abstract}

\subsection{English}

Introduction. In South Africa, the HIV epidemic has risen sharply in numbers over the past decade, and a growing number of children are treated with antiretroviral therapy. This study aimed to examine adherence in a paediatric outpatient cohort and to compare an objective electronic monitoring system to subjective caregivers' self-reports. It also assessed the impact of social determinants on adherence and antiretroviral treatment outcome.

Methods. Seventy-eight children and their caregivers were monitored prospectively over 3 months. Adherence was measured with the Medication Event Monitoring System (MEMS) and by caregivers' self-report on a Visual Analogue Scale (VAS). A specifically designed questionnaire examined individual cultural beliefs about HIV and its treatment, and socio-economic data were collected by caregiver report. Virological data were available for study baseline and follow-ups.

Results. Adherence was lower when measured by MEMS (88\%) than when measured by VAS (100\%). MEMS adherence was a significant predictor of virological outcome. Socio-economic factors were not associated with adherence. Caregivers' beliefs in the efficacy of antiretroviral treatment and higher knowledge thereof were linked to better adherence levels; while social stigma was associated with lower adherence levels.

Discussion. This first study of paediatric adherence in South Africa shows that adherence levels are as good as in developed countries, but not high enough to sustain therapeutic success. MEMS seems to be a more accurate method to measure adherence than VAS, and is feasible with liquid formulations and in resource-limited settings. Further research is needed to disentangle the complex relationship of adherence, caregiver knowledge, attitudes and therapeutic success and a qualitative heuristic methodology should be considered. 


\subsection{German}

Hintergrund. Die Zahl der HIV-infizierten Kinder, die in Südafrika mit antiretroviralen Medikamenten behandelt werden, steigt drastisch. Das korrekte Befolgen der Therapie (die sogenannte Adhärenz) ist ein Schlüsselfaktor für deren Erfolg. Diese Studie untersuchte die Adhärenz von jungen ambulanten Patienten und führte einen Vergleich zwischen der objektiven Messmethode Medication Event Monitoring System (MEMS) und einer subjektiven Messmethode durch. Außerdem wurden soziale Determinanten von Adhärenz und Therapieerfolg untersucht.

Methoden. Achtundsiebzig Kinder und Erziehungsberechtigte wurden in einer prospektiven Studie drei Monate lang begleitet. Die Messung der Adhärenz erfolgte mit MEMS und einer Visuellen Analogskala (VAS). Kulturelle Vorstellungen über HIV und Therapie sowie soziodemographische Variablen wurden mit einem neu entwickelten Fragebogen erfasst. Zu Beginn und Ende der Studie wurden virologische Parameter der Kinder erfasst.

Ergebnisse. Die Adhärenz-Messung mit MEMS (88\%) ergab niedrigere Werte als die VAS-Messung (100\%). MEMS-Adhärenz zeigte sich als signifikanter Prädiktor für die virologische Entwicklung im Verlauf. Sozioökonomische Faktoren konnten Adhärenz nicht vorhersagen. Wissen über die Therapie und Vertrauen in deren Erfolg waren mit höherer Adhärenz assoziiert, soziale Stigmatisierung dagegen mit niedrigerer Adhärenz.

Diskussion. Diese erste Studie zu pädiatrischer Adhärenz in Südafrika zeigt, dass die Adhärenz ähnlich gut ist wie in westlichen Ländern - jedoch nicht gut genug, um dauerhafte Therapieerfolge zu sichern. MEMS scheint als Messmethode besser geeignet $\mathrm{zu}$ sein als die VAS, und ist auch mit flüssigen Darreichungsformen und in Entwicklungsländern durchführbar. Um die komplexen Beziehungen zwischen Adhärenz, Wissen und Einstellungen der Erziehungsberechtigten sowie Therapieerfolg besser verstehen zu können, sollten auch qualitative heuristische Methoden eingesetzt werden. 


\section{Appendix - Questionnaires}

\subsection{EUROHIS-QoL}

This set of questions asks how you feel about your quality of life, health or other areas of your life.

Please think about your life in the past two weeks and tick the appropriate box. Thank you!

1. How would you rate your quality of life?

\begin{tabular}{|l|l|l|l|l|}
\hline very poor & poor & $\begin{array}{l}\text { neither poor nor } \\
\text { good }\end{array}$ & good & very good \\
\hline
\end{tabular}

2. How satisfied are you with your health?

\begin{tabular}{|l|l|l|l|l|}
\hline very poor & poor & $\begin{array}{l}\text { neither poor nor } \\
\text { good }\end{array}$ & good & very good \\
\hline
\end{tabular}

3. Do you have enough energy for everyday life?

\begin{tabular}{|l|l|l|l|l|}
\hline very poor & poor & $\begin{array}{l}\text { neither poor nor } \\
\text { good }\end{array}$ & good & very good \\
\hline
\end{tabular}

4. How satisfied are you with your ability to perform your daily living activities?

\begin{tabular}{|l|l|l|l|l|}
\hline very poor & poor & $\begin{array}{l}\text { neither poor nor } \\
\text { good }\end{array}$ & good & very good \\
\hline
\end{tabular}

5. How satisfied are you with yourself?

\begin{tabular}{|l|l|l|l|l|}
\hline very poor & poor & $\begin{array}{l}\text { neither poor nor } \\
\text { good }\end{array}$ & good & very good \\
\hline
\end{tabular}

6. How satisfied are you with your personal relationships?

\begin{tabular}{|l|l|l|l|l|}
\hline very poor & poor & $\begin{array}{l}\text { neither poor nor } \\
\text { good }\end{array}$ & good & very good \\
\hline
\end{tabular}

7. Have you enough money to meet your needs?

\begin{tabular}{|l|l|l|l|l|}
\hline very poor & poor & $\begin{array}{l}\text { neither poor nor } \\
\text { good }\end{array}$ & good & very good \\
\hline
\end{tabular}

8. How satisfied are you with the conditions of your living place?

\begin{tabular}{|l|l|l|l|l|}
\hline very poor & poor & $\begin{array}{l}\text { neither poor nor } \\
\text { good }\end{array}$ & good & very good \\
\hline
\end{tabular}




\subsection{Visual Analogue Scale (VAS)}

Most children with HIV have many medicines to take at different times during the day. Many caregivers find it hard to always remember to give medicines. For example:

- $\quad$ Some people get busy and forget to carry the bottles with them.

- Some people find it hard to give the medicine according to all the instructions, such as "with food" or "on an empty stomach," "every 8 hours," or "with plenty of fluids."

- $\quad$ Some people decide to skip giving medicine to avoid side effects or to just not give medicine that day.

We need to understand what people with HIV are really doing with their medicines. Please tell us what you are actually doing. Don't worry about telling us you don't give all the medicine. We need to know what is really happening, not what you think we "want to hear". The results of this survey will not influence your treatment at the clinic.

INSTRUCTIONS: Please put an " $X$ " on the line at the point showing your best guess about how much medicine you have given in the last four weeks. We would be surprised if this was $100 \%$ for most people.

For example, $0 \%$ means you have given no medicine $50 \%$ means you have given half of the medicine $100 \%$ means you have given every single dose of the medicine

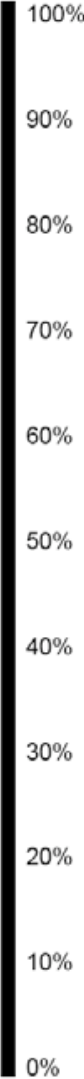




\subsection{Assessment of Demographics and Socioeconomics questionnaire (ADS)}

Thank you for taking part in this study! All data collected will be strictly confidential and will only be available to the research team. Your answers will not influence your current or future treatment at this or any other clinic in any way! It will help us to improve our patient service. Please answer the following questions honestly and completely!

\begin{tabular}{|c|c|c|}
\hline 1 & How old are you? & \\
\hline 2 & Which area do you stay in? & $\begin{array}{l}\text { Khayelitsha } \\
\square \text { Gugulethu } \\
\square \text { Nyanga } \\
\square \text { Crossroads } \\
\square \text { Langa } \\
\square \text { Mitchell's Plain } \\
\square \text { other (please specify): }\end{array}$ \\
\hline 3 & Up to which standard/ grade did you go to school? & \\
\hline 4 & How many years of education did you have? & \\
\hline 5 & What is your current employment? & $\begin{array}{l}\square \text { formal (e.g. cleaner) } \\
\square \text { informal (e.g. selling fruit) } \\
\text { not employed }\end{array}$ \\
\hline 6 & $\begin{array}{l}\text { Do you have a regular income? How much is it } \\
\text { monthly? }\end{array}$ & $\begin{array}{l}R 100-R 500 \\
\square R 500-R 1000 \\
\square R 1000-R 1500 \\
\square R 1500-R 2000 \\
\square R 2000-R \ldots \ldots\end{array}$ \\
\hline 7 & Do you get any social grant? If so, which one? & $\begin{array}{l}\text { none } \\
\square \text { Care dependency grant (R 780) } \\
\square \text { Child support grant (R 180) } \\
\square \text { Foster care grant (R 520) } \\
\square \text { Old age pension } \\
\square \text { Disability grant ( } R 780) \\
\square \text { Grant in aid } \\
\square \text { Social relief }\end{array}$ \\
\hline 8 & What is your religion? & $\begin{array}{l}\text { Methodist } \\
\square \text { Catholic } \\
\square \text { Lutheran } \\
\square \text { Anglican } \\
\square \text { Zionist Church } \\
\square \text { New Apostolic } \\
\square \text { Muslim } \\
\square \text { traditional } \\
\square \text { none } \\
\square \text { other: }\end{array}$ \\
\hline 9 & What is your home language? & $\begin{array}{l}\text { Xhosa } \\
\square \text { English } \\
\square \text { Afrikaans } \\
\square \text { other: }\end{array}$ \\
\hline
\end{tabular}




\begin{tabular}{|c|c|c|}
\hline 10 & What is your marital status? & $\begin{array}{l}\text { single (never married) } \\
\square \text { married/ living with someone } \\
\square \text { separated/ divorced } \\
\square \text { widow }\end{array}$ \\
\hline 11 & How many rooms does your house consist of? & \\
\hline 12 & What kind of house do you live in? & $\begin{array}{l}\text { brick house } \\
\text { shack } \\
\square \text { other (please specify): }\end{array}$ \\
\hline 13 & Do you have a tap at home? & $\square$ yes \\
\hline 14 & Do you have electricity in your house? & $\square$ yes \\
\hline 15 & Do you have a watch /cell phone at home? & $\square$ yes \\
\hline 16 & How many people live in your house? & \\
\hline 17 & How many children (under 16) do you look after? & \\
\hline 18 & How many sick children do you look after? & \\
\hline 19 & $\begin{array}{l}\text { How are you related to the HIV positive child you } \\
\text { look after? }\end{array}$ & $\begin{array}{l}\text { mother } \\
\square \text { child's grandmother } \\
\square \text { child's older sister/ brother } \\
\square \text { child's aunt/ uncle } \\
\square \text { neighbour } \\
\square \text { child's father } \\
\square \text { staff at children's home } \\
\square \text { other (please specify): }\end{array}$ \\
\hline 20 & $\begin{array}{l}\text { Who is responsible for the medication of your HIV } \\
\text { infected child? }\end{array}$ & $\begin{array}{l}\text { myself } \\
\square \text { child's grandmother } \\
\square \text { child's older sister/ brother } \\
\square \text { child's aunt/ uncle } \\
\square \text { neighbour } \\
\square \text { child's father } \\
\square \text { staff at children's home } \\
\square \text { other (please specify): }\end{array}$ \\
\hline 21 & Does the father live with you? & $\square$ yes \\
\hline 22 & Do you get maintenance from the child's father? & $\square$ yes \\
\hline 23 & $\begin{array}{l}\text { Do your family and friends know about your child's } \\
\text { status? }\end{array}$ & $\square$ yes \\
\hline 24 & Do your family and friends know about your status? & $\square$ yes \\
\hline 25 & $\begin{array}{l}\text { Did you disclose to your mother? } \\
\text { If not, why? }\end{array}$ & $\square$ yes \\
\hline
\end{tabular}




\begin{tabular}{|l|l|ll|}
\hline 26 & $\begin{array}{l}\text { Did anyone in your family/ close surrounding die of } \\
\text { AIDS? }\end{array}$ & $\square$ yes \\
\hline 27 & $\begin{array}{l}\text { Which kind of transport do you normally use to get } \\
\text { to the Hospital? }\end{array}$ & $\begin{array}{l}\square \text { minibus taxi } \\
\square \text { own car } \\
\square \text { car from another person } \\
\square \text { bus } \\
\square \text { train } \\
\square \text { other: }\end{array}$ \\
\hline 28 & $\begin{array}{l}\text { How much do you spend on transport for each visit } \\
\text { to Hospital? }\end{array}$ & $\begin{array}{l}\text { Does transport cost keep you from coming to the } \\
\text { clinic? }\end{array}$ & $\begin{array}{l}\square \text { yes } \\
\square \text { no }\end{array}$ \\
\hline 30 & Do you feel safe on your way to the clinic? & $\begin{array}{l}\square \text { yes } \\
\square \text { no }\end{array}$ & $\square$ don't know \\
\hline 31 & Do you participate in the support group? & $\square$ yes & $\square$ no \\
\hline 32 & Do you participate in the beadwork project? & $\square$ yes & $\square$ no \\
\hline 33 & Do you go to a support group in your community? & $\square$ yes & \\
\hline
\end{tabular}




\subsection{Social Environment, Attitude and Culture Assessment Scale (SACAS)}

Please rate the following statements according to their correctness. Think about each sentence and decide how much you would agree or disagree. Please put a tick in the appropriate box 1 to 4 to express your opinion! Please tick only one box for each answer (either 1, 2, 3 or 4).

All results will be anonymous, and your doctor will not see what you have answered. Please answer what you really think - don't tell us what you think we want to hear!

strongly disagree

1 disagree

2 agree

3 strongly agree

4

\section{Example}

1 I am happy today

\section{Questions}

\begin{tabular}{|c|c|c|c|c|c|}
\hline & & 1 & 2 & 3 & 4 \\
\hline 1 & I enjoy the time I can spend with my child & & & & \\
\hline 2 & My HIV infected child is in a good health state & & & & \\
\hline 3 & When my child is better it is not necessary to give all the ARV's anymore & & & & \\
\hline 4 & I am confident in speaking English when speaking with the doctor & & & & \\
\hline 5 & I have difficulties in reading & & & & \\
\hline 6 & Antiretrovirals are efficient against HIV & & & & \\
\hline 7 & My everyday life does not stress me & & & & \\
\hline 8 & I am ashamed of asking the doctor something I have not understood & & & & \\
\hline 9 & I know how antiretrovirals work in the body & & & & \\
\hline 10 & It is difficult to remember the names of the antiretrovirals my child takes & & & & \\
\hline 11 & My child's doctor knows a lot about HIV and treatment possibilities & & & & \\
\hline 12 & I know how to administer my child's antiretrovirals correctly & & & & \\
\hline
\end{tabular}




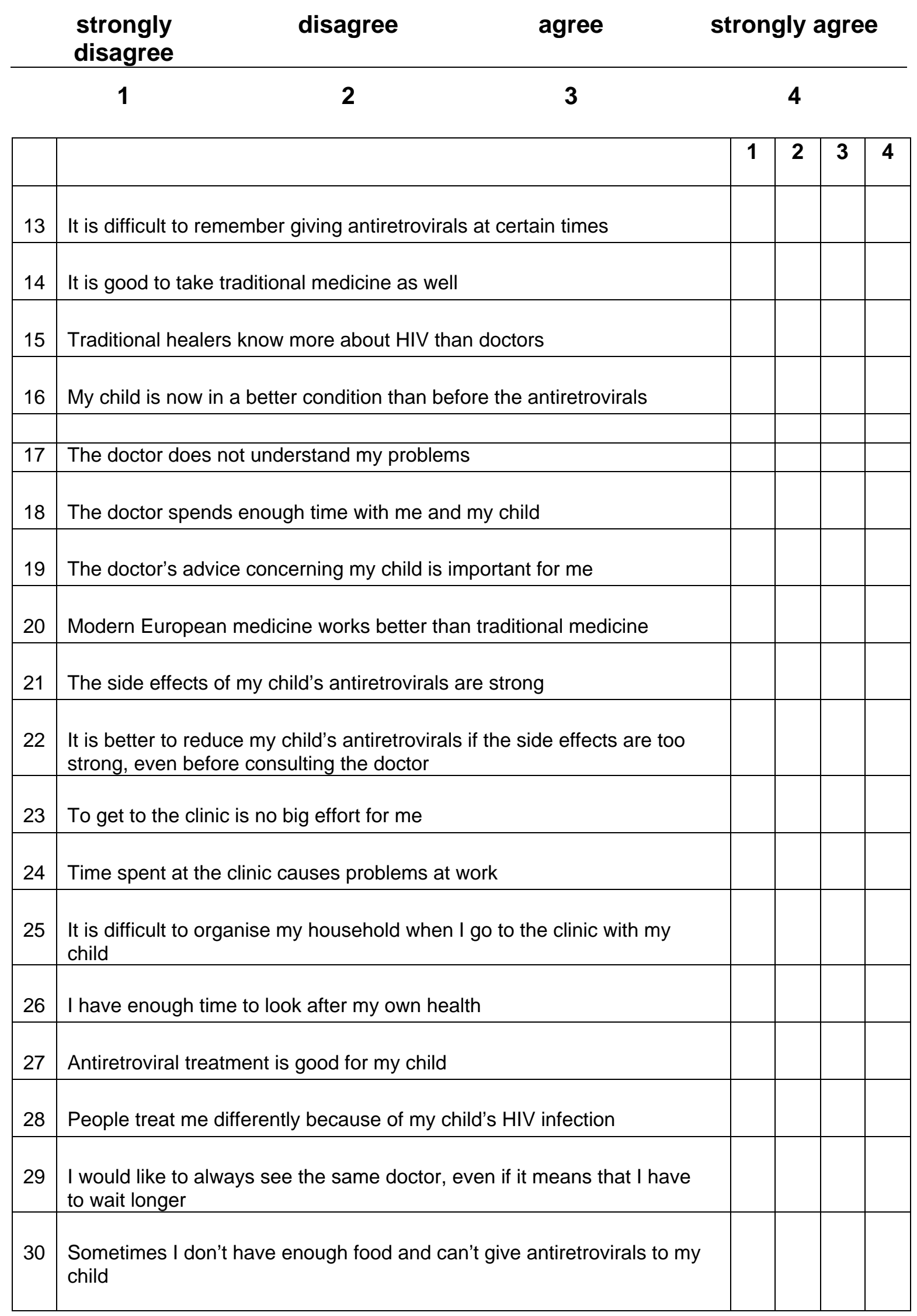


strongly

disagree

agree

strongly agree

disagree

1

2

3

4

\begin{tabular}{|c|c|c|c|c|c|}
\hline & & 1 & 2 & 3 & 4 \\
\hline 31 & $\begin{array}{l}\text { A traditional healer can be a good addition to the treatment received at } \\
\text { the clinic }\end{array}$ & & & & \\
\hline 32 & I would feel comfortable if there was a traditional healer at the clinic & & & & \\
\hline 33 & $\begin{array}{l}\text { If I am not sure about something concerning my child's medication, I first } \\
\text { ask friends or neighbours and then I ask the doctor }\end{array}$ & & & & \\
\hline 34 & I trust the doctor & & & & \\
\hline 35 & There is a person who I trust and who I can turn to for advice & & & & \\
\hline 36 & I get enough support from my family and friends & & & & \\
\hline
\end{tabular}




\section{References}

AARDEX Ltd.: (accessed 21.2.2009), www.aardexgroup.com

Abrams EJ, El-Sadr W, Rabkin M: The ICAP Pediatric Clinical Manual. The International Centre for AIDS Programs, Columbia University Mailman School of Public Health, New York 2004.

Acquadro C, Jambon B, Ellis D, Maquis P: Language and translation issues; in: Quality of life and pharmacoeconomics in clinical trials; editor: Spilker B; Raven, New York: 1996, 575-585.

Albano F, Spagnuolo MI, Berni CR, Guarino A (1999): Adherence to antiretroviral therapy in HIV-infected children in Italy. AIDS Care 11, 711-714

Arnsten JH, Demas PA, Farzadegan H, Grant RW, Gourevitch MN, Chang CJ, Buono D, Eckholdt H, Howard Aa, Schoenbaum EE (2001): Antiretroviral therapy adherence and viral suppression in HIV-infected drug users: comparison of self-report and electronic monitoring. Clin Infect Dis $\underline{33}, 1417-1423$

Attaran M, Friedberg KA, Hirsch M (2001): Dead wrong on AIDS. The Washington Post (Washington). 15 July

Bangsberg DR, Hecht FM, Charlebois ED, Zolopa AR, Holodniy M, Sheiner L, Bamberger JD, Chesney MA, Moss A (2000): Adherence to protease inhibitors, HIV-1 viral load, and development of drug resistance in an indigent population. AIDS 14, 357-366

Bartlett J: Antiretroviral Therapy. The abbreviated guide to medical management of HIV infection; Johns Hopkins University, Division of Infectious Diseases, Baltimore 2002, 23-47.

Bartlett J: Antiretroviral Therapy; in: A Guide to Primary Care of People with HIV/AIDS; editors: Bartlett J, Cheever L, Johnson M, Paauw D; Department of Health and Human Services, Rockville 2004, p. 29-38

Berg KM, Arnsten JH (2006): Practical and conceptual challenges in measuring antiretroviral adherence. J Acquir Immune Defic Syndr 43 Suppl 1, S79-S87 
Biadgilign S, Deribew A, Amberbir A, Deribe K (2008): Adherence to highly active antiretroviral therapy and its correlates among HIV infected pediatric patients in Ethiopia. BMC Pediatr $\underline{8}, 53$

Bikaako-Kajura W, Luyirika E, Purcell DW, Downing J, Kaharuza F, Mermin J, Malamba S, Bunnell R (2006): Disclosure of HIV status and adherence to daily drug regimens among HIVinfected children in Uganda. AIDS Behav 10, S85-S93

Bobat R, Coovadia H, Moodley D, Coutsoudis A (1999): Mortality in a cohort of children born to HIV-1 infected women from Durban, South Africa. S Afr Med J $\underline{89}, 646-648$

Boni S, Pontali E, De Gol P, Pedemonte P, Bassetti D (2000): Compliance to combination antiretroviral therapy in HIV-1 infected children. Int J Antimicrob Agents 16, 371-372

Bova CA, Fennie KP, Knafl GJ, Dieckhaus KD, Watrous E, Williams AB (2005): Use of electronic monitoring devices to measure antiretroviral adherence: practical considerations. AIDS Behav $\underline{9}, 103-110$

Broder S, Gallo RC (1984): A pathogenic retrovirus (HTLV-III) linked to AIDS. N Engl J Med $\underline{311}, 1292-1297$

Byakika-Tusiime J, Oyugi JH, Tumwikirize WA, Katabira ET, Mugyenyi PN, Bangsberg DR (2005): Adherence to HIV antiretroviral therapy in HIV+ Ugandan patients purchasing therapy. Int J STD AIDS $\underline{16}, 38-41$

Byrne M, Honig J, Jurgrau A, Heffernan SM, Donahue MC (2002): Achieving adherence with antiretroviral medications for pediatric HIV disease. AIDS Read $\underline{12}, 151-154$

Carrieri MP, Raffi F, Lewden C, Sobel A, Michelet C, Cailleton V et al. (2003): Impact of early versus late adherence to highly active antiretroviral therapy on immuno-virological response: a 3year follow-up study. Antivir Ther $\underline{8}, 585-594$

Chesney MA (2003): Adherence to HAART regimens. AIDS Patient Care STDS $\underline{17}, 169-177$ 
Chesney MA, Ickovics J, Hecht FM, Sikipa G, Rabkin J (1999): Adherence: a necessity for successful HIV combination therapy. AIDS 13 Suppl A, S271-S278

Coetzee D, Hildebrand K, Boulle A, Maartens G, Louis F, Labatala V, Reuter H, Ntwana N, Goemaere E (2004): Outcomes after two years of providing antiretroviral treatment in Khayelitsha, South Africa. AIDS $\underline{18}, 887-895$

Cohen K, Swart A, Orrell C, Bekker L-G, Maartens G, Roux P: Antiretroviral Treatment Protocol Western Cape (Version 2). Provincial Administration of the Western Cape, Cape Town 2004.

CSDH: Closing the gap in a generation: health equity through action on the social determinants of health. Final Report of the Commission on Social Determinants of Health. World Health Organization, Geneva 2008, p. 62-65

Cupsa A, Gheonea C, Bulucea D, Dinescu S (2000): Factors with a negative influence on compliance to antiretroviral therapies. Ann N Y Acad Sci 918, 351-354

Davies MA, Boulle A, Fakir T, Nuttall J, Eley B (2008): Adherence to antiretroviral therapy in young children in Cape Town, South Africa, measured by medication return and caregiver selfreport: a prospective cohort study. BMC Pediatr $\underline{8}, 34-46$

De Clercq E (2001): 2001 ASPET Otto Krayer Award Lecture. Molecular targets for antiviral agents. J Pharmacol Exp Ther 297, 1-10

de Martino M, Tovo PA, Balducci M, Galli L, Gabiano C, Rezza, Pezzotti P (2000): Reduction in mortality with availability of antiretroviral therapy for children with perinatal HIV-1 infection. Italian Register for HIV Infection in Children and the Italian National AIDS Registry. JAMA 284 , 190-197

Dorrington R, Johnson L, Bradshaw D, Daniel T: The demographic impact of HIV/AIDS in South Africa - National and provincial indicators for 2006. Centre for Actuarial Research, South African Medical Research Council and Actuarial Society of South Africa, Cape Town 2006. 
Eley B, Nuttall J, Davies MA, Smith L, Cowburn C, Buys H, Hussey G (2004): Initial experience of a public sector antiretroviral treatment programme for HIV-infected children and their infected parents. S Afr Med J 94, 643-646

Elise A, France AM, Louise WM, Bata D, Francois R, Roger S, Philippe M (2005): Assessment of adherence to highly active antiretroviral therapy in a cohort of African HIV-infected children in Abidjan, Cote d'Ivoire. J Acquir Immune Defic Syndr 40, 498-500

Eshleman SH, Hoover DR, Hudelson SE, Chen S, Fiscus SA, Piwowar-Manning E, Jackson JB, Kumwenda NI, Taha TE (2006): Development of nevirapine resistance in infants is reduced by use of infant-only single-dose nevirapine plus zidovudine postexposure prophylaxis for the prevention of mother-to-child transmission of HIV-1. J Infect Dis $\underline{193}, 479-481$

Eshleman SH, Mracna M, Guay LA, Deseyve M, Cunningham S, Mirochnick M et al. (2001): Selection and fading of resistance mutations in women and infants receiving nevirapine to prevent HIV-1 vertical transmission (HIVNET 012). AIDS $\underline{15}, 1951-1957$

Farley J: Adherence to antiretroviral therapy in children and youth; in: Handbook of Pediatric HIV Care; editors: Zeichner SL, Read JS; Cambridge University Press, New York 2006, 206-218.

Farley J, Hines S, Musk A, Ferrus S, Tepper V (2003): Assessment of adherence to antiviral therapy in HIV-infected children using the Medication Event Monitoring System, pharmacy refill, provider assessment, caregiver self-report, and appointment keeping. J Acquir Immune Defic Syndr $\underline{33}, 211-218$

Farmer KC (1999): Methods for measuring and monitoring medication regimen adherence in clinical trials and clinical practice. Clin Ther 21, 1074-1090

Fassinou P, Elenga N, Rouet F, Laguide R, Kouakoussui KA, Timite M, Blanche S, Msellati P (2004): Highly active antiretroviral therapies among HIV-1-infected children in Abidjan, Cote d'Ivoire. AIDS 18, 1905-1913

Feingold AR, Rutstein RM, Meislich D, Brown T, Rudy BJ (2000): Protease inhibitor therapy in HIV-infected children. AIDS Patient Care STDS 14, 589-593 
Feldman DE, De Civita M, Dobkin PL, Malleson P, Meshefedjian G, Duffy CM (2007):

Perceived adherence to prescribed treatment in juvenile idiopathic arthritis over a one-year period. Arthritis Rheum 57, 226-233

Fennie KP, Bova CA, Williams AB (2006): Adjusting and censoring electronic monitoring device data. Implications for study outcomes. J Acquir Immune Defic Syndr 43 Suppl 1, S88-S95

Flexner C (1998): HIV-protease inhibitors. N Engl J Med 338, 1281-1292

Funk MB, Buchholz B, Notheis G, Neubert J, Feiterna-Sperling C, Ganschow R et al. (2008): Disease progression in HIV-1 infected children and adolescents--results of a German-Austrian cohort study. Eur J Med Res $\underline{13}, 371-378$

Garcia dO, Knobel H, Carmona A, Guelar A, Lopez-Colomes JL, Cayla JA (2002): Impact of adherence and highly active antiretroviral therapy on survival in HIV-infected patients. J Acquir Immune Defic Syndr 무, 105-110

Gerson AC, Furth SL, Neu AM, Fivush BA (2004): Assessing associations between medication adherence and potentially modifiable psychosocial variables in pediatric kidney transplant recipients and their families. Pediatr Transplant $\underline{8}, 543-550$

Giacomet V, Albano F, Starace F, de Franciscis A, Giaquinto C, Gattinara GC et al. (2003): Adherence to antiretroviral therapy and its determinants in children with human immunodeficiency virus infection: a multicentre, national study. Acta Paediatr 92, 1398-1402

Giaquinto C, Morelli E, Fregonese F, Rampon O, Penazzato M, de Rossi A, D'Elia R (2008): Current and future antiretroviral treatment options in paediatric HIV infection. Clin Drug Investig $\underline{28}, 375-397$

Gibb DM, Goodall RL, Giacomet V, McGee L, Compagnucci A, Lyall H (2003): Adherence to prescribed antiretroviral therapy in human immunodeficiency virus-infected children in the PENTA 5 trial. Pediatr Infect Dis J 22, 56-62 
Gill CJ, Hamer DH, Simon JL, Thea DM, Sabin LL (2005): No room for complacency about adherence to antiretroviral therapy in sub-Saharan Africa. AIDS $\underline{19}, 1243-1249$

Giordano TP, Guzman D, Clark R, Charlebois ED, Bangsberg DR (2004): Measuring adherence to antiretroviral therapy in a diverse population using a visual analogue scale. HIV Clin Trials $\underline{5}$, 74-79

Goode M, McMaugh A, Crisp J, Wales S, Ziegler JB (2003): Adherence issues in children and adolescents receiving highly active antiretroviral therapy. AIDS Care $\underline{15}$, 403-408

Gortmaker SL, Hughes M, Cervia J, Brady M, Johnson GM, Seage GR, III, Song LY, Dankner WM, Oleske JM, Pediatric AIDS Clinical Trials Group Protocol 219 Team (2001): Effect of combination therapy including protease inhibitors on mortality among children and adolescents infected with HIV-1. N Engl J Med $\underline{345}, 1522-1528$

Gottlieb MS, Schroff R, Schanker HM, Weisman JD, Fan PT, Wolf RA, Saxon A (1981):

Pneumocystis carinii pneumonia and mucosal candidiasis in previously healthy homosexual men: evidence of a new acquired cellular immunodeficiency. N Engl J Med 305, 1425-1431

Grossberg R, Zhang Y, Gross R (2004): A time-to-prescription-refill measure of antiretroviral adherence predicted changes in viral load in HIV. J Clin Epidemiol 57, 1107-1110

Hammami N, Nostlinger C, Hoeree T, Lefevre P, Jonckheer T, Kolsteren P (2004): Integrating adherence to highly active antiretroviral therapy into children's daily lives: a qualitative study. Pediatrics 114, e591-e597

Hansudewechakul R, Jourdain G, Plangraun N, Chiang Mai Paediatric ARV Team (2006): A comprehensive programme to strenghten adherence to antiretroviral drug therapy and achieve virological control in HIV infected children in Thailand. Vulnerable Children and Youth Studies $\underline{2}, 180-191$

Harries AD, Nyangulu DS, Hargreaves NJ, Kaluwa O, Salaniponi FM (2001): Preventing antiretroviral anarchy in sub-Saharan Africa. Lancet $\underline{358}, 410-414$ 
Havens, P., Van Dyke, R. B., Weinberg, G., and Working Group on Antiretroviral Therapy and Medical Management of HIV-infected Children: Guidelines for the use of antiretroviral agents in pediatric HIV infection. National Institutes of Health, Rockville 2008

Hawkins C, Murphy R (2007): Adherence to antiretroviral therapy in resource-limited settings: everything matters. AIDS $\underline{21}, 1041-1042$

Howard AA, Arnsten JH, Lo Y, Vlahov D, Rich JD, Schuman P, Stone VE, Smith DK, Schoenbaum EE, HER Study Group (2002): A prospective study of adherence and viral load in a large multi-center cohort of HIV-infected women. AIDS 16, 2175-2182

Hubley AM, Zumbo BD (1996): A Dialectic on Validity: Where We Have Been and Where We Are Going. J Gen Psychol 123, 207-215

Humblet P, Calmy A, Pinoges L, Ahoua L, Cirera A, Pascual F, Szumilin E, Torres V, Zachariah R, Ferradini L: Offering HAART to children in resource-poor settings: The experience of Medecins Sans Frontieres; in: XV International Conference on AIDS; IAS, Bangkok 2004, TuPeB4461

Hussey G: Infections in Childhood; in: Paediatrics and Child Health - A Manual for Health Professionals in the Third World; editors: Coovadia H, Wittenberg D; Oxford University Press Southern Africa, Cape Town 2001, 241-353.

Ickovics JR, Cameron A, Zackin R, Bassett R, Chesney M, Johnson VA, Kuritzkes DR, Adult AIDS Clinical Trials Group 370 Protocol Team (2002): Consequences and determinants of adherence to antiretroviral medication: results from Adult AIDS Clinical Trials Group protocol 370. Antivir Ther $\underline{7}, 185-193$

Idigbe EO, Adewole TA, Eisen G, Kanki P, Odunukwe NN, Onwujekwe DI et al. (2005): Management of HIV-1 infection with a combination of nevirapine, stavudine, and lamivudine: a preliminary report on the Nigerian antiretroviral program. J Acquir Immune Defic Syndr $\underline{40}, 65-$ 69 
Iliyasu Z, Kabir M, Abubakar IS, Babashani M, Zubair ZA (2005): Compliance to antiretroviral therapy among AIDS patients in Aminu Kano Teaching Hospital, Kano, Nigeria. Niger J Med $\underline{14}$, 290-294

Ivanova JI, Birnbaum HG, Hsieh M, Yu AP, Seal B, van der Molen T, Emani S, Rosiello RA, Colice GL (2008): Adherence to inhaled corticosteroid use and local adverse events in persistent asthma. Am J Manag Care 14, 801-809

Jaspan HB, Berrisford AE, Boulle AM (2008): Two-Year Outcomes of Children on NonNucleoside Reverse Transcriptase Inhibitor and Protease Inhibitor Regimens in a South African Pediatric Antiretroviral Program. Pediatr Infect Dis J 27, 993-998

Jibril HB, Bowman D, Kurup S, Motsamai OA, Schwarzwald H, Yarosh O, Anabwani GM, Evens DL, Musa-Aisien AS, Woldestadik EA, Kostova E: Response to antiretroviral therapy among treatment naive children in Botswana; in: XV International Conference on AIDS, IAS, Bangkok 2004, TuOrB1191

Katko E, Johnson GM, Fowler SL, Turner RB (2001): Assessment of adherence with medications in human immunodeficiency virus-infected children. Pediatr Infect Dis J 20, 1174-1176

Kempf DJ, King MS, Bernstein B, Cernohous P, Bauer E, Moseley J, Gu K, Hsu A, Brun S, Sun E (2004): Incidence of resistance in a double-blind study comparing lopinavir/ritonavir plus stavudine and lamivudine to nelfinavir plus stavudine and lamivudine. J Infect Dis $\underline{189}, 51-60$

Kerr T, Walsh J, Lloyd-Smith E, Wood E (2005): Measuring adherence to highly active antiretroviral therapy: implications for research and practice. Curr HIV /AIDS Rep 2, 200-205

Kiboneka A, Wangisi J, Nabiryo C, Tembe J, Kusemererwa S, Olupot-Olupot P et al. (2008): Clinical and immunological outcomes of a national paediatric cohort receiving combination antiretroviral therapy in Uganda. AIDS 22, 2493-2499

Kirkland LR, Fischl MA, Tashima KT, Paar D, Gensler T, Graham NM et al. (2002): Response to lamivudine-zidovudine plus abacavir twice daily in antiretroviral-naive, incarcerated patients with HIV infection taking directly observed treatment. Clin Infect Dis $\underline{34}, 511-518$ 
Kline MW, Rugina S, Ilie M, Matusa RF, Schweitzer AM, Calles NR, Schwarzwald HL (2007):

Long-term follow-up of 414 HIV-infected Romanian children and adolescents receiving lopinavir/ritonavir-containing highly active antiretroviral therapy. Pediatrics $\underline{119}$, e1116-e1120

Knobel H, Guelar A, Carmona A, Espona M, Gonzalez A, Lopez-Colomes JL, Sabalis P, Gimeno JL, Diez A (2001): Virologic outcome and predictors of virologic failure of highly active antiretroviral therapy containing protease inhibitors. AIDS Patient Care STDS $\underline{15}, 193-199$

Koenig SP, Leandre F, Farmer PE (2004): Scaling-up HIV treatment programmes in resourcelimited settings: the rural Haiti experience. AIDS 18 Suppl 3, S21-S25

Kooten Niekerk NK, Knies MM, Howard J, Rabie H, Zeier M, van Rensburg A et al. (2006): The first 5 years of the family clinic for HIV at Tygerberg Hospital: family demographics, survival of children and early impact of antiretroviral therapy. J Trop Pediatr 52, 3-11

Landay A, da Silva BA, King MS, Albrecht M, Benson C, Eron J et al. (2007): Evidence of ongoing immune reconstitution in subjects with sustained viral suppression following 6 years of lopinavir-ritonavir treatment. Clin Infect Dis $\underline{44}, 749-754$

Lau RC, Matsui D, Greenberg M, Koren G (1998): Electronic measurement of compliance with mercaptopurine in pediatric patients with acute lymphoblastic leukemia. Med Pediatr Oncol $\underline{30}$, $85-90$

Laurance J, Davies E (2005): HIV/AIDS: the $21^{\text {st }}$ century plague. The Independent (London). $22^{\text {nd }}$ November

Laurent C, Kouanfack C, Koulla-Shiro S, Nkoue N, Bourgeois A, Calmy A et al. (2004):

Effectiveness and safety of a generic fixed-dose combination of nevirapine, stavudine, and lamivudine in HIV-1-infected adults in Cameroon: open-label multicentre trial. Lancet $\underline{364}, 29-34$

Laurent C, Ngom Gueye NF, Ndour CT, Gueye PM, Diouf M, Diakhate N et al. (2005): Longterm benefits of highly active antiretroviral therapy in Senegalese HIV-1-infected adults. J Acquir Immune Defic Syndr $\underline{38}, 14-17$ 
Levine AJ, Hinkin CH, Castellon SA, Mason KI, Lam MN, Perkins A et al. (2005): Variations in patterns of highly active antiretroviral therapy (HAART) adherence. AIDS Behav $\underline{9}, 355-362$

Liu H, Golin CE, Miller LG, Hays RD, Beck CK, Sanandaji S et al. (2001): A comparison study of multiple measures of adherence to HIV protease inhibitors. Ann Intern Med 134, 968-977

Lockman S, Shapiro RL, Smeaton LM, Wester C, Thior I, Stevens L et al. (2007): Response to antiretroviral therapy after a single, peripartum dose of nevirapine. N Engl J Med $\underline{356}, 135-147$

Lodha R, Upadhyay A, Kabra SK (2005): Antiretroviral Therapy in HIV-1 Infected Children. Indian Pediatr $\underline{42}, 789-796$

Low-Beer S, Yip B, O'Shaughnessy MV, Hogg RS, Montaner JS (2000): Adherence to triple therapy and viral load response. J Acquir Immune Defic Syndr 23, 360-361

Lu M, Safren SA, Skolnik PR, Rogers WH, Coady W, Hardy H, Wilson IB (2008): Optimal recall period and response task for self-reported HIV medication adherence. AIDS Behav 12, 86-94

Maikranz JM, Steele RG, Dreyer ML, Stratman AC, Bovaird JA (2007): The relationship of hope and illness-related uncertainty to emotional adjustment and adherence among pediatric renal and liver transplant recipients. J Pediatr Psychol 32, 571-581

Mannheimer S, Friedland G, Matts J, Child C, Chesney MA (2002): The consistency of adherence to antiretroviral therapy predicts biologic outcomes for human immunodeficiency virus-infected persons in clinical trials. Clin Infect Dis $\underline{34}, 1115-1121$

Marais BJ, Esser M, Godwin S, Rabie H, Cotton MF (2008): Poverty and human immunodeficiency virus in children: a view from the Western Cape, South Africa. Ann N Y Acad Sci 1136, 21-27

Marhefka SL, Farley JJ, Rodrigue JR, Sandrik LL, Sleasman JW, Tepper VJ (2004): Clinical assessment of medication adherence among HIV-infected children: examination of the Treatment Interview Protocol (TIP). AIDS Care 16, 323-338 
Martin S, Elliott-DeSorbo DK, Wolters PL, Toledo-Tamula MA, Roby G, Zeichner S, Wood LV (2007): Patient, caregiver and regimen characteristics associated with adherence to highly active antiretroviral therapy among HIV-infected children and adolescents. Pediatr Infect Dis J 26, 61-67

McKinney R: Antiretroviral Therapy; in: Handbook of Pediatric HIV Care; editors: Zeichner SL, Read JS; Cambridge University Press, Cambridge 2006, 335-359.

McNabb JJ, Nicolau DP, Stoner JA, Ross J (2003): Patterns of adherence to antiretroviral medications: the value of electronic monitoring. AIDS $\underline{17}, 1763-1767$

Mellins CA, Brackis-Cott E, Dolezal C, Abrams EJ (2004): The role of psychosocial and family factors in adherence to antiretroviral treatment in human immunodeficiency virus-infected children. Pediatr Infect Dis J 23, 1035-1041

Mills EJ, Nachega JB, Buchan I, Orbinski J, Attaran A, Singh S et al. (2006): Adherence to antiretroviral therapy in sub-Saharan Africa and North America: a meta-analysis. JAMA $\underline{296}$, 679690

Montagnier L, Chermann JC, Barre-Sinoussi F, Klatzmann D, Wain-Hobson S, Alizon M et al. (1984): Lymphadenopathy associated virus and its etiological role in AIDS. Princess Takamatsu Symp $\underline{15}, 319-331$

Moore DM, Hogg RS, Yip B, Wood E, Harris M, Montaner JS (2006): Regimen-dependent variations in adherence to therapy and virological suppression in patients initiating protease inhibitor-based highly active antiretroviral therapy. HIV Med 7, 311-316

Mukhtar-Yola M, Adeleke S, Gwarzo D, Ladan Z (2006): Preliminary investigation of adherence to antiretroviral therapy among children in Aminu Kano Teaching Hospital, Nigeria. Afr J AIDS Res $\underline{5}, 141-144$

Naar-King S, Frey M, Harris M, Arfken C (2005): Measuring adherence to treatment of paediatric HIV/AIDS. AIDS Care $\underline{17}$, 345-349 
Nabukeera-Barungi N, Kalyesubula I, Kekitiinwa A, Byakika-Tusiime J, Musoke P (2007): Adherence to antiretroviral therapy in children attending Mulago Hospital, Kampala. Ann Trop Paediatr 27, 123-131

Nachega JB, Stein DM, Lehman DA, Hlatshwayo D, Mothopeng R, Chaisson RE, Karstaedt AS (2004): Adherence to antiretroviral therapy in HIV-infected adults in Soweto, South Africa. AIDS Res Hum Retroviruses 20, 1053-1056

Natu SA, Daga SR (2007): Antiretroviral therapy in children: Indian experience. Indian Pediatr $\underline{44}, 339-343$

Nicholson O, Mellins C, Dolezal C, Brackis-Cott E, Abrams EJ (2006): HIV treatment-related knowledge and self-efficacy among caregivers of HIV-infected children. Patient Educ Couns $\underline{61}$, 405-410

Nyandiko WM, Ayaya S, Nabakwe E, Tenge C, Sidle JE, Yiannoutsos CT, Musick B, WoolsKaloustian K, Tierney WM (2006): Outcomes of HIV-infected orphaned and non-orphaned children on antiretroviral therapy in western Kenya. J Acquir Immune Defic Syndr $\underline{43}$, 418-425

Orrell C, Bangsberg DR, Badri M, Wood R (2003): Adherence is not a barrier to successful antiretroviral therapy in South Africa. AIDS $\underline{17}, 1369-1375$

Osterberg L, Blaschke T (2005): Adherence to medication. N Engl J Med 353, 487-497

Oyugi JH, Byakika-Tusiime J, Charlebois ED, Kityo C, Mugerwa R, Mugyenyi P, Bangsberg DR (2004): Multiple validated measures of adherence indicate high levels of adherence to generic HIV antiretroviral therapy in a resource-limited setting. J Acquir Immune Defic Syndr $\underline{36}$, 11001102

Palella FJ, Jr., Delaney KM, Moorman AC, Loveless MO, Fuhrer J, Satten GA, Aschman DJ, Holmberg SD (1998): Declining morbidity and mortality among patients with advanced human immunodeficiency virus infection. HIV Outpatient Study Investigators. N Engl J Med 338, 853860 
Palumbo PE, Raskino C, Fiscus S, Pahwa S, Fowler MG, Spector SA, Englund JA, Baker CJ (1998): Predictive value of quantitative plasma HIV RNA and CD4+ lymphocyte count in HIVinfected infants and children. JAMA 279 , 756-761

Paterson DL, Swindells S, Mohr J, Brester M, Vergis EN, Squier C, Wagener MM, Singh N (2000): Adherence to protease inhibitor therapy and outcomes in patients with HIV infection. Ann Intern Med 133, 21-30

Piliero PJ (2004): Pharmacokinetic properties of nucleoside/nucleotide reverse transcriptase inhibitors. J Acquir Immune Defic Syndr 37 Suppl 1, S2-S12

Pontali E (2005): Facilitating adherence to highly active antiretroviral therapy in children with HIV infection: what are the issues and what can be done? Paediatr Drugs $\underline{7}, 137-149$

Popp D, Fisher JD (2002): First, do no harm: a call for emphasizing adherence and HIV prevention interventions in active antiretroviral therapy programs in the developing world. AIDS $\underline{16}, 676-678$

Prendergast A, Tudor-Williams G, Jeena P, Burchett S, Goulder P (2007): International perspectives, progress, and future challenges of paediatric HIV infection. Lancet $\underline{370}$, 68-80

Rabkin M, El-Sadr W, Abrams EJ: Adherence assessment and support; in: Care and Treatment of HIV/AIDS in Resource-Limited Settings - The Columbia Clinical Manual; Columbia University Mailman School of Public Health, New York 2005.

Raboud JM, Harris M, Rae S, Montaner JS (2002): Impact of adherence on duration of virological suppression among patients receiving combination antiretroviral therapy. HIV Med $\underline{3}, 118-124$

Ransohoff DF, Feinstein AR (1978): Problems of spectrum and bias in evaluating the efficacy of diagnostic tests. N Engl J Med 299, 926-930

Reddi A, Leeper SC, Grobler AC, Geddes R, France KH, Dorse GL et al. (2007): Preliminary outcomes of a paediatric highly active antiretroviral therapy cohort from KwaZulu-Natal, South Africa. BMC Pediatr $\underline{7}, 13$ 
Reddington C, Cohen J, Baldillo A, Toye M, Smith D, Kneut C, Demaria A, Bertolli J, Hsu HW (2000): Adherence to medication regimens among children with human immunodeficiency virus infection. Pediatr Infect Dis J $\underline{19}, 1148-1153$

Rouet F, Fassinou P, Inwoley A, Anaky MF, Kouakoussui A, Rouzioux C, Blanche S, Msellati P, ANRS 1244/1278 Programme Enfants Yopougon (2006): Long-term survival and immunovirological response of African HIV-1-infected children to highly active antiretroviral therapy regimens. AIDS $\underline{20}, 2315-2319$

Safreed-Harmon K, Siripong A, Kerr SJ, Gruskin S, Pancharoen C, Ananworanich J (2007): Antiretroviral therapy adherence did not differ between Thai children with biological and those with nonbiological parents. Clin Infect Dis $\underline{45}, 669-670$

Safren SA, Kumarasamy N, Hosseinipour M, Harwood MM, Hoffman I, McCauley M et al. (2006): Perceptions about the acceptability of assessments of HIV medication adherence in Lilongwe, Malawi and Chennai, India. AIDS Behav 10, 443-450

Schmidt S, Muhlan H, Power M (2005): The EUROHIS-QOL 8-item index: psychometric results of a cross-cultural field study. Eur J Public Health $\underline{16}$, 420-428

Schoenthaler A, Ogedegbe G (2008): Patients' perceptions of electronic monitoring devices affect medication adherence in hypertensive African Americans. Ann Pharmacother 42, 647-652

Shellmer DA, Zelikovsky N (2007): The challenges of using medication event monitoring technology with pediatric transplant patients. Pediatr Transplant $\underline{11}, 422-428$

Shemesh E (2004): Non-adherence to medications following pediatric liver transplantation. Pediatr Transplant $\underline{8}, 600-605$

Simoni JM, Kurth AE, Pearson CR, Pantalone DW, Merrill JO, Frick PA (2006): Self-Report Measures of Antiretroviral Therapy Adherence: A Review with Recommendations for HIV Research and Clinical Management. AIDS Behav 10, 227-245 
Simoni JM, Montgomery A, Martin E, New M, Demas PA, Rana S (2007): Adherence to antiretroviral therapy for pediatric HIV infection: a qualitative systematic review with recommendations for research and clinical management. Pediatrics $\underline{119}$, e1371-e1383

Singh N, Berman SM, Swindells S, Justis JC, Mohr JA, Squier C, Wagener MM (1999):

Adherence of human immunodeficiency virus-infected patients to antiretroviral therapy. Clin Infect Dis $29,824-830$

Skevington SM (1999): Measuring quality of life in Britain: introducing the WHOQOL-100. J

Psychosom Res $\underline{47}$, 449-459

Skevington SM, Lotfy M, O'Connell KA (2004): The World Health Organization's WHOQOLBREF quality of life assessment: psychometric properties and results of the international field trial. A report from the WHOQOL group. Qual Life Res $\underline{13}$, 299-310

South African Department of Health: National Antiretroviral Treatment Guidelines. SA Dept Health, Pretoria 2004.

South African Department of Health: National HIV and syphilis antenatal prevalence survey, South Africa, 2007. SA Dept Health, Pretoria 2007.

Spira R, Lepage P, Msellati P, Van De PP, Leroy V, Simonon A, Karita E, Dabis F (1999): Natural history of human immunodeficiency virus type 1 infection in children: a five-year prospective study in Rwanda. Mother-to-Child HIV-1 Transmission Study Group. Pediatrics 104, e56

Squires KE (2001): An introduction to nucleoside and nucleotide analogues. Antivir Ther 6 Suppl $\underline{3}, 1-14$

Steele RG, Anderson B, Rindel B, Dreyer ML, Perrin K, Christensen R, Tyc V, Flynn PM (2001): Adherence to antiretroviral therapy among HIV-positive children: examination of the role of caregiver health beliefs. AIDS Care $\underline{13}, 617-629$ 
Steiner JF, Prochazka AV (1997): The assessment of refill compliance using pharmacy records: methods, validity, and applications. J Clin Epidemiol 50, 105-116

Temple ME, Koranyi KI, Nahata MC (2001): The safety and antiviral effect of protease inhibitors in children. Pharmacotherapy $\underline{21}, 287-294$

UNAIDS: Report on the global HIV/AIDS epidemic 2006. Joint United Nations Programme on HIV/AIDS (UNAIDS), Geneva 2006.

UNAIDS: Report on the global HIV/AIDS epidemic 2008: executive summary. Joint United Nations Programme on HIV/AIDS (UNAIDS), Geneva 2008.

Van Dyke RB, Lee S, Johnson GM, Wiznia A, Mohan K, Stanley K, Morse EV, Krogstad PA, Nachman S, Pediatric AIDS Clinical Trials Group Adherence Suubcommittee Pediatric AIDS Clinical Trials Group 377 Study Team (2002): Reported adherence as a determinant of response to highly active antiretroviral therapy in children who have human immunodeficiency virus infection. Pediatrics $\underline{109}$, e61

van Oosterhout JJ, Bodasing N, Kumwenda JJ, Nyirenda C, Mallewa J, Cleary PR, de Baar MP, Schuurman R, Burger DM, Zijlstra EE (2005): Evaluation of antiretroviral therapy results in a resource-poor setting in Blantyre, Malawi. Trop Med Int Health 10, 464-470

van Rossum AM, Bergshoeff AS, Fraaij PL, Hugen PW, Hartwig NG, Geelen SP, Wolfs TF, Weemaes CM, De Groot R, Burger DM (2002a): Therapeutic drug monitoring of indinavir and nelfinavir to assess adherence to therapy in human immunodeficiency virus-infected children. Pediatr Infect Dis J 21, 743-747

van Rossum AM, Fraaij PL, de Groot R (2002b): Efficacy of highly active antiretroviral therapy in HIV-1 infected children. Lancet Infect Dis $\underline{2}$, 93-102

Vreeman RC, Wiehe SE, Pearce EC, Nyandiko WM (2008): A systematic review of pediatric adherence to antiretroviral therapy in low- and middle-income countries. Pediatr Infect Dis J 27 , 686-691 
Walsh JC, Mandalia S, Gazzard BG (2002): Responses to a 1 month self-report on adherence to antiretroviral therapy are consistent with electronic data and virological treatment outcome. AIDS $\underline{16}, 269-277$

Watson DC, Farley JJ (1999): Efficacy of and adherence to highly active antiretroviral therapy in children infected with human immunodeficiency virus type 1. Pediatr Infect Dis J $\underline{18}, 682-689$

Weiser S, Wolfe W, Bangsberg D, Thior I, Gilbert P, Makhema J et al. (2003): Barriers to antiretroviral adherence for patients living with HIV infection and AIDS in Botswana. J Acquir Immune Defic Syndr 34, 281-288

Wendel CS, Mohler MJ, Kroesen K, Ampel NM, Gifford AL, Coons SJ (2001): Barriers to use of electronic adherence monitoring in an HIV clinic. Ann Pharmacother $\underline{35}$, 1010-1015

WHO: Adherence to Long Term Therapies: Evidence for Action. World Health Organization, Geneva 2003

WHO: Scaling up antiretroviral therapy in resource-limited settings: Treatment guidelines for a public health approach. World Health Organization, Geneva 2004

WHO: Antiretroviral treatment of HIV infected in infants and children in resource-limited settings: Towards universal access. World Health Organization, Geneva 2005

WHO: Report on adherence to medications in children (accessed 21.2.2009), http://archives.who.int/eml/expcom/children/Items/ADHERENCE.pdf

Williams PL, Storm D, Montepiedra G, Nichols S, Kammerer B, Sirois PA, Farley J, Malee K, PACTG 219C Team (2006): Predictors of adherence to antiretroviral medications in children and adolescents with HIV infection. Pediatrics $\underline{118}$, e1745-e1757

Wilson D, Naidoo S, Bekker L-G, Cotton M, Maartens G. Handbook of HIV Medicine. Cape Town: Oxford University Press Southern Africa, 2004. 


\section{Publications and presentations of the results this study}

\section{Publications}

Müller AD, Bode S, Myer L, Roux P and von Steinbüchel N (2008). Electronic measurement of adherence to pediatric antiretroviral therapy in South Africa. Pediatr Infect Dis J 27: 257-62.

\section{Presentations}

Müller AD, Myer L, Jaspan HB, Bode S, Roux P, von Steinbüchel N: Innovative Use of Electronic Measurements for Adherence to Liquid Antiretrovirals in an Urban South African Paediatric HIV Clinic. Presented on $2^{\text {nd }}$ October 2006 at $2^{\text {nd }}$ Priorities in AIDS Care and Treatment Conference, October $1^{\text {st }}-3^{\text {rd }} 2006$, Cape Town, South Africa.

Müller AD, Bode S, Myer L, von Steinbüchel N: Monitoring of Adherence to Liquid Antiretroviral Medication in South African Children - Results and Challenges. Presented at $10^{\text {th }}$ European Symposium on Patient Compliance and Persistence, November $30^{\text {th }}$ 2006, Bonn, Germany.

Müller AD, Jaspan HB, Myer L, Bode S, Roux P, von Steinbüchel N: Pediatric Adherence in South Africa Measured by Medication Event Monitoring System and Its Effect on Treatment Efficacy (OI-186). Presented on 29 ${ }^{\text {th }}$ March 2007 at NIMH/IAPAC $2^{\text {nd }}$ International Conference on HIV Treatment Adherence, March 28-30 ${ }^{\text {th }} 2007$, Jersey City, USA.

Müller AD, Bode S, von Steinbüchel N, Myer L: Predictors of Antiretroviral Treatment Adherence and Therapeutic Success Among Children in Cape Town, South Africa (MOPE0200). Presented on $4^{\text {th }}$ August 2008 at XVII International Conference on AIDS, August $3-8^{\text {th }} 2008$ in Mexico City, Mexico. 


\section{Acknowledgements}

I would like to thank Prof. von Steinbüchel for her ongoing support in realising this research project, from the first idea until the finishing touches.

I would further like to express my gratitude to Dr. Paul Roux in Cape Town, who welcomed me in his department and put me in contact with caregivers, children and coworkers and thus facilitated the crucial components of this research project.

The truly inspiring health care team of ward G25 at Groote Schuur Hospital was an invaluable source of knowledge, support, motivation and good spirits during the often very challenging research residence in South Africa.

Stefan Bode from the MPI for Human Cognitive and Brain Sciences Leipzig accompanied and supervised this project from the beginning until the very end. He was indispensable in the development of the statistical analyses and the consecutive writing process.

I would like to recognise the support and motivation by Landon Myer and Heather Jaspan, both lecturers at the University of Cape Town, during my stay in South Africa and beyond.

This project has been carried out on two continents. I sincerely thank everybody involved for their willingness to work with me via email and telephone. Thank you for your patience during our communication. 


\section{Curriculum Vitae (German)}

\section{Persönliche Daten}

Ich wurde am 17. März 1983 in Ludwigshafen am Rhein geboren.

Meine Mutter Sabine Müller arbeitet als mathematisch-technische Assistentin.

Mein Vater Ekkehard Müller arbeitet als selbständiger Ingenieur.

Mein Bruder Jens Müller ist in Ausbildung zum Fachinformatiker.

\section{Schulbildung}

Von 1989 bis 1993 besuchte ich die Grundschule Domholzschule in Limburgerhof.

Von 1993 bis 2002 besuchte ich das Geschwister-Scholl-Gymnasium in Ludwigshafen/Rh., dort erlangte ich im März 2002 das Abitur mit den Leistungskursen Französisch, Biologie und Sozialkunde, mein zusätzliches mündliches Prüfungsfach war Japanisch.

Besonderheiten: $\quad$ Ich belegte einen deutsch-französischen bilingualen Zug, in welchem die Fächer Erdkunde und Geschichte auf Französisch unterrichtet wurden.

\section{Hochschulbildung}

Im Oktober 2002 begann ich mein Studium der Humanmedizin an der Georg-August Universität Göttingen.

Im August 2004 legte ich nach Ende der Vorklinik mein Physikum ab.

Von Januar bis Oktober 2006 belegte ich einen Zertifikatskurs in „HIV Care and Counselling“ an der University of South Africa (Abschluss cum laude).

Im April 2010 werde ich aller Voraussicht nach mein Studium mit der 2. Ärztlichen Prüfung abschließen.

Während meines Studiums war ich als studentische Hilfskraft in der Anatomie, der Medizinischen Psychologie und Soziologie sowie in der Allgemeinchirurgie der Universitätsmedizin Göttingen tätig.

\section{Stipendien}

Im März 2005 wurde ich als Stipendiatin in das Evangelische Studienwerk Villigst e.V. aufgenommen. 


\section{Wissenschaftliche Tätigkeit}

Von Oktober 2005 bis Oktober 2006 besuchte ich im Rahmen eines Forschungsaufenthaltes die University of Cape Town in Südafrika.

Von Februar bis Oktober 2007 arbeitete ich im Rahmen eines Forschungsaufenthaltes am Desmond Tutu HIV Centre an der University of Cape Town.

\section{Publikationen}

Bozorgmehr K, Last K, Müller AD, Schubert K (2009): Lehre am Puls der Zeit - Global Health in der Medizinischen Ausbildung: Positionen, Lernziele und methodische Empfehlungen. GMS Z Med Ausbild 26: Doc20

Müller AD, Myer L and Jaspan H (2009): Virological suppression achieved with suboptimal adherence levels among South African children receiving boosted protease inhibitor-based antiretroviral therapy. Clin Infect Dis $\underline{48}$ : e3-5

Müller AD, Bode S, Myer L, Roux P and von Steinbüchel N (2008): Electronic measurement of adherence to pediatric antiretroviral therapy in South Africa. Pediatr Infect Dis J 27: 257-62

\section{Vorträge und Präsentationen}

Innovative Use of Electronic Measurements for Adherence to Liquid Antiretrovirals in an Urban South African Paediatric HIV Clinic. $2^{\text {nd }}$ Priorities in AIDS Care and Treatment Conference, 1.-3. October 2006 in Kapstadt, Südafrika

Monitoring of Adherence to Liquid Antiretroviral Medication in South African Children - Results and Challenges. $10^{\text {th }}$ European Symposium on Patient Compliance and Persistence, 30. November 2006 in Bonn, Deutschland

Pediatric Adherence in South Africa Measured by Medication Event Monitoring System and Its Effect on Treatment Efficacy (OI-186). NIMH/IAPAC $2^{\text {nd }}$ International Conference on HIV Treatment Adherence, 28.-30. März 2007 in Jersey City, USA

Adhärenz bei kindlicher HIV-Infektion. Jahrestreffen der Arbeitsgemeinschaft Tropenpädiatrie, 28.-30. Januar 2008 in Würzburg, Deutschland

A Comparison of Multiple Methods to Measure Adherence in Young Children. NIMH/IAPAC $3^{\text {rd }}$ International Conference on HIV Treatment Adherence, 17./18. März 2008 in Jersey City, USA

Predictors of Antiretroviral Treatment Adherence and Therapeutic Success Among Children in Cape Town, South Africa (MOPE0200). XVII International AIDS Conference, 3.-8. August 2008 in Mexico City, Mexico 


\section{Famulaturen}

Im Februar 2005 absolvierte ich eine Famulatur in Chirurgie am Krankenhaus Neu-Bethlehem in Göttingen

Im März 2005 absolvierte ich eine Famulatur im All Saints Hospital in Engcobo in Südafrika (Fachgebiete: Gynäkologie, Geburtshilfe und Innere Medizin)

Im Juli 2005 absolvierte ich eine Famulatur in der Clinique Najjar in Nouakchott in Mauretanien (Fachgebiete: Gynäkologie und Geburtshilfe)

Von August - September 2006 absolvierte ich eine Famulatur im Groote Schuur Hospital in Kapstadt sowie in der Nolungile Community Health Clinic in Khayelitsha in Südafrika (Fachgebiete: Pädiatrie, Innere Medizin und Infektiologie mit Schwerpunkt HIV)

\section{Praktisches Jahr}

Von Februar bis Juni 2009 leiste ich das Tertial Innere Medizin am Albert-SchweitzerKrankenhaus in Northeim ab.

Von Juni bis September 2009 werde ich mein Chirurgie Tertial ebenfalls am ASK in Northeim absolvieren.

Für mein Wahlfach Pädiatrie werde ich von Oktober 2009 bis Januar 2010 am Groote Schuur Hospital in Kapstadt in Südafrika arbeiten.

\section{Aktivitäten ausserhalb des Curriculums}

Seit Oktober 2003 arbeite ich ehrenamtlich in der AIDS-Hilfe Göttingen e.V.

Von 2004 bis 2006 leitete ich das Präventionsprojekt der Bundesvertretung der Medizinstudierenden in Deutschland (bvmd) „Mit Sicherheit Verliebt“ in Göttingen.

Seit Januar 2008 engagiere ich mich in der „Globalisation and Health Initiative“ (GandHI) der bvmd. Ich leite Workshops an Universitäten zum Thema Global Health und erarbeite in einem Team Leitlinien zur Lehre von Global Health im medizinischen Curriculum.

\section{Sprachen}

Ich spreche Englisch und Französisch fließend und besitze gute Kenntnisse in Spanisch, Xhosa, Afrikaans und Japanisch. 